\title{
Beiträge zur Kenntniss des Cigarrenrauches.
}

\section{Von}

\section{J. Habermann.}

Mit einer Tafel und vier Abbildungen.

(Aus dem Laboratorium für allgemeine und analytische Chemie der $k$. $k$. technischen Hochschule in Brünn.)

(Der Redaction zugegangen am 12. Juni 1901.)

Tabak und Tabakrauch waren schon vielfach Gegenstand chemischer und physiologischer Untersuchungen. : Eine, wenn auch nicht erschöpfende, kritische Zusammenstellung der auf den Tabakrauch bezüglichen Publicationen bildet die Einleitung der Abhandlung über «den Gehalt des Cigarrenrauches an Nicotin unter gleichzeitiger Berücksichtigung der giftig wirkenden Verbrennungsprodukte des Tabakes» von Rich. Kissling (Dingl. Polytech. Journal, Jahrg. 1882, Bd. 244, S. 64 und 234).

$\mathrm{Da}$ sich diese Zusammenstellung, in ihren wesentlichen Theilen bis zum Jahre 1893 ergänzt, in dem verbreiteten «Kurzgefassten Handbuch der Tabakkunde» von Dr. Richard Kissling (Berlin 1893) wiederfindet, wird es genügen, an dieser Stelle auf jene Zusammenstellung zu verweisen und anzuführen, dass seit 1893 nach meinem Wissen keine Arbeit erschienen ist, welche die Resultate der Untersuchung von Kissling erschüttert oder in erheblicher W'eise. ergänzt hätte. Kann indessen diese allgemeine Bemerkung genügen, um die Unterlassung der Besprechung der einschlägigen Litteratur $\mathrm{zu}$ rechtfertigen, so vermag sie; wie ich meine, mich nicht der Pflicht zu entbinden, den Leser, wenn auch nur in flüchtigen Zügen, an den gegenwärtigen Stand unserer Kenntnisse über die Zusammensetzung des Tabakrauches zu 
erinnern. Da sich diese Kenntnisse wesentlich auf die obcitirte Arbeit von Dr. R. Kissling stützen, so dürfte es dem Zweck am besten entsprechen, an dieses unser Wissen mit den eigenen Worten Kisslings zu erinnern. Diesbezüglich heisst es auf Seite 245 der obcitirten Abhandlung: «Die Ergebnisse meiner Untersuchung fasse ich schliesslich in folgenden Sätzen zusammen: Als stark giftig wirkende Bestandtheile des Tabakrauches sind zu bezeichnen: Kohlenoxyd, Schwefelwasserstoff, Cyanwasserstoff, die Pikolinbasen und das Nicotin». - "Der Gehalt des Rauches an den drei zuerst genannten Stoffen ist aber einerseits zu gering, andererseits von zu grosser Flüchtigkeit, um bei der Beurtheilung der Wirkung des Tabakgenusses auf den Organismus Berücksichtigung zu verdienen. Auch die Pikolinbasen sind in relativ geringer Menge im Tabakrauche enthalten, so dass die Giftigkeit desselben so gut wie ausschliesslich seinem grossen Nicotingehalte zuzuschreiben ist.» — «Der Nicotingehalt des Tabakrauches wird im Wesentlichen nur von demjenigen des ihn erzeugenden Tabakes bedingt; doch hängt die relative Nicotinmenge, welche aus einer Cigarre in den Rauch übergeht, hauptsächlich von der Grösse des nicht verrauchten Cigarrenendes $a b$, da der Nicotingehalt des nicht verrauchten Theiles einer Cigarre zu der Grösse desselben in umgekehrtem Verhältnisse steht.» — «Der durch den Verbrennungsprocess zerstörte Theil des in der Cigarre enthaltenen Nicotins ist relativ gering.»

Die im Vorstehenden wörtlich angeführten Lehrmeinungen R. Kisslings, welche sich in Umschreibungen in seiner «Tabakkunde» auf Seite $260 \mathrm{u}$. ff. wiederfinden, bilden zugleich eine Rechtfertigung dessen, dass sich der obcitirte Titel seiner Abhandlung mit dem Inhalte derselben, wenigstens insoweit R. Kissling s eigene Untersuchungen in Betracht kommen, nicht vollständig deckt, indem sich Kissling bei seinen Untersuchungen des Tabakrauches im Wesentlichen auf den Nachweis und die quantitative Bestimmung des Nicotins des Tabakrauches beschränkt.

Im Hinblick auf diese Thatsache und um dem Leser Gelegenheit zu geben, sich über den Grad der Verlässlichkeit 
unserer dermaligen Kenntnisse über den Nicotingehalt des Tabakrauches in objectiver Weise ein selbständiges Urtheil bilden zu können, wird es verständlich erscheinen, dass nunmehr zunächst einiges über das von Kissling zur Bestimmung des Nicotins im Tabakrauch eingehaltene Verfahren mitgetheilt wird. Der Apparat, dessen sich R. Kissling bei seinen Rauchversuchen bediente, bestand aus einem längeren Kühlrohre, welches mit einem System von fünf Flaschen und einem Aspirator so verbunden war, dass das Kühlrohr das eine, der Aspirator das andere Ende des Systems bildete. Von den fünf Flaschen waren die erste und die dritte leer, während die zweite mit Alkohol, die vierte mit verdünnter Schwefelsäure und die fünfte mit mässig verdünnter Natronlauge beschickt waren. Der Rauchprocess wurde mittelst des Aspirators geführt und erfolgte nicht intermittirend wie beim Gewohnheitsraucher, sondern ununterbrochen, d. h. der Rauch der brennenden Cigarre, welche an dem einen Ende der Kühlröhre befestigt war, wurde mit Hülfe des Aspirators continuirlich durch die Kühlröhre und das Flaschensystem gesaugt. Der Rauchprocess wurde so regulirt, dass eine Cigarre etwa eine halbe Stunde vorhielt. Es wurden im Ganzen vier Rauchversuche ausgeführt und bei den einzelnen der vier Versuche je 50, 42, 132, respective 100 Cigarren angewendet, deren Gewicht in bei $50^{\circ}$ getrocknetem Zustande vor dem Versuche ebenso bestimmt worden war, wie nachher das Gewicht der abgeschnittenen Spitzen und nicht verrauchten Enden (Stümpfe) der Cigarren des betreffenden Versuches. Von jeder der für die Rauchversuche verwendeten Cigarrensorte war der Nicotingehalt bekannt und betrug bei den Cigarren des ersten und des zweiten Versuches $3,75 \%$, bei jenen des dritten Versuches $0,295 \%$ und bei denen des vierten Versuches 0,19\%.

In Bezug auf die verwendeten Cigarrensorten bemerkt Kissling in Fussnoten, dass sämmtliche der verwendeten Cigarren eigens für die Versuche hergestellt worden waren, und zwar die beim dritten und vierten Versuche verwendeten aus an Nicotin sehr armen und von Nicotin befreiten Tabaken, während er die bei den Versuchen 1 und 2 verbrauchten Cigarren 
«als wègen «ihrer Stärke» (Nicotingehalt?) «unrauchbar * bezeichnet.

Aus der Anzahl und dem Gesammtgewicht der für jeden Versuch verwendeten Cigarren ergibt sich das Durchschnittsgewicht einer Cigarre im bei $50^{\circ}$ getrockneten Zustande bei den Versuchen 1 und $2 \mathrm{zu} 8,1 \mathrm{~g}$, beim Versuche $3 \mathrm{zu} 6,0 \mathrm{~g}$ und bei jenen des Versuches $4 \mathrm{zu} 5,1 \mathrm{~g}$.

In Betreff der Methoden, welche bei der Untersuchung der in dem Kühler und Flaschensystem condensirten, respective absorbirten Rauchprodukte eingehalten, und der Resultate, welche erzielt wurden, ergibt sich aus den Mittheilungen Kisslings das Folgende: Die in der fünften Flasche befindliche Natronlauge wurde in einem passenden Apparat auf Schwefel- und Cyanwasserstoff in der Weise geprüft, dass sie mit Schwefelsäure angesäuert und die durch Erhitzen ausgetriebenen Gase durch Lösungen von Bleiacetat und Silbernitrat geleitet wurden. Da beide Absorptionsflüssigkeiten stets vollständig klar blieben, folgert $R$. Kissling, dass der im Tabakrauch befindliche Schwefel- und Cyanwasserstoff in dem ersten Kolben zurückgehalten worden war. Hierzu sei gleich bemerkt, dass R. Kissling den Gehalt des Tabakrauches an Cyanwasserstoff in zwei besonderen Versuchen, die er unter der Bezeichnung $7 \mathrm{a}$ und $7 \mathrm{~b}$ in seiner Abhandlung anführt, nach der von Vogel und Reischauer eingehaltenen Methode mit je 5 Cigarren im Gesammtgewicht von je $26 \mathrm{~g}$ bestimmt hat. Der weitere Gang der Untersuchung war beim ersten Rauchversuch folgender: Der Inhalt des ersten Kolbens wurde mittelst des zum Ausspülen des Kühlrohres benutzten Aetherweingeistes in Lösung gebracht, von dieser Lösung der Aether grösstentheils abdestillirt und der hierbei erzielte Rückstand nach Zusatz von Natronlauge im Wasserdampfstrom so lange destillirt, bis das Uebergehende nur noch schwach alkalisch reagirte. Aus dem Destillate schied sich an der Oberfläche ein grünliches $\mathrm{Oel} a b$, welches durch "wiederholte Aetherschichtung» von dem wässerigen Antheil des Destillates getrennt, nach dem Abdestilliren des Aethers fractionirt destillirt und der Elementaranalyse unterworfen wurde. Die- 
selbe ergab einen Gehalt von 83,56\% Kohlenstoff, 10,51\% Wasserstoff und, wie Kissling sagt, «etwas Stickstoff». Bei der fractionirten Destillation konnte ein bestimmter Siedepunkt nicht beobachtet werden. $\mathrm{K}$ issling kennzeichnet seine diesbezüglichen Resultate mit folgenden Worten: "Wahrscheinlich ist es ein mit stickstoffhaltigen Basen verunreinigter Kohlenwasserstoff, dessen Existenz ja übrigens kaum weiteres Interesse bietet.» Der nach Abscheidung des grünlichen Oeles mittelst "Aetherschichtung" hinterbleibende, wässerige Antheil des Destillates wurde mit Schwefelsäure angesäuert, bis zur Syrupdicke eingedampft, unter Kühlung mit Natronkalk und Seesand zu einem halbtrockenen Pulver abgerieben, dieses mittelst Aether ausgezogen, vom Aetherauszug der Aether abdestillirt, der hinterbleibende Rückstand im Wasserstoffstrom fractionirt destillirt und dabei in die Fraction «bis $230^{\circ}$, , in jene von «230 bis $245^{\circ}$ » und den «verharzten Rückstand» geschieden. Die Fraction "bis $230^{\circ}$ » und der Rückstand waren sehr gering, während das Gewicht der Fraction * 230 bis $245^{\circ}$ » 5,222 g betrug. Diese zweite Fraction wurde neuerlich im Wasserstoffstrom fractionirt destillirt, wobei die Hauptmenge im Gewichte von 4,117 $\mathrm{g}$ zwischen 238 bis 242 überdestillirte. Nach den von Kissling ermittelten Daten verlor diese Fraction beim Trocknen über Schwefelsäure $1,63 \%$ von ihrem Gewichte, so dass also den 4,117 $\mathrm{g}$ der ursprünglichen 4,05 g über Schwefelsäure getrockneter Substanz entsprechen. Von der Fraction hat Kissling den Kohlenstoff und den Wasserstoff zweimal bestimmt und Zahlen erhalten, welche sehr befriedigend mit jenen übereinstimmen, welche die Formel des Nicotins $\mathrm{C}_{10} \mathrm{H}_{14} \mathrm{~N}_{2}$ verlangt. Die Bestimmung des Stickstoffs hat Kissling bei diesem, wie bei allen ähnlichen Produkten der anderen Versuche unterlassen. Hingegen wurde von dieser Fraction auch das Platindoppelsalz quantitativ dargestellt und hierbei $87,2 \%$ jener Ausbeute erhalten, welche reines Nicotin geliefert hätte. Kissling folgert daraus, dass die untersuchte Substanz, welche, wie gesagt, Kohlenstoff und Wasserstoff fast genau in den Mengen enthält, welche im reinen Nicotin enthalten sind, nur $87,2 \%$ reines Nicotin enthielt. Aus der bei der ersten 
Fractionirung erhaltenen ersten Fraction und aller Abfälle der zweiten Fractionirung wurden die Stickstoffbasen mittelst salzsaurem Platinchlorid quantitativ abgeschieden, der Gehalt an Platin bestimmt, und da der Platingehalt $34,21 \%$, also mehr als $34,15 \%$ betrug, als im Wesentlichen aus salzsaurem Nicotinplatinchlorid $\left(\mathrm{C}_{10} \mathrm{H}_{14} \mathrm{~N}_{2} \mathrm{H}_{2} \mathrm{Cl}_{2} \mathrm{PtCl}_{4}\right)$ bestehend angesehen und das Nicotin daraus berechnet. Ihre Menge betrug nach dem Trocknen bei $100^{\circ} 3,1429 \mathrm{~g}$. Die Nicotinplatinverbindung der angegebenen Formel enthält nach $\mathrm{K}$ issling $34,38 \%$, nach meiner Berechnung 34,07\% $\%^{1}$ ) Platin.

In gleicher Weise wurden aus dem bei der ersten Fractionirung erhaltenen, von Kissling als «unbedeutend» bezeichneten Rückstande $1,137 \mathrm{~g}$ bei $100^{\circ}$ getrocknetes «schmutzigbräunliches » Platindoppelsalz dargestellt, dessen Analyse 35,07\% Platingehalt ergab. Bei der Prüfung des Inhalts des zweiten und dritten Kölbchens und bei jenem des vierten Kölbchens auf den Gehalt an mit Wasserdampf flüchtigen Basen wurde zunächst in ähnlicher Weise wie beim ersten Kolben vorgegangen, jedoch mit der Abweichung, dass bezüglich der gewonnenen Substanz durch Destillation und Aetherextraction allein festgestellt wurde, dass der Siedepunkt über $200^{\circ}$ lag und die Basen durchwegs als Platinverbindung abgeschieden, gewogen und der Gehalt der Verbindung an Platin ermittelt wurde.

Damit erscheint das von R. Kissling zur Bestimmung der basischen Bestandtheile des Tabakrauches beim ersten Rauchversuch eingehaltene Verfahren mit thunlichster Genauigkeit beschrieben und kann die Bemerkung genügen, dass dieses Verfahren mit unwesentlichen Aenderungen und Kürzungen auch beim $z$ weiten, dritten und vierten Rauchversuche eingehalten wurde.

Ergänzend muss noch angeführt werden, dass die alkalische Flüssigkeit, welche nach dem Abtreiben der flüchtigen Basen mit Wasserdampf im Kochkolben hinterblieb, mit Schwefelsäure übersättigt und neuerdings im Wasserdampfstrom

1) Benützt wurden die in $\mathrm{Erdm}$ a n $n$ 's Lehrbuch der unorganischen Chemie angegebenen Atomgewichte. 
destillirt wurde. Bei der Prüfung dieses Destillates wurde beim zweiten Rauchversuche das Vorhandensein geringer Mengen von Essigsäure und Buttersäure, beim dritten Rauchversuche von Ameisensäure, beim vierten Rauchversuche von Essigsäure und Propionsäure, theils durch den Geruch, theils mit Hülfe der fractionirten Destillation und der Silbersalze als wahrscheinlich nachgewiesen.

Die nach dem Abtreiben der flüchtigen Säuren im Kochkolben hinterbleibende, freie Schwefelsäure enthaltende Flüssigkeit, wurde wieder mit Natronlauge schwach übersättigt, eingedampft, mit Seesand verrieben, mit Aether extrahirt und der nach dem Abdestilliren des Aethers hinterbleibende Rückstand auf stickstoffhaltige Basen geprüft. Hierbei konnten beim ersten Versuch $0,959 \mathrm{~g}$ Platindoppelsalz mit 34,03\%/0 Platin, beim dritten Versuche $1,250 \mathrm{~g}$ Platindoppelsalz mit $35,12 \%$ Platingehalt, beim vierten Versuche 0,058 g Doppelsalz mit 34,00\% Platin abgeschieden werden, während beim zweiten Versuche «relativ bedeutende Mengen Paraffin nachgewiesen wurden».

Unter der Bezeichnung « 5 . Versuch» kennzeichnet R. Kissling das Verfahren und die Resultate, welche er bei der Nicotinbestimmung in $47 \mathrm{~g}$ vom ersten Rauchversuche herrührender Cigarrenspitzen und Enden (Stumpfe) ermittelte. Danach wurden die über Schwefelsäure getrockneten Enden mit alkoholischer Natronlauge und Aether extrahirt, der Aetherauszug mit alkoholischer Oxalsäure gefällt, der Niederschlag abfiltrirt, in wenig Wasser gelöst, unter Kühlung mit Natronkalk und Seesand zu einem trockenen Pulver abgerieben und dieses mit Aether ausgezogen. Der nach dem Abdestilliren des Aethers hinterbleibende Rückstand wurde durch Fractionirung in die Fractionen «bis $238^{\circ}$, "von 238 bis $242^{\circ}$ » und den Destillationsrückstand geschieden, die zweite Fraction als solche gewogen $(2,3682 \mathrm{~g})$ und von derselben der Gehalt an Kohlenstoff und Wasserstoff durch Elementaranalyse bestimmt. Die Resultate der Elementaranalyse stimmen mit den aus der Nicotinformel berechneten in sehr befriedigender Weise überein. Aus der ersten Fraction und dem Destillationsrückstande 
wurden die Stickstoffbasen resp. das Nicotin mittelst Platinchlorid quantitativ abgeschieden und in einem Theile der gewogenen Platindoppelverbindung der Platingehalt ermittelt.

Aus der ersten Fraction wurden 0,1176 g Doppelsalz mit 33,26\% Platin, aus dem Destillationsrückstande 0,6 g Doppelsalz mit 33,04\% Platin erhalten.

Nach einem etwas modificirten Verfahren wurde der Gehalt an Stickstoffbasen resp. Nicotin in $30 \mathrm{~g}$ vom zweiten Rauchversuche herrührender Cigarrenspitzen und Enden bestimmt und hierbei schliesslich 4,800 g Platindoppelsalz mit $34,33 \%$ Platin erhalten.

Die vom dritten und vierten Rauchversuche herrührenden Spitzen und Enden hat R. Kissling nicht untersucht. Die unmittelbar durch Wägung oder durch Rechnung gefundenen Resultate der vier Rauchversuche und des «5. Versuches», sowie jene, welche sich aus der als " 6 . Versuch" bezeichneten Untersuchung von "Cigarrenenden, die ein Raucher übrig gelassen hatte», ergeben, hat R. Kissling auf Seite 242 und 243 in einer Tabelle zusammengestellt.

Die zweite auf Seite. 244 abgedruckte Tabelle bildet in gewissem Sinne eine Zusammenfassung und procentische Darstellung der aus der ersten Tabelle sich ergebenden Schlussresultate. Zum Verständniss beider Tabellen muss bemerkt werden:

1. dass R. Kissling die Resultate, welche im Text als «5. Versuch» angeführt sind, in beiden Tabellen in den Rubriken *Versuch 1» und "Versuch 2» eingereiht sind, während die im Texte als $* 6$. Versuch» mitgetheilten Resultate in beiden Tabellen als "Versuch 5» mitgetheilt werden.

2. Die Zahlen, welche in der ersten Tabelle in den mit «Stickstoffbasen» bezeichneten Rubriken angeführt sind, erscheinen in der zweiten Tabelle zusammengefasst und in procentischer Darstellung durchwegs unter der Bezeichnung "Nicotin».

3. Die aus den ermittelten Gewichten der Platindoppelsalze nach dem Verhältniss $\mathrm{PtCl}_{6} \mathrm{H}_{2} \cdot \mathrm{C}_{10} \mathrm{H}_{14} \mathrm{~N}_{2}: \mathrm{C}_{10} \mathrm{H}_{14} \mathrm{~N}_{2}$ berechneten Stickstoffbasen resp. Nicotinmengen werden schätzungs- 
weise nach Gesichtspunkten, welche auf Seite 243 und 244 entwickelt sind, theils mit $100 \%$, also voll, theils mit $90 \%$ und theils mit $80 \%$ in die betreffenden Rubriken (Stickstoffbasen resp. Nicotin) eingesetzl oder ganz weggelassen. (Letzteres, wenn die Verbindung weniger als $33,7 \%$ betrug.)

4. Beim ersten Rauchversuche wurde die zwischen 238-2420 übergehende Fraction nach dem Trocknen über Schwefelsäure mit dem ganzen Gewichte $(4,0498 \mathrm{~g})$ als Stickstoffbasen (1. Tabelle) resp. als Nicotin (2. Tabelle) in Rechnung gesetzt, obwohl Kissling auf Seite 236 des Textes bei Besprechung der Darstellung des Platindoppelsalzes aus dieser Fraction angibt, dass nur 87,2\% der theoretischen Ausbeute erhalten wurden, und hierzu bemerkt, "dass darnach anzunehmen wäre, dass die Fraction 87,2\% an reinem Nicotin enthielte.» Aehnliches gilt für den zweiten Rauchversuch, wo aus der analogen Fraction von der theoretischen Menge nur 88,3\% Platindoppelsalz erhalten wurden, und Aehnliches wohl auch von den in analoger Weise ermittelten und in die Tabellen eingesetzten Gewichtsmengen.

Alle diese Umstände müssen einen sehr bedeutenden Einfluss auf die Genauigkeit der in der 2. Tabelle mitgetheilten Schlussresultate üben und lassen es mehr als gerechtfertigt erscheinen, dass Kissling auf Seite 244 sagt, "dass den in Tabelle 2 zusammengestellten Zahlen eine absolute Bedeutung schlechterdings nicht beigelegt werden kann». In welchem Maasse den Schlussresultaten die absolute Genauigkeit fehlt, mag das folgende Beispiel beleuchten: Nach Kissling enthielten die beim ersten Rauchversuch verwendeten $406,675 \mathrm{~g}$ Cigarren 15,25 g, die 56,255 g nichtverrauchten Spitzen und Enden 2,832 g Nicotin, sodass also 350,42 g Cigarren und damit nach der Rechnung 15,250-2,832 = 12,418 g Nicotin verraucht wurden. (Nach Kissling 13,141 g.) Aus dem Rauche wurden nach Kissling 6,850. g Nicotin gewonnen. Diese Zahl setzt sich zusammen:

aus $4,050 \mathrm{~g}$ Substanz, welche die 2. Fraction der zweiten Fractionirung bildet, von welcher nach Kissling anzunehmen wäre, dass sie $87,2 \%$ an reinem Nicotin enthielte; 
aus 2,16 g Stickstoff basen, aus 7,622 g Platindoppelsalz berechnet und mit 100\% in Rechnung gesetzt;

aus $0,64 \mathrm{~g}$ Stickstoffbasen, erhalten durch Rechnung aus 2,511 g Doppelsalz, wobei die zunächst erhaltene Zahl $(0,712 \mathrm{~g})$ mit 90\% in Rechnung gesetzt wurde.

Das gibt in Summe $6,850 \mathrm{~g}$.

Auf Grund dieser Daten berechnet nun Kissling, wie aus der II. Tabelle, Versuch 1, ersichtlich ist, dass die Menge des aus dem Rauch gewonnenen Nicotins 52,02\% des verrauchten oder $44,83 \%$ des in den Cigarren überhaupt enthaltenen Nicotins beträgt. Bei dieser Berechnung wird die Gesammtmenge des verrauchten Nicotins mit 13,141 g angegeben und rechnerisch benützt, während nach der Tabelle II die Summe des Nicotins, welche aus dem Rauch gewonnen wurde $(6,85 \mathrm{~g})$, und des zerstörten Nicotins $(5,582 \mathrm{~g}) \cdot 12,432 \mathrm{~g}$ beträgt und sich aus der Gesammtmenge Nicotin der Cigarren $(15,250 \mathrm{~g})$ und der Menge Nicotin, welche aus den nichtverrauchten Enden und Spitzen gewonnen wurde $(2,832 \mathrm{~g})$, die Menge des verrauchten Nicotins als Differenz mit $12,418 \mathrm{~g}$. ergibt. Setzt man diese letzte Zahl in Rechnung, dann beträgt die von Kissling im Rauch aufgefundene Menge des Nicotins nicht $52,02 \%$, sondern $55,16 \%$ des verrauchten Nicotins.

Setzt man nun aber bei Berechnung der im Rauch nachgewiesenen Stickstoffbasen (Nicotin) nicht die ganze Zahl per $4,05 \mathrm{~g}$, sondern aus dem früher angegebenen Grunde nur $87,2 \%$ derselben, also mit 3,532 $\mathrm{g}$ in Rechnung, so ergibt sich, auch wenn man alle andern bei Berechnung der Tabellen angewendeten Correcturen ausser Betracht lässt, dass im Rauch des ersten Versuches $3,532+2,164+0,641=6,337$ g Nicotin, d. i. $51,03 \%$ vom verrauchten oder $41,55 \%$ des Gesammtnicotins der benützten Cigarren enthalten waren.

Aehnliche Abweichungen werden sich ergeben, wenn man beim zweiten Versuche die als solche gewogene Fraction der aus dem Rauch abgeschiedenen und als Platindoppelsalz gewogenen Stickstoffbasen nicht voll $(1,068 \mathrm{~g})$, sondern nur mit $88,3 \%$ in Rechnung setzt.

Endlich muss noch darauf hingewiesen werden, dass bei. 
den durch Fractionirung gewonnenen und nach ihrem Gewichte unmittelbar in Rechnung gesetzten Produkten die Bestimmung des Stickstoffs immer, bei den Platinverbindungen fast immer fehlt, und dass über kein einziges Produkt eine vollständige Analyse aller elementaren Bestandtheile vorliegt, was umsomehr die Bildung eines Urtheils über den Werth der analytischen Resultate erschwert, weil damit die Basis fehlt, auf welcher der Grad der Reinheit der analysirten Produkte in verlässlicher Weise beurtheilt werden kann.

Diese aus dem Studium der Untersuchung über den Tabakrauch und der "Tabakkunde» von Dr. R. Kissling sich ergebenden Mängel und die meistens sehr ungünstige Beurtheilung, welche die einschlägigen Arbeiten von Le Bon, G. Molnar, Vohl u. A. durch Kissling erfahren, lassen allein schon eine neue, chemische Untersuchung des Gegenstandes gerechtfertigt erscheinen. Für ein solches Unternehmen können indessen noch andere, nicht unwichtige Gründe geltend gemacht werden, von welchen sich manche aus den folgenden Ausführungen ergeben werden.

Nach meiner Auffassung wird die chemische Analyse des Tabakrauches ihren leicht erkennbaren, wichtigen Zweck erst dann erfüllen, wenn der der chemischen Analyse zu unterwerfende Tabakrauch nach einer Methode erzeugt wird, welche das beim Gewohnheitsraucher übliche Verfahren nach jeder Richtung mit thunlichster Sorgfalt nachahmt. Je vollständiger die Nachahmung des Gewohnheitsrauchers gelingt, desto grösser wird der Werth der analytischen Resultate selbst dann sein, wenn uns zur Nachweisung und quantitativen Bestimmung der einzelnen Bestandtheile des Tabakrauches keine völlig einwandfreien, analytischen Methoden zur Verfügung stehen. Die analytischen Resultate werden in letzterem Falle, wie in ähnlichen Fällen, bei entsprechend gleichmässiger Handhabung des Verfahrens, zwar nicht absolut genau, aber zu einem Vergleiche untereinander und mit den Resultaten analog ausgeführter Versuche anderer Forscher sehr brauchbar sein und dadurch einen nicht geringen Werth besitzen. Dementsprechend muss das Versuchsrauchen vor Allem intermittirend gestaltet

Hoppe-Seyler's Zeitschrift f. physiol. Chemie. XXXIII. 
werden, da es ja einleuchtend ist, dass bei einer brennenden Cigarre die Destillation der mehr oder weniger schwer flüchtigen und die trockene Destillation der nicht flüchtigen Produkte bei einer andauernd gleichmässig vordringenden, kräftigen Gluthzone anders verlaufen, $d . h$. andere Destillationsprodukte, oder doch die Destillationsprodukte in einem andern Mengenverhältnisse liefern wird, als wenn die Gluthzone abwechselnd für kurze Zeit, kräftig und rasch fortschreitend und sodann für relativ längere Zeit in der Stärke zurückgehend und an der Cigarre langsam vorschreitend wird. Denn es ist doch yohl klar, dass beim gleichmässigen Fortschreiten einer unverändert kräftigen Gluthzone eine geringere Anhäufung der Destillationsprodukte in dem nicht verrauchten Theile der Cigarre und deshalb eine viel geringere, neuerliche Einwirkung der fortschreitenden Gluthzone auf die in diesem Theile condensirten Destillationsprodukte stattfinden wird, als bei dem intermittirenden Rauchen, wie es jeder Raucher übt. Es kann von vornherein als wahrscheinlich erachtet werden, dass von den schwer flüchtigen, aber leicht veränderlichen Destillationsprodukten des Tabakrauches, zu welchen auch das Nicotin gehört, durch die Einwirkung der Gluthzone ein grösserer Theil zerstört werden wird, wenn diese Einwirkung sich öfter wiederholt und sodann immer wieder bei schwacher Gluth länger andauert. Mit Rücksicht auf diese Bemerkungen wird auch die Annahme weiter verständlich erscheinen, dass, wenn nicht die Art, so doch das Mengenverhältniss der, einzelnen Rauchprodukte nach dem Zeitausmaass mehr oder weniger verschieden sein wird, welches zum Verrauchen desselben Cigarrengewichtes aufgewendet wurde. Daraufbezügliche, wenn auch in dem Zusammenhange unbestimmte Verschiedenheiten wird jeder Raucher ebenso vermuthen, wie in Bezug. auf den Einfluss, welchen der Feuchtigkeitsgehalt der Cigarre auf den Verlauf des Rauchprocesses nimmt. In letzterer Beziehung kann es keinem Zweifel unterliegen, dass bei grösserem Feuchtigkeitsgehalt der Cigarre der Rauchprocess schon deshalb anders verlaufen wird, weil die dem grösseren Feuchtigkeitsgehalt entsprechende, grössere Menge des sich entwickeln- 
den Wasserdampfes die leicht veränderlichen Destillationsprodukte der Einwirkung der Gluthzone rascher entführen wird, als die geringere Menge Wasserdampf bei geringerem Feuchtigkeitsgehalte der Cigarre. In Bezug hierauf sei die Bemerkung gestattet, dass auf diesen Umstand vielleicht zum Theile die Wahrnehmung zurückgeführt werden kann, dass den meisten Rauchern bei derselben Sorte die feuchte Cigarre stärker erscheint als die trockene.

Unter allen Umständen muss, um beim Versuchsrauchen Resultate $\mathrm{zu}$ erhalten, welche zur Erklärung der Wirkungen des Gewohnheitsrauchens eine verlässliche Grundlage bilden sollen, die Cigarre in demselben Zustand der. Trockenheit angewendet werden, in welchem sie der Raucher in der Regel verwendet, also nach dem Trocknen bei Zimmertemperatur, d. h. bei genügend langem Ablagern in einem trockenen Zimmer.

Ebenso scheint es mir wahrscheinlich, dass nicht allein die Tabakqualität, sondern auch die Form der Cigarre auf den Verlauf des Rauchprocesses wenigstens insofern einen gewissen, vielleicht nicht sehr erheblichen Einfluss üben wird, als der in dem nicht verrauchten Stück der Cigarre zurückgehaltene Theil der Destillationsprodukte nicht nur von der Tabaksorte, sondern zum sehr erheblichen Theile auch von der Form dieses Cigarrenstückes abhängen wird. Denn dieses Zurückhalten beruht auf Condensation und Absorption. Nun aber beweisen die überaus mannigfaltigen Condensations- und Absorptionsapparate, welche in den chemischen Laboratorien und in der Technik angewendet werden, allein schon, wie sehr bei der Construction dieser Apparate in Uebereinstimmung mit den Forderungen der Theorie der Einfluss der Form auf die Aeusserungen jener beiden Eigenschaften berücksichtigt wird. Wenn nun berücksichtigt wird, dass beim Cigarrenrauchen der unverrauchte Theil in gewissem Sinne als Condensations- und Absorptionsapparat wirkt, so wird die Annahme als zulässig erscheinen, dass der Verlauf des Rauchprocesses, respective die Zusammensetzung des Cigarrenrauches auch von der Form der Cigarre beeinflusst wird und deshalb 
bei Rauchversuchen die Form der Cigarre nach Thunlichkeit berücksichtigt werden soll.

Ich hoffe endlich aber auch keinem Widerspruch zu begegnen, wenn ich die Ansicht ausspreche, dass meine, von rein chemischen Gesichtspunkten ausgehende, neuerliche Untersuchung des Tabakrauches in Beziehung auf die Qualität der Bestandtheile möglichst vollständig und in quantitativer Richtung unbedingt die hervorragend giftigen oder in grösserer Menge auftretenden Stoffe umfassen und ohne jede Voreingenommenheit durchgeführt werden muss, um dadurch die Arbeit des Physiologen in wirksamer Weise vorzubereiten, welche dahin wird gehen müssen, den Antheil an den temporären und chronischen Wirkungen des Tạbakrauches festzustellen, welchen jeder der verschiedenen Rauchbestandtheile auf die Körperfunctionen des Rauchers auszuüben vermag.

Die Erfüllung dieser an sich dankbaren chemischen Aufgabe findet leider eine sehr bedeutende Einschränkung in dem Fehlen einer allgemein anwendbaren Methode und in der grossen Unvollkommenheit der meisten, speciellen qualitativen und quantitativen Methoden der chemischen Analyse von Gemischen organischer Körper. Zum nicht geringen Theile aus dem Grunde, um die Unzulänglichkeit unserer diesbezüglichen Hülfsmittel zu kennzeichnen, habe ich das analytische Verfahren ausführlich besprochen, welches bei einer Untersuchung angewendet wurde, die bei ihrer 1882 erfolgten Veröffentlichung und seither zum mindesten keinerlei ungünstige Beurtheilung erfahren hat. Und doch wird dieses Verfahren von R. Kissling selbst als unzulänglich angesehen, wie dies aus seinen Ausführungen hervorgeht. Dass aber eine bessere analytische Methode nicht leicht $\mathrm{zu}$ finden ist, scheint mir schon daraus hervorzugehen, dass eine solche gerade auch R. Kissling nicht gefunden hat, dem wir unter Anderem eine vortreffliche Methode zur Bestimmung des Nicotins im Tabak veraanken, die ich im Laufe meiner eigenen Untersuchung überaus oft und mit stets befriedigendem Erfolge angewendet und auch für die Bestimmung des Nicotins im Tabakrauch anwendbar gemacht habe. Um aber auch die Mängel dieses für den be- 
sonderen Fall zurechtgelegten, analytischen Verfahrens in entsprechender Weise zur Beurtheilung seiner Brauchbarkeit zur Erscheinung zu bringen, habe ich die Rauchversuche mit sehr -vielen Cigarrensorten angestellt und auch bei jeder Sorte die Versuche mehrfach unter wechselnden Versuchsbedingungen wiederholt.

Ich erinnere an die grosse Zahl der von mir ausgeführten Rauchversuche und der damit zusammenhängenden Bestimmungen schon jetzt, weil ich der Ansicht bin, dass bei der -wechselnden Beschaffenheit des Ausgangsmaterials, d. i. der Cigarre, selbst bei der gleichen Cigarrensorte den gleichen Fabrikationsort vorausgesetzt, nur die aus zahlreichen Einzelversuchen sich ergebenden Mittelwerthe ein einigermaassen verlässliches Bild über die Zusammensetzung des Tabakrauches zu geben vermögen.

Indem ich nunmehr zur Besprechung meiner eigenen Untersuchung übergehe, will ich zunächst angeben, in welcher Weise ich den Anforderungen zu entsprechen versucht habe, welchen nach meiner Auffassung die chemische. Untersuchung über die Zusammensetzung des Tabakrauches genügen soll.

Um für die einzelnen Versuche und Versuchsreihen ein in Bezug auf Rohmaterial und Fabrikationsweise möglichst constantes Ausgangsprodukt zu haben, habe ich durchwegs österreichische Regiecigarren verwendet. Wie ich gleich bemerken will, wurden meine diesbezüglichen Voraussetzungen durch die gesammelten Erfahrungen insofern bestätigt, als dieselbe Cigarrensorte desselben Verschleissortes eine ziemlich constante Beschaffenheit zeigte, was in der Uebereinstimmung der Resultate mehrfacher quantitativer Bestimmungen seinen Ausdruck fand.

Die Aschenbestimmung wurde stets im Zusammenhange mit Rauchversuchen in der Weise ausgeführt, dass die für den Versuch bestimmte Cigarre im lufttrockenen Zustande und sodann das unverrauchte Ende der Cigarre, nachdem es völlig lufttrocken geworden war, gewogen, die beim Rauch- 
versuch entstandene Asche möglichst ohne Verlust gesammelt und gleichfalls gewogen wurde. Selbstverständlich machen die só ausgeführten Bestimmungen keinen Anspruch auf völlige Genauigkeit. Als annähernd richtig können die Resultate gleichwohl angesehen werden, und der angestrebte Zweck, ein einigermassen verlässliches Urtheil darüber $\mathrm{zu}$ gewinnen, ob und inwieweit das bei der ganzen Untersuchung benützte Rohmaterial in seiner Beschaffenheit die erwünschte Gleichmässigkeit besitzt, wurde, wie ich meine, und wie die in der folgenden Tabelle (Tabelle I) enthaltenen Zahlen beweisen, in befriedigender Weise erreicht.

Im Hinblick darauf, dass bei allen Versuchen die Veraschung der Cigarre zwar vom Standpunkt des Rauchers eine befriedigende, im Sinne der chemischen Analyse aber niemals eine absolut vollständige war, können Differenzen, welche bei den einzelnen Cigarrensorten gegenüber dem berechneten Mittelwerthe fast immer weniger als $1 \%$ betragen, gewiss als befriedigend angesehen werden; und dies umsomehr, als auch aus andern Gründen eine grössere Genauigkeit bei dem eingehaltenen Verfahren nicht erwartet werden konnte.

Mit Rücksicht auf dieses Ergebnis und bei dem Umstande, dass die einzelnen der verwendeten Cigarren zu sehr verschiedenen Zeiten aus verschiedenen Verschleisslocalen bezogen wurden, glaube ich sagen zu können, dass durch die Aschenbestimmungen der Beweis erbracht wurde, dass die für die Versuche verwendeten Cigarrensorten die erwünschte gleichmässige Beschaffenheit andauernd besitzen, und ich kann schon jetzt bemerken, dass die später mitzutheilenden Bestimmungen der Feuchtigkeit und des Nicotins diese Auffassung bestätigen.

Um das Versuchsrauchen intermittirend $\mathrm{zu}$ gestalten, habe ich einen Aspirator construirt, welcher sich bei allen überaus zahlreichen Rauchversuchen vorzüglich bewährt hat und den ich nunmehr an der Hand der nebenstehenden Zeichnung beschreiben will.

Der neue Aspirator besteht aus der zweimal tubulirten Glasflasche $\mathrm{A}$ und dem Gefässe B. In die obere Oeffnung der Flasche $\mathrm{A}$ ist ein zweimal durchbohrter Pfropf dicht eingefügt: 
In die beiden Bohrungen sind, wie aus der Zeichnung ersichtlich, die beiden rechtwinklig gebogenen Glasröhrchen $a$ und $b$ eingesteckt. Ich bemerke hierzu, dass der zweimal durchbohrte Pfropf und die Röhrchen a und $b$ durch einen einmal durchibohrten Pfropf und ein Trohr ersetzt werden können. Durch das Röhrchen a, resp. durch das diesem entsprechende Stück des Trohres, kann der Aspirator mittelst Kautschukschlauch mit den Condensations-und Absorptionsapparaten und durch diese mit der Rauchvorrichtung in Verbindung gesetzt werden, während das Röhrchen b dazu dient, mittelst Kautschukschlauch eine Verbindung mit dem kleinen Glasgefäss B herzustellen. Das kleine Glasgefäss B ist jene Vorrichtung, welche das

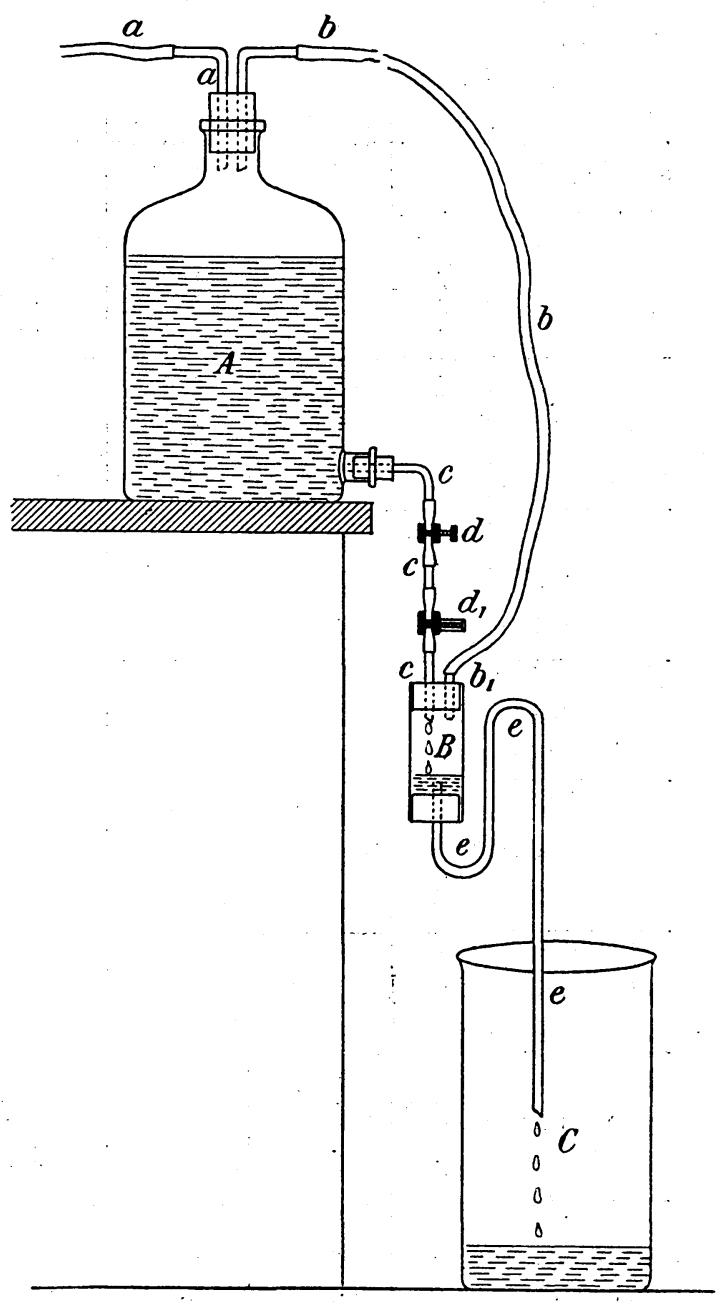

Fig. 1. intermittirende Rauchen bewirkt. Dieselbe besteht aus einem kleinen Glascylinder, welcher beiderseits durch Pfropf dicht geschlossen ist. Der obere Pfropf ist zweifach durchbohrt; 
Tabelle I

enthaltend die Resultate der Aschenbestimmungen

\begin{tabular}{|c|c|c|c|c|c|c|}
\hline \multirow{4}{*}{$\begin{array}{c}\text { Name } \\
\text { der } \\
\text { Cigarrensorte }\end{array}$} & \multirow{4}{*}{$\begin{array}{l}\text { Nommer } \\
\text { der } \\
\text { Analyse }\end{array}$} & \multicolumn{2}{|c|}{ Gewicht } & \multicolumn{3}{|c|}{ Gewicht d. Asehe d. verranchten Theils d. Cigarret. } \\
\hline & & \multirow{2}{*}{ der ganzen } & \multirow{2}{*}{\begin{tabular}{|c|} 
des ver- \\
rauchten \\
Theiles der \\
\end{tabular}} & \multirow{3}{*}{$\begin{array}{c}\text { erhalten } \\
\text { durch } \\
\text { direkte } \\
\text { Wägung in } \\
\text { Grammen }\end{array}$} & \multicolumn{2}{|c|}{ in Procenten } \\
\hline & & & & & \begin{tabular}{|c|} 
bei der \\
Einzeln-
\end{tabular} & im Mittel \\
\hline & & \multicolumn{2}{|c|}{ Cigarre in Grammen } & & bestimmung & \\
\hline $\begin{array}{l}\text { Gemischte Ansländer } \\
\text { (Kurze Cigarren) }\end{array}$ & $\begin{array}{l}1 \\
2\end{array}$ & $\begin{array}{l}4,33 \\
4,31\end{array}$ & $\begin{array}{l}3,04 \\
3,27\end{array}$ & $\begin{array}{l}0,605 \\
0,650\end{array}$ & $\begin{array}{l}19,9 \\
19,9\end{array}$ & 19,9 \\
\hline Portorico & $\begin{array}{l}1 \\
2 \\
3\end{array}$ & $\begin{array}{l}4,35 \\
4,63 \\
4,16\end{array}$ & $\begin{array}{l}3,73 \\
4,08 \\
3,58\end{array}$ & $\begin{array}{l}0,676 \\
0,762 \\
0,710\end{array}$ & $\begin{array}{l}18,1 \\
18,7 \\
19,8\end{array}$ & 18,9 \\
\hline $\begin{array}{l}\text { Cuba- } \\
\text { Portorico } \\
\text { (Cuba) }\end{array}$ & $\begin{array}{l}1 \\
2 \\
3 \\
4\end{array}$ & $\begin{array}{l}5,85 \\
5,95 \\
6,19 \\
5,37\end{array}$ & $\begin{array}{l}5,33 \\
5,33 \\
5,59 \\
4,75\end{array}$ & $\begin{array}{l}1,002 \\
1,085 \\
1,085 \\
1,020\end{array}$ & $\begin{array}{l}18,8 \\
20,3 \\
19,4 \\
21,5\end{array}$ & 20,0 \\
\hline Operas & $\begin{array}{l}1 \\
2 \\
3 \\
4\end{array}$ & $\begin{array}{l}5,55 \\
5,53 \\
4,69 \\
5,81\end{array}$ & $\begin{array}{l}4,81 \\
5,04 \\
4,23 \\
5,33\end{array}$ & $\begin{array}{l}0,935 \\
0,964 \\
0,812 \\
1,011\end{array}$ & $\begin{array}{l}19,4 \\
19,1 \\
19,2 \\
19,0\end{array}$ & 19,2 \\
\hline $\begin{array}{l}\text { Panetelas } \\
\text { (Havanna) }\end{array}$ & $\begin{array}{l}1 \\
2 \\
3\end{array}$ & $\begin{array}{l}5,21 \\
5,16 \\
5,14\end{array}$ & $\begin{array}{l}3,57 \\
3,61 \\
3,24\end{array}$ & $\begin{array}{l}0,742 \\
0,717 \\
0,602\end{array}$ & $\begin{array}{l}20,8 \\
19,9 \\
18,6\end{array}$ & 19,8 \\
\hline Britannica & $\begin{array}{l}1 \\
2 \\
3 \\
4\end{array}$ & $\begin{array}{l}6,51 \\
6,01 \\
6,03 \\
5,38\end{array}$ & $\begin{array}{l}6,02 \\
5,23 \\
5,47 \\
5,35\end{array}$ & $\begin{array}{l}1,259 \\
1,032 \\
1,049 \\
1,165\end{array}$ & $\begin{array}{l}20,9 \\
19,7 \\
19,2 \\
21,8\end{array}$ & 20,4 \\
\hline Trabuco & $\begin{array}{l}1 \\
2 \\
3\end{array}$ & $\begin{array}{l}4,94 \\
4,76 \\
4,58\end{array}$ & $\begin{array}{l}4,47 \\
4,44 \\
3,94\end{array}$ & $\begin{array}{l}1,030 \\
0,915 \\
0,890\end{array}$ & $\begin{array}{l}23,0 \\
20,7 \\
22,6\end{array}$ & 22,1 \\
\hline Regalitas & $\begin{array}{l}1 \\
2 \\
3 \\
4\end{array}$ & $\begin{array}{l}5,57 \\
5,64 \\
6,25 \\
6,75\end{array}$ & $\begin{array}{l}5,01 \\
4,84 \\
4,27 \\
4,37\end{array}$ & $\begin{array}{l}1,063 \\
1,037 \\
0,712 \\
0,752\end{array}$ & $\begin{array}{l}21,2 \\
21,4 \\
16,7 \\
17,2\end{array}$ & 19,1 \\
\hline $\begin{array}{l}\text { Brasil- } \\
\text { Virginier }\end{array}$ & $\begin{array}{l}1 \\
2 \\
3 \\
4\end{array}$ & $\begin{array}{r}4,36 \\
5,63 \\
\cdot 4,29 \\
4,91\end{array}$ & $\begin{array}{l}2,25 \\
2,83 \\
2,41 \\
1,56\end{array}$ & $\begin{array}{l}0,382 \\
0,542 \\
0,492 \\
0,297\end{array}$ & $\begin{array}{l}17,0 \\
19,1 \\
20,4 \\
19,1\end{array}$ & 18,9 \\
\hline Virginier & $\begin{array}{l}1 \\
2 \\
3 \\
4\end{array}$ & $\begin{array}{l}5,68 \\
4,78 \\
5,35 \\
5,25\end{array}$ & $\begin{array}{l}3,24 \\
2,53 \\
2,75 \\
2,73\end{array}$ & $\begin{array}{l}0,492 \\
0,425 \\
0,462 \\
0,462\end{array}$ & $\begin{array}{l}15,2 \\
16,8 \\
16,8 \\
16,9\end{array}$ & 16,4 \\
\hline
\end{tabular}


durch die eine Bohrung ist mittelst des Röhrchens $b$, wie in der Zeichnung ersichtlich ist, die Verbindung mit der oberen Oeffnung des Aspirators hergestellt, sodass die Luft aus dem Gefässe B eventuell in die Aspiratorflasche A entweichen, resp. aus dieser in das Gefäss B gesaugt werden kann. Durch die zweite Bohrung ist das Innere des Gefässes B mittelst der Glas- und Kautschukröhrchen mit der unteren, seitlichen Oeffnung der Aspiratorflasche verbunden, so dass das Wasser des Aspirators zunächst stets in das Gefäss B abfliessen muss. An dem Kautschukröhrchen der Verbindung $c$ sind die beiden Schraubenquetschhähne $d$ und $d_{1}$ angebracht. $d$ ist ein gewöhnlicher Quetschhahn, durch welchen der Wasserabfluss von $A$ nach $B$ hergestellt oder vollständig unterbrochen werden kann. Der Quetschhahn di hingegen kann nur mittelst eines passenden Schlüssels eingestellt werden und dient dazu, den Wasserabfluss für eine Versuchsreihe in bestimmter Weise zu reguliren und gleichmässig zu erhalten. Ich bemerke hierzu, dass ich diesen zweiten Hahn bei dem grössten Theile, aber keineswegs bei allen der bisher ausgeführten Versuche angebracht habe, und dass ich dies bei Mittheilung der Versuchsresultate anführen werde. Der untere Pfropf des Gefässes B ist einmal durchbohrt. In diese Bohrung ist das zweimal gebogene Glasrohr e eingefügt. Die Entfernung der beiden Biegungen des Rohres e ist so gewählt, dass die obere Biegung annähernd im Niveau des oberen Pfropfes des Glasgefässes B liegt. Das Röhrchen e hat beiläufig den Durchmesser eines Bleistiftes. Die Wirkung der ganzen Vorrichtung ist nun leicht verständlich. Fliesst aus der Flasche A Wasser ab nach B, so wird die Luft aus dem Gefässe $B$ in die Flasche A übertreten, und es wird ein Ansaugen durch die Röhrchenverbindung a zunächst nicht stattfinden. Gleichzeitig füllt sich nicht allein das Gefäss $B$, sondern auch der aufwärts gerichtete Theil des Röhrchens e mit Wasser. Ist das Gefäss B ganz mit Wasser gefüllt, dann füllt sich auch der längere Schenkel des Röhrchens e, dieses wirkt nun als Winkelheber, das Wasser fliesst aus $B$ nach $G$ sehr rasch und jedenfalls viel schneller ab, als. Wasser aus der Flasche $A$ nach $B$ nach- 
fliesst. In Folge dessen macht der Aspirator durch die Verbindungen $b$ und a seine saugende Wirkung nunmehr geltend. Das Saugen währt so lange, bis der Winkelheber das Gefäss B völlig entleert hat, worauf das frühere Spiel von Neuem beginnt, d. h. die saugende Wirkung des Aspirators macht sich erst wieder geltend, bis B sich aus A mit Wasser neuerlich vollständig gefüllt hat, und es findet somit ein intermittirendes Ansaugen, also im gegebenen Falle ein intermittirendes Rauchen statt.

Es bedarf wohl keiner weiteren Ausführungen, um es verständlich erscheinen zu lassen, dass man durch entsprechende Stellung des Hahnes $d_{1}$, durch entsprechende Dimensionirung des Gefässes $B$, welches bei den von mir bisher benützten Apparaten eine Capacität von 25 bis $45 \mathrm{ccm}$. besitzt und theilweise auch durch das entsprechend weit gewählte Heberrohr e die Aufeinanderfolge der einzelnen Saugwirkungen des Apparates innerhalb ziemlich weiter Grenzen reguliren kann. Hierzu bietet aber auch noch das Heberrohr e insofern Gelegenheit, als man durch Hineinschieben des nach aufwärts gebogenen in dem unteren Pfropf des Gefässes B befestigten Endes des Heberrohres e in das Innere von B, den wirksamen Raum des Gefässes B und damit wieder, bei unveränderter Stellung des Hahnes $d_{1}$, die zwischen zwei Saugwirkungen verlaufende Zeit innerhalb gewisser Grenzen reguliren kann. Alle diese Umstände sichern dem Apparate, wenn ich so sagen darf, jenes Anpassungsvermögen, welches nach meinen Erfahrungen die verschiedenen Sorten der von mir benützten Cigarren bis zu einem gewissen Grade verlangen, wenn man darauf ausgeht, die einmal entzündete Cigarre bis zum Ende des Versuches bei intermittirendem Rauchen ohne Unterbrechung in Brand zu erhalten. Ich erwähne, dass nach meinen Beobachtungen beispielsweise bei der österreichischen Virginiercigarre die Zeit zwischen zwei unmittelbar aufeinander folgenden Saugewirkungen kaum mehr als ein Drittel jener betragen darf, die diesbezüglich bei einer Trabucocigarre von mittlerer Güte zulässig ist.

Schliesslich will ich bezüglich des neuen Aspirators noch bemerken, dass manchmal durch Tropfenbildung im längeren 
Schenkel des Heberrohres e die saugende Wirkung des Apparates, wenn auch abgeschwächt; fortdauert, worauf dann kurzes, kräftiges Saugen eintritt u. s. w., d. h. der Apparat functionirt unter Umständen unregelmässig. Wenn das Heberrohr einen nicht zu kleinen Durchmesser besitzt und der Hahn d in passender Weise eingestellt ist, kann man diese Unregelmässigkeit schon dadurch beseitigen, dass man das Gefäss B und mit diesem das Heberrohr e aus der verticalen in eine leicht $\mathrm{zu}$ ermittelnde, passend schwach geneigte Lage bringt und darin während des Versuches dauernd festhält. Unter Benützung dieses Kunstgriffes hat der Apparat bei mehrhundertfacher Verwendung stets tadellos functionirt.

Um einer anderen jener Anforderungen, welche nach meinem Dafürhalten an das Versuchsrauchen gestellt werden müssen, entsprechen zu können, habe ich mein Können als Raucher in dem Sinne verwerthet, dass ich beim eigenen Rauchen beiläufig die Zeit ermittelte, welche beim mässigen Rauchen zum ununterbrochenen Verrauchen einer Cigarre der betreffenden Sorte im Mittel erforderlich ist. Auf Grund der so ermittelten Werthe habe ich beim Versuchsrauchen mit dem neuen Aspirator die Geschwindigkeit des Rauchens entsprechend regulirt.

Was aber die Berücksichtigung der Feuchtigkeit der für die Versuche verwendeten Cigarren anbelangt, so bin ich nach mehrfachen Experimenten dazu gekommen, dass es zweckmässig ist, die Cigarre erst nach mindestens 6 tägigem Lagern an einem staubfreien Orte in einem trockenen, gutventilirten Zimmer zu verwenden. Um mich der Zulässigkeit dieses Vorganges zu versichern, habe ich bei sämmtlichen in Verwendung gezogenen Cigarrensorten nach mindestens 6 tägigem Ablagern die Bestimmung der Feuchtigkeit mehrfach ausgeführt. Dabei bin ich, mich an einen Vorschlag Kissling's anlehnend (Zeitschr. f. analyt. Chem., 21. Jahrg., 1882, S. 75-77), aus den dort angegebenen Gründen vorgegangen und habe die lufttrockene, gewogene Cigarre bei $50-60^{\circ}$ bis zur annähernden Gewichtsconstanz getrocknet. Die hierbei ermittelten Werthe sind in der folgenden Tabelle enthalten. 
Tabelle II.

\begin{tabular}{|c|c|c|c|c|c|c|}
\hline \multirow{3}{*}{$\begin{array}{l}\text { 曾 } \\
\text { 兽 } \\
\text { 意 } \\
\end{array}$} & \multirow{3}{*}{$\begin{array}{c}\text { Name } \\
\text { der } \\
\text { Cigarrensorte }\end{array}$} & \multirow{3}{*}{$\begin{array}{c}\text { Bereichnong } \\
\text { der } \\
\text { Analyse }\end{array}$} & \multicolumn{2}{|c|}{ Gewicht der } & \multirow{2}{*}{\multicolumn{2}{|c|}{$\begin{array}{c}\text { Wassergehalt } \\
\text { in } \\
\text { Procenten }\end{array}$}} \\
\hline & & & $\begin{array}{l}\text { luft- } \\
\text { trockenen }\end{array}$ & $\begin{array}{c}\text { ge- } \\
\text { trockneten }\end{array}$ & & \\
\hline & & & \multicolumn{2}{|c|}{ Cigarren in $\mathrm{g}$} & Einzelbest. & Mittel \\
\hline$\therefore$ & & 1 Best: & 5.259 & 4062 & 5,65 & \\
\hline 1 & Kurze & 2. & 4,448 & 4,171 & 6,23 & 5,94 \\
\hline \multirow{2}{*}{2} & \multirow{2}{*}{ Portorico } & 1. Best. & 4,082 & 3,811 & 6,65 & \multirow{2}{*}{6,84} \\
\hline & & 2. $\gg$ & 3,5338 & 3,289 & 7,02 & \\
\hline \multirow{4}{*}{3} & Kuba-Portorico & 1. Best. & 6,680 & 6,133 & 8,50 & 708 \\
\hline & Nentitsehein) & 2. $>$ & 7,100 & 6,573 & 7,42 & 1,00 \\
\hline & \multirow{2}{*}{$\begin{array}{c}\text { Kuba-Portorico } \\
\text { (Tersehleissbezirk } \\
\text { Brünn) }\end{array}$} & 1. Best. & 7,200 & 6,665 & 7,43 & \multirow{2}{*}{7,27} \\
\hline & & 2. & 7,182 & 6,673 & 7,08 & \\
\hline \multirow{2}{*}{4} & \multirow{2}{*}{ Operas } & 1. Best. & 5,634 & 5,219 & 7,36 & \multirow{2}{*}{6,96} \\
\hline & & 2. $>$ & 5,047 & 4,716 & 6,56 & \\
\hline \multirow{2}{*}{5} & \multirow{2}{*}{$\begin{array}{l}\text { Panetelas } \\
\text { (Havanna) }\end{array}$} & 1. Best. & 5,218 & 4,855 & 6,96 & \multirow{2}{*}{6,80} \\
\hline & & 2., & 5,484 & 5,122 & 6,60 & \\
\hline \multirow{2}{*}{6} & \multirow{2}{*}{ Britannica } & 1. Best. & 6,383 & 5,966 & 6,53 & \multirow{2}{*}{6,34} \\
\hline & & 2. & 6,823 & 6,403 & 6,15 & \\
\hline \multirow{2}{*}{7} & \multirow{2}{*}{ Trabuco } & 1. Best. & 4,992 & 4,632 & 7,20 & \multirow{2}{*}{7,03} \\
\hline & & 2. & 5,285 & 4,923 & $6,8 \check{5}$ & \\
\hline \multirow{2}{*}{8} & \multirow{2}{*}{ Regalitas } & 1. Best. & 6,433 & $\check{0}, 972$ & 7,16 & \multirow{2}{*}{7,16} \\
\hline & & 2. $>$ & 4,861 & 4,513 & 7,16 & \\
\hline \multirow{2}{*}{9} & \multirow{2}{*}{ Brasil-Virginier } & 1. Best. & 4,562 & 4,239 & 7,07 & \multirow{2}{*}{6,90} \\
\hline & & 2. Best. & 5,514 & 5,143 & 6,73 & \\
\hline \multirow{2}{*}{10 . } & \multirow{2}{*}{ Virginier } & 1. Best. & 5,013 & 4,713 & 5,99 & \multirow{2}{*}{5,67} \\
\hline & & 2. > & 5,180 & 4,883 & 5,36 & \\
\hline
\end{tabular}

Mittlerer Wassergehalt aller 10 Cigarrensorten demnach 7,49\%. 
Vergleicht man die nach dem gekennzeichneten Verfahren ffestgestellten Feuchtigkeitsgehalte der verschiedenen Cigarrensorten, so scheint mir aus denselben noch bestimmter als bei den Aschenbestimmungen die Ansicht Bestätigung zu finden, dass bei allen für die Rauchversuche benützten Sorten der österreichischen Regiecigarren die Cigarren derselben Sorte in ausreichendem Maasse die erwünschte gleichmässige $\mathrm{Be}$ schaffenheit besitzen, dass hingegen der Feuchtigkeitsgehalt verschiedener Sorten und damit wohl auch deren Hygroskopicität recht verschieden sein kann.

Den vermutheten Einfluss der Form der Cigarre auf den Verlauf des Rauchprocesses hoffte ich schon durch Benützung österreichischer Regiecigarren $\mathrm{zu}$ ermitteln, weil durch diese ziemlich extreme Cigarrenformen repräsentirt sind, wie ein Blick auf die nebenstehenden Abbildungen lehrt. Eine erläuternde Bemerkung verlangen wohl nur die als Brasil-Virginierund Virginier-Cigarren bezeichneten Sorten, deren Eigenthümlichkeit bekanntlich darin besteht, dass jede Cigarre dieser beiden Sorten ein aus einem kurzen Stück dicken Strohhalmes bestehendes Mundstück besitzt, während durch die ganze Länge der Cigarre, gewissermassen deren Achse bildend, ein dünner Strohhalm angebracht ist, dessen Enden aus der Cigarre etwas herausragen, und der vor dem Anbrennen der Cigarre herausgezogen wird, so dass durch das Herausziehen des Strohhalms ein capillarer Luftkanal in der Cigarre entsteht.

Nun verkenne ich keineswegs, dass ich durch die blosse Wahl der österreichischen Regiecigarren den angestrebten Zweck, eine Grundlage für die Beurtheilung des Einflusses der Cigarrenform auf den Verlauf des Rauchprocesses zu gewinnen, nur sehr unvollkommen erreichen konnte, weil den verschiedenen Cigarrenformen nicht selten auch sehr verschiedene Tabaksorten entsprechen, und es unter diesen Umständen schwierig ist, zu ermitteln, welchen Antheil die Form und welchen Antheil die Tabaksorte an dem Verlaufe des Rauchprocesses hat.

Diese Schwierigkeit könnte durch Herstellung der verschiedenen Cigarrenformen aus ein und derselben Tabaksorte 
leicht behoben werden. So nahe dieser Gedanke liegt, so habe ich doch, wenigstens vorläufig, auf die Verwirklichung desselben aus Gründen verzichtet, die sich der Erörterung entziehen. Ich konnte dies auch mit Rücksicht auf die denn doch ziemlich deutlichen Resultate, welche ich erhalten habe und die ich an entsprechender Stelle anführen und interpretiren werde.

Muss all das bisher Angeführte in gewissem Sinne als Vorbereitung der eigentlichen Untersuchung angeführt werden, so will ich nunmehr diese selbst besprechen und mit der Besprechung der Bestimmung des Nicotingehaltes der österreichischen Regiecigarren beginnen.

Nicotingehalt der österreichischen Regiecigarren.

Im Sinne von früher gemachten Bemerkungen deckt sich der Titel dieses Abschnittes mit seinem Inhalte nur insofern, als sich die meisten der folgenden Resultate auf Cigarren des Brünner Verschleissbezirkes und nur bei einer Sorte auch auf einen anderen Verschleissbezirk beziehen, ein Umstand, dessen Bedeutung, wie aus dieser einen Abweichung hervorgehen wird, entsprechende Würdigung verdient.

Die Nicotinbestimmung wurde mit einigen, nicht sehr wesentlichen Abweichungen nach der Vorschrift von Kissling (Zeitschr. f. analyt. Chem., 1882, 21. Jahrg., S. 64) ausgeführt. Als Indicator wurde mit viel Vortheil anstatt der von Kissling angewendeten Rosolsäure Methylorange benützt. Der Farbenumschlag erfolgt bei diesem Indicator schneller als bei der Rosolsäure und ist auch bei Auerlicht sehr gut wahrnehmbar, so dass Titrationen ohne Anstand auch bei künstlicher Beleuchtung ausgeführt werden können. Dabei ist es jedoch nothwendig, mit dem Zusatze von Indicatorlösung sparsam zu sein und annähernd für die gleichen Mengen von zu titrirender Flüssigkeit die gleiche Menge Indicatorlösung zu verwenden. Bei nachstehenden und allen folgenden Nicotinbestimmungen wurden für je $100 \mathrm{ccm}$. des nicotinhaltigen 
Destillates う Tropfen einer mässig verdünnten Lösung von Methylorange angewendet und diese Menge bei sehr trüben Destillaten auf 6 bis 7 Tropfen erhöht. Für die Extraction der grobgeschnittenen, mit alkoholischer Natronlage präparirten Cigarren mit Aether wurde mit vielem Vortheil der Soxhletsche Extractionsapparat angewendet. Bei der Destillation des nach dem Abdestilliren des Aethers hinterbleibenden, mit $50 \mathrm{ccm}$. ganz verdünnter Natronlauge verdünnten Extractes, wurde der durch nebenstehende Zeichnung versinnbildete Destillationsaufsatz verwendet, nachdem ich mit verschiedenen Aufsätzen anderer Construction bei der nach der Vorschrift Kissling's im Wasserdampfstrom sehr rasch $\mathrm{zu}$ führenden Destillation recht unangenehme Erfahrungen gemacht

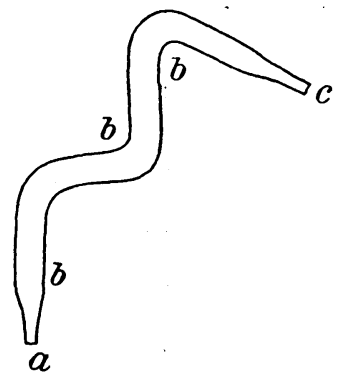

Fig. 2.

habe. Der nach der Zeichnung leicht verständliche und leicht herzustellende Apparat wird aus einem Glasrohr von ca. $12 \mathrm{~mm}$. lichter Weite hergestellt, welches bei $a$ vor der Glasbläserlampe zweckmässig auf 7-8 $\mathrm{mm}$. verengt wird, während die Verengung bei $c$ eine erheblich stärkere sein kann. ${ }^{1}$ ) Die Cigarren wurden stets im lufttrockenen Zustande verwendet und die Ueberführung in diesen Zustand in der früher angegebenen Weise bewirkt. Die erzielten Resultate sind in der Tabelle III enthalten.

Die Resultate haben an sich wohl nur für den österreichischen Cigarrenraucher Interesse, bedürfen aber auch für diesen keiner besonderen Erläuterung. Grösseres Interesse, wenigstens in Rücksicht auf die Zielè meiner Untersuchung,

1) Einen durchaus ähnlichen Destilliraufsatz hat H. Mehring in der Zeitschrift für analyt. Chemie, Jahrg. 39, S. 162, beschrieben. Beim Erscheinen der darauf bezüglichen Mittheilung hatte ich den von mir angefertigten Destilliraufsatz schon durch Monate benützt und den seine Beschreibung enthaltenden Theil meines Manuscriptes fertiggestellt, so dass ich kein Unrecht $\mathrm{zu}$ begehen glaube, dass ich den Apparat trotz jener Publication beschreibe. 
Tabelle III.

\begin{tabular}{|c|c|c|c|c|c|c|}
\hline \multirow{2}{*}{$\begin{array}{c}\text { Name } \\
\text { der } \\
\text { Cigarrensorte }\end{array}$} & \multirow{2}{*}{$\begin{array}{c}\text { Nammer } \\
\text { der } \\
\text { Analyse }\end{array}$} & \multirow{2}{*}{$\begin{array}{l}\text { Zahl der } \\
\text { rerwen- } \\
\text { deten } \\
\text { Cigarren }\end{array}$} & \multirow{2}{*}{$\begin{array}{l}\text { Gesammt- } \\
\text { gewicht } \\
\text { der } \\
\text { verwen. } \\
\text { deten } \\
\text { Cigarren }\end{array}$} & \multicolumn{2}{|c|}{$\begin{array}{c}\text { Nicotingehalt } \\
\text { bezogen auf lufttrockene } \\
\text { Cigarren }\end{array}$} & \multirow{2}{*}{$\begin{array}{l}\text { Mittlerer } \\
\text { Nicotin- } \\
\text { gehalt } \\
\text { in } \\
\text { Procenten }\end{array}$} \\
\hline & & & & $\underset{\text { in }}{\text { Grammen }}$ & $\begin{array}{l}\text { in } \\
\text { Procenten }\end{array}$ & \\
\hline $\begin{array}{c}\text { Gemischte Aus- } \\
\text { länder Cigarren } \\
\text { (Kurze) }\end{array}$ & $\begin{array}{l}1 \\
2 \\
3 \\
4\end{array}$ & $\begin{array}{l}4 \\
4 \\
4 \\
4\end{array}$ & $\begin{array}{l}21,29 \\
19,77 \\
19,72 \\
18,47\end{array}$ & $\begin{array}{l}0,3805 \\
0,3884 \\
0,3616 \\
0,3114\end{array}$ & $\begin{array}{l}1,84 \\
2,08 \\
1,94 \\
1,67\end{array}$ & 1,88 \\
\hline Portorico & $\begin{array}{l}1 \\
2\end{array}$ & $\begin{array}{l}5 \\
5\end{array}$ & $\begin{array}{l}19,54 \\
20,07\end{array}$ & $\begin{array}{l}0,2739 \\
0,2860\end{array}$ & $\begin{array}{l}1,40 \\
1,42\end{array}$ & 1,41 \\
\hline $\begin{array}{c}\text { Cuba-Portorico } \\
\text { (Verschleissbezirk } \\
\text { Neutitschein) }\end{array}$ & $\begin{array}{l}1 \\
2\end{array}$ & $\begin{array}{l}3 \\
3\end{array}$ & $\begin{array}{l}20,04 \\
21,30\end{array}$ & $\begin{array}{l}0,4749 \\
0,5586\end{array}$ & $\begin{array}{l}2,37 \\
2,62\end{array}$ & 2,50 \\
\hline $\begin{array}{l}\text { Kuba-Portorico } \\
\text { (Verschleissbezirk Brünn) }\end{array}$ & $\begin{array}{l}1 \\
2\end{array}$ & $\begin{array}{l}3 \\
3\end{array}$ & $\begin{array}{l}17,63 \\
17,60\end{array}$ & $\begin{array}{l}0,2849 \\
0,2474\end{array}$ & $\begin{array}{l}1,62 \\
1,40\end{array}$ & 1,51 \\
\hline Operas & $\begin{array}{l}1 \\
2\end{array}$ & 7 & $\begin{array}{l}18,81 \\
18,81\end{array}$ & $\begin{array}{l}0,2672 \\
0,2685\end{array}$ & $\begin{array}{l}1,43 \\
1,43\end{array}$ & 1,43 \\
\hline $\begin{array}{r}\text { Panetelas } \\
\text { (Havanna) }\end{array}$ & $\begin{array}{l}1 \\
2\end{array}$ & $\begin{array}{l}4 \\
4\end{array}$ & $\begin{array}{l}21,67 \\
21,94\end{array}$ & $\begin{array}{l}0,3481 \\
0,4399\end{array}$ & $\begin{array}{l}1,61 \\
2,01\end{array}$ & 1,81 \\
\hline Britannica & $\begin{array}{l}1 \\
2\end{array}$ & 7 & $\begin{array}{l}18,79 \\
18,26\end{array}$ & $\begin{array}{l}0,24566 \\
0,2321\end{array}$ & $\begin{array}{l}1,31 \\
1,27\end{array}$ & 1,29 \\
\hline Trabuco & $\begin{array}{l}1 \\
2 \\
3\end{array}$ & $\begin{array}{l}3 \\
4 \\
4\end{array}$ & $\begin{array}{l}14,94 \\
21,01 \\
20,40\end{array}$ & $\begin{array}{l}0,1956 \\
0,3737 \\
0,3562\end{array}$ & $\begin{array}{l}1,31 \\
1,78 \\
1,74\end{array}$ & 1,61 \\
\hline Regalitas & $\begin{array}{l}1 \\
2\end{array}$ & 7 & $\begin{array}{l}19,17 \\
20,20\end{array}$ & $\begin{array}{l}0,5451 \\
0,5991\end{array}$ & $\begin{array}{l}2,84 \\
2,97\end{array}$ & 2,90 \\
\hline Brasil-Viginier & 1 & $\begin{array}{l}5 \\
5\end{array}$ & $\begin{array}{l}21,70 \\
23,34\end{array}$ & $\begin{array}{l}0,31 \preceq ̌ 7 \\
0,3468\end{array}$ & $\begin{array}{l}1,45 \\
1,49\end{array}$ & 1,47 \\
\hline Virginier & $\begin{array}{l}1 \\
2 \\
3\end{array}$ & $\begin{array}{l}4 \\
4 \\
4\end{array}$ & $\begin{array}{l}22,42 \\
20,77 \\
22,77\end{array}$ & $\begin{array}{l}0,95660 \\
0,7907 \\
0,8905\end{array}$ & $\begin{array}{l}4,26 \\
3,81 \\
3,91\end{array}$ & 3,99 \\
\hline
\end{tabular}




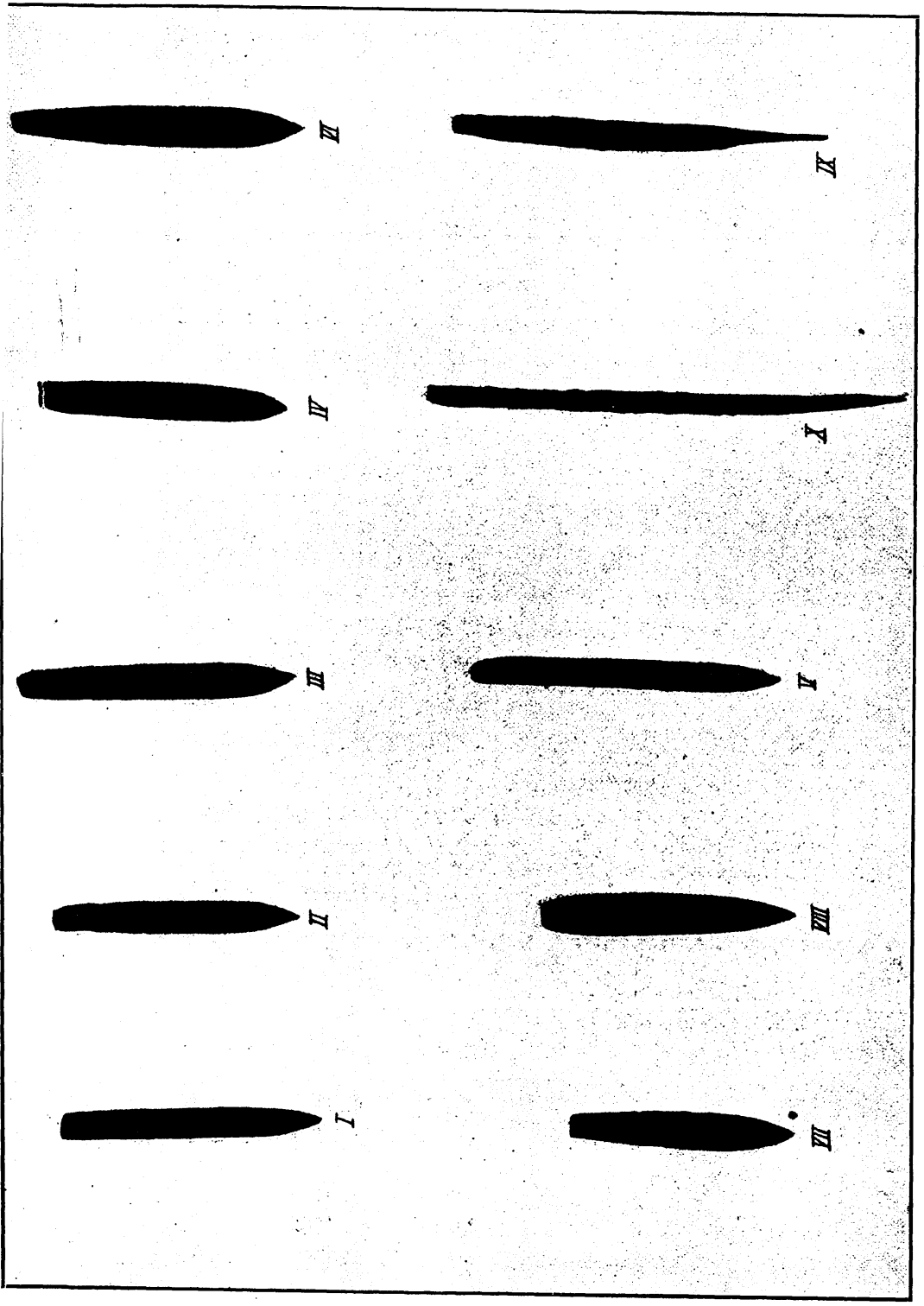

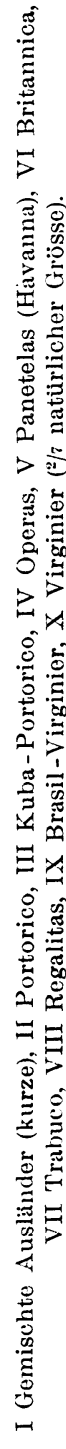


'Brought to you by | University of Arizc Authenticated

Download Date | 6/4/15 2:43 PM 
erlangen dieselben schon, wenn man sie im Zusammenhange mit den Ergebnissen der Untersuchung über den Aschen- und Feuchtigkeitsgehalt, welche in den Tabellen I und II niedergelegt sind, prüft. Um eine solche Prüfung zu erleichtern, habe ich die mittleren Procentgehalte der Cigarren an Asche, Feuchtigkeit und Nicotin in der Tabelle IV zusammengestellt.

$$
\text { Tabelle IV, }
$$

enthaltend die procentischen Mittelwerthe für Asche, Feuchtigkeit und Nicotin der österreichischen Regiecigarren.

\begin{tabular}{l|l|l|l}
\hline \hline Name der Cigarrensorte & Asche & Feuchtigkeit & Nicotin \\
\hline Kurze . . . . . . . . & 19,9 & 5,94 & 1,88 \\
Portorico . . . . . . . & 18,9 & 6,84 & 1,41 \\
Cuba-Portorico....... & 20,0 & 7,27 & 1,40 \\
Operas . . . . . . . & 19,2 & 6,96 & 1,43 \\
Panetelas (Havanna)..... & 19,8 & 6,80 & 1,81 \\
Britannica . . . . . . . & 20,4 & 6,34 & 1,29 \\
Trabuco . . . . . . . & 22,1 & 7,03 & 1,61 \\
Regalitas . . . . . . & 19,1 & 7,16 & 2,90 \\
Brasil-Virginier . . . . . & 18,9 & 6,90 & 1,47 \\
Virginier . . . . . . . & 16,4 & 5,64 & 3,99 \\
& & &
\end{tabular}

Ein Vergleich der Daten dieser Tabelle lehrt nun, dass vier der untersuchten Cigarrensorten procentisch den gleichen Nicotingehalt besitzen, und dass dieselben vier Cigarrensorten auch eine sehr weitgehende Uebereinstimmung im Feuchtigkeitsgehalt und im Hinblick auf die unvollkommene Methode der Aschenbestimmung immerhin eine bemerkenswerthe Uebereinstimmung in den Aschengehalten zeigen. Es könnte darum, wie ich meine, mit einiger Berechtigung gefolgert werden, dass vier Cigarrensorten, welche in den Tabellen als "Portorico», «Cuba-Portorico» (Brünn), «Operas» und «Brasil-Virginier» angeführt sind, aus derselben Tabaksorte oder derselben Tabakmischung erzeugt werden. Untereinander eine ähnliche Uebereinstimmung zeigen wieder die als «Kurze" und "Havanna" 
bezeichneten Sorten, auf welche demgemäss auch die eben gemachte Folgerung sinngemäss Anwendung finden kann. Da nun in diesen Sorten fast alle Formen der österreichischen Regiecigarren vertreten sind, so scheint auf diesem Wege eine brauchbare Grundlage gewonnen, um von ihr aus später die Grösse des Einflusses der Cigarrenform auf den Verlauf des Rauchprocesses beurtheilen zu können.

Rauchversuche.

Was die Ausführung der Rauchversuche selbst anbelangt, so muss ich zunächst bemerken, dass ich bis jetzt ausschliesslich die früher genannten Cigarrensorten verwendet habe und bei Ausführung der Versuche folgendermassen vorgegangen bin: die einzelnen Cigarren kamen ohne Auswahl zur Verwendung; nachdem sie in der früher gekennzeichneten Weise lufttrocken gemacht worden waren. Unmittelbar vor der Verwendung wurde die Cigarre bis auf $1 / 100 \mathrm{~g}$ genau gewogen, die Spitze mit stets möglichst gleichmässiger Schnittfläche abgeschnitten und auch deren Gewicht mit der angegebenen Genauigkeit bestimmt. Die Menge des verrauchten Theiles der Cigarre war bei den verschiedenen Versuchsreihen, von welchen jede alle früher genannten Cigarrensorten umfasste, nach Bedarf erheblich verschieden, so zwar, dass bei einzelnen Reihen, welche hauptsächlich der Bestimmung des Nicotins im Cigarrenrauche dienen sollten, mehr als $3 / 4$, bei andern hingegen kaum mehr als die Hälfte vom Gewichte der Cigarre verraucht wurde. Am Ende eines jeden Rauchversuches wurde der unverrauchte Theil der Cigarre (Cigarrenstumpf) in eine Eprouvette eingeschlossen, nach dem Erlöschen der Glut mittelst eines Haarpinsels von den anhängenden Theilen der Asche sorgfältig befreit und in einem trockenen, gut ventilirten Zimmer, vor Staub geschützt, etwa drei Tage liegen gelassen, sodann bis auf $1 / 100 \mathrm{~g}$ genau gewogen, nach weiterem 24 stündigen Liegen neuerdings gewogen, und das Wägen so oft wiederholt, bis bei zwei aufeinanderfolgenden Wägungen sich Gewichtsconstanz zeigte. In den meisten Fällen war dies nach 5 bis 6 tägigem Lagern der Stumpfe der Fall. Aus dem 
Gewichte der Cigarre, der Spitze und des Stumpfes wurde das Gewicht des verrauchten Theiles der Cigarre berechnet, wobei es selbstverständlich erscheint, dass auch hierbei von einer absoluten Genauigkeit keine Rede sein kann, und zwar schon mit Rücksicht darauf, dass die aus mit "Rauchtheer durchtränkter und theilweise aus verkohlter Substanz bestehenden Stumpfe einen ganz andern Grad von Hygroskopicität zeigen müssen, als die ganzen, unverbrauchten Cigarren.

Was nun die Auswahl und Anordnung der bei der Untersuchung verwendeten Condensations- und Absorptionsgefässe anbelangt, so mussten dieselben selbstverständlich den speciellen Zweck, welchem die betreffende Versuchsreihe dienen sollte, nach Thunlichkeit angepasst werden. Mit Rücksicht auf diesen Umstand werde ich die hierauf bezüglichen Einzelheiten bei dem betreffenden Abschnitte besprechen und mich vorläufig mit folgender Ausführung begnügen :

Die Verdichtung und Absorption des Tabakrauches hat mir, namentlich am Beginne der Untersuchung, nicht geringe Schwierigkeiten bereitet. Der Tabakrauch besitzt die für Untersuchungen unangenehme Eigenschaft der Produkte der trockenen Destillation mancher organischer Substanzen, einen schwer verdichtbaren Nebel zu bilden, welcher durch die mannigfaltigen Condensations- und Absorptionsgefässe durchgeht. Trotz der Anwendung geräumiger Condensations- und Absorptionsapparate, welche zum Theil mit Glasperlen und energisch wirkenden Absorptionsmitteln gefüllt waren, und deren Zahl bei einzelnen Versuchen bis auf 6 und selbst darüber stieg, gelang es mir bis jetzt nicht, die Condensation, respective Absorption der Rauchbestandtheile so vollständig zu bewirken, dass das Wasser des Aspirators, welches stets für eine grössere Anzahl von Einzelversuchen immer wieder benutzt wurde, völlig geruchlos geblieben wäre. Dasselbe nahm vielmehr unter allen Umständen schon nach dem Verrauchen einiger Cigarren einen leicht wahrnehmbaren, im Anfange nicht gerade unangenehmen Geruch an, welcher, bei Weiterbenutzung desselben Wassers für eine grössere Anzahl von Rauchversuchen, allmählich immer stärker und sodann unangenehm wurde, wobei das 
Wasser eine bräunlich gelbe Farbe annahm und schwach opalisirend wurde.

Vielleicht bedingen die in das Wasser des Aspirators übergehenden, an und für sich übelriechenden Stoffe in starker Verdünnung in ähnlicher Weise den Wohlgeruch des Tabakrauches, wie viele in concentrirtem Zustande unangenehm riechende Essenzen bei starker Verdünnung Wohlgeruch verbreiten. Die Menge dieser im Tabakrauch enthaltenen, eigentlichen Riechstoffe ist indessen nach allen meinen Beobachtungen sehr gering, und es gelang mir nicht, sie in solcher Menge aus dem Aspiratorwasser zu erhalten, um sie chemisch charakterisiren zu können, trotzdem z. B. bei einem darauf bezüglichen Versuche $700 \mathrm{~g}$ Cigarren mit demselben Aspiratorwasser verraucht worden waren. Indessen glaube ich jedoch soviel sagen zu können, dass ihre Anwesenheit im nicht condensirbaren Theil des Rauches, ob ihrer Geringfügigkeit, die Resultate der Gasanalyse in keiner erkennbaren Weise $\mathrm{zu}$ beeinflussen vermag.

Bezüglich der Verdichtung der condensirbaren Bestandtheile des Tabakrauches will ich im Allgemeinen noch bemerken, dass ich nach mehreren, darauf bezüglichen, zeitraubenden und umständlichen, jedoch unbefriedigenden Versuchen schliesslich bei einem Verfahren stehen geblieben bin, welches im Wesentlichen auf den Beobachtungen basirt, dass der Tabakrauch die Tendenz hat, sich am Boden der Condensationsgefässe anzusammeln, um sich sodann, wenn das Zuströmen des Rauches zeitweise auf hört, ziemlich rasch und zum grösseren Theile $\mathrm{zu}$ verdichten, und dass wir in der entfetteten Baumwolle ein ganz ausgezeichnetes Mittel besitzen, den Rauchtheer, also die condensirbaren Theile des Tabakrauches, hinlänglich vollständig zurückzuhalten.

Die nebenstehende Figur (Fig. 3) zeigt die Einrichtung, welche ich dem ersten, der bei den Rauchversuchen verwendeten Condensationsgefässe schliesslich gegeben habe, wozu ich bemerke, dass ich als erstes dasjenige Condensationsgefäss bezeichne, an welchem die zu verrauchende Cigarre unmittelbar angebracht wurde, und welches also das dem Aspirator 
entgegengesetzte Ende des ganzen Rauchapparates bildete. Der Erlenmeyerkolben A hat je nach Bedarf eine Capacität von $1 / 4$ bis $1 / 2$ Liter und ist mittelst des zweimal durchbohrten Pfropfes B verschlossen, während der Boden des Kolbens mit entfetteter Baumwolle in etwa $2 \mathrm{~cm}$. hoher Schichte bedeckt ist. In der einen, weiteren Bohrung des Propfes B steckt das beiderseits offene Glasrohr $\mathrm{C}$, dessen lichter Durchmesser annähernd ebenso gross ist, wie das weitere Ende einer gewöhnlichen Cigarrenspitze, so dass also wie bei dieser die Cigarre an das äussere Ende des Glasrohres, und ohne ihr Deckblatt zu verletzen, angefügt werden kann. Das obere, freie, für die Aufnahme der Cigarre bestimmte Rohrende $\mathrm{C}$ ragt einige Centimeter über den $\mathrm{Pfropf} B$ heraus, während das untere Ende so weit in den Kolben hineinreicht, dass dieses Ende die am Boden des Kolbens angebrachte Baumwollschichte gut berührt. Vom äussersten, unteren Ende bis fast zum oberen Ende des Propfens ist das Rohr C mit entfetteter Baumwolle lose, jedoch in zusammenhängender, möglichst gleichmässiger Schicht gefüllt. In der zweiten engeren Bohrung des Propfens B steckt das

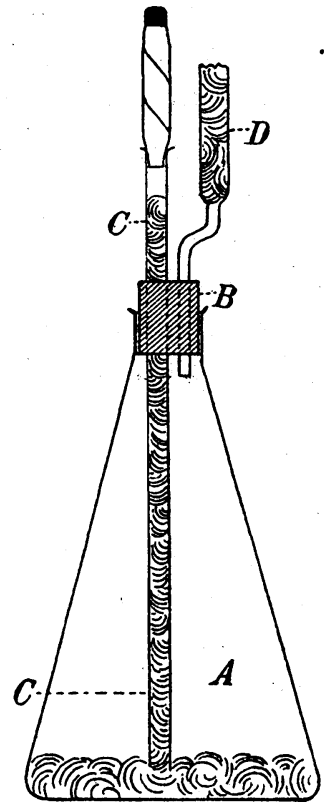

Fig. 3. verjüngte und, wie aus der Zeichnung ersichtlich, zweimal gebogene Rohr D, welches in seinem nicht verjüngten Theile einen lichten-Durchmesser von ca. $18 \mathrm{~mm}$. und eine im Allgemeinen den Anforderungen des Versuches angepasste, $75 \mathrm{~cm}$. niemals überschreitende Länge hat. Diese erläuternden Bemerkungen werden zum Verständniss der in Figur 3 dargestellten Einrichtung genügen, und es kann an dieselbe die Besprechung der einzelnen Versuchsreihen unmittelbar angeschlossen werden. 
Prüfung des Cigarrenrauches auf Schwefelwas serstoff, Cyanwasserstoff und Kohlenoxyd.

Die chemische Prüfung des Cigarrenrauches auf die im Titel des Abschnittes genannten Verbindungen wurde von mir bisher stets nur qualitativ durchgeführt, jedoch immer mit im lufttrockenen Zustande gewogenen Cigarren. Die qualitative Prüfung auf Schwefelwasserstoff, Kohlenoxyd und Fettsäuren schien mir durchaus nothwendig, trotzdem mehrere darauf bezügliche Untersuchungen anderer Autoren vorliegen. Denn einerseits sind diese Untersuchungen nach der mir zugänglichen Litteratur nicht sehr zahlreich und erstrecken sich nur auf einige wenige Versuche, welche untereinander kaum einen Vergleich zulassen. Und andererseits erscheint mir das Vorhandensein dieser Stoffe im Cigarrenrauch, "trotzdem der Tabak Sulfate, organische Stickstoffverbindungen und Alkalien in grosser Menge enthält», nicht so selbstverständlich wie Kissling, weil ich der Ansicht bin, dass die Anwesenheit der genannten Stoffe im Tabak allenfalls das Vorhandensein von Sulfiden und Cyaniden der Alkalien und alkalischen Erden in der Asche als wahrscheinlich erscheinen lässt, aber keineswegs das Auftreten von Schwefel- und Cyanwasserstoff im Tabakrauch gegeben erscheint. Bei meinen diesbezüglichen Versuchen wurden von jeder Cigarrensorte in der Regel drei Stück verraucht und der Rauch aller Cigarren derselben Sorte gemeinschaftlich geprüft. Der hierbei benutzte Apparat ist durch nebenstehende Zeichnung (Fig. 4) soweit gekennzeichnet, dass er nur weniger, erläuternder Bemerkungen bedarf.

A ist das erste Condensationsgefäss, dessen Ausgestaltung ich kurz vorher beschrieben habe und an dem die Versuchscigarre a angebracht ist. Das mässig lange Rohr $D$ ist mit entfetteter Baumwolle, das Rohr E hingegen mit Bleibaumwolle ${ }^{1}$ )

1) Ich bezeichne mit dem Namen Bleibaumwolle ein Präparat, welchès ich durch Tränken von entfetteter Baumwolle mit einer mässig concentrirten Bleizuckerlösung, Pressen zwischen Filtrirpapier, Tränken mit einer Lösung von Natriumcarbonat, Auswaschen mit Wasser, neuerliches Pressen, Trocknen und Zerzupfen des Pressballens dargestellt habe. Die so hergestellte Bleibaumwolle eignet sich wegen ihrer ausserordentlich grossen Empfindlichkeit ganz vorzüglich zur Prüfung von Gasen auf Schwefelwasserstoff. 
gefüllt. An das Rohr E schliessen sich die beiden, mit Kalilauge gefüllten Absorptionskölbchen $\mathrm{F}$ und an diese der Aspirator. Bei Ausführung der Versuche konnte stets beobachtet werden, dass der durch die Rauchröhre bis auf den Boden des Kolbens geleitete Cigarrenrauch sich in der diesen Boden bedeckenden Baumwollschichte und nur sehr wenig darüber ausbreitet, und dass der Nebel dieses Rauches sich bis zum nächsten Zug des intermittirend wirkenden Aspirators fast vollständig verdichtet, so zwar, dass der mittlere und obere Theil des Kolbens bei guter Leitung des Versuches durch Nebel fast nicht mehr getrübt erscheinen, und sich die entfettete Baum-

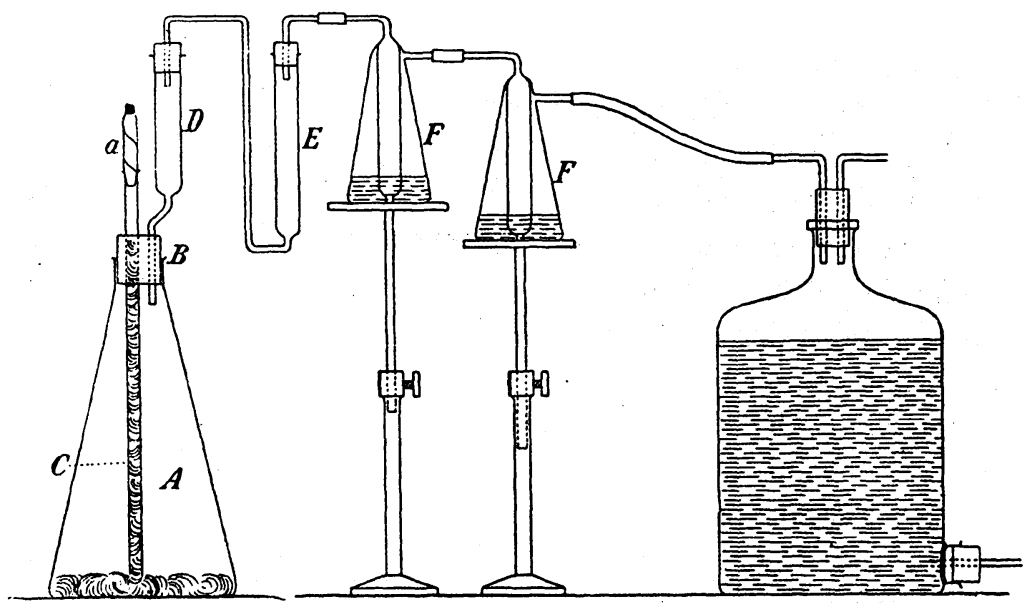

Fig. 4.

wolle des Rohres D in dem untern Theil des Rohres nur sehr allmählich und nur wenig bräunlichgelb färbt, während der obere Theil der Baumwolle dieses Rohres beim Verrauchen völlig weiss bleibt. Die Bleibaumwolle des Rohres $\mathrm{E}$ hingegen färbt sich am Eintrittsorte des Rohres $E$ fast unmittelbar nach dem Beginne des Versuchsrauchens, und die Rauchgase geben, wie das Fortschreiten der Färbung in dem Rohre E zeigt, den Schwefelwasserstoff rasch und vollständig ab. Hat man auf die gleichmässige Füllung des Rohres $\mathrm{E}$ die nöthige Sorgfalt verwendet, so schreitet die durch den Schwefelwasserstoff bedingte Färbung der Bleibaumwolle bei fortdauerndem Rauchen 
sehr allmählich und sehr gleichmässig von unten nach oben fort, und man erhält, wenn man die Versuchsverhältnisse sonst möglichst gleichartig gestaltet, in der Länge der gefärbten Schichte der Bleibaumwolle und in der Stärke der Färbung derselben nicht ganz werthlose Anhaltspunkte zur Beurtheilung der Menge des Schwefelwasserstoffs in dem Rauche der verschiedenen Cigarrensorten. Dass die mit Kalilauge beschickten Kölbchen F vor Allem bestimmt waren, den im Rauch etwa vorhandenen Cyanwasserstoff zu binden, erscheint ebenso selbstverständlich wie die Bemerkung, dass von der Kalilauge auch die Kohlensäure und die anderen sauren Bestandtheile des Cigarrenrauches zurückgehalten wurden. Der Aetzkali im reichen Ueberschuss enthaltende Inhalt der beiden Kölbchen F wurde nach vollendetem Rauchen in einem Porzellanschälchen auf dem Wasserbad concentrirt und mittelst der Berlinerblaureaction auf 'Blausäure geprüft.

Bevor ich nun die Resultate der qualitativen Prüfung des Cigarrenrauches auf Schwefelwasserstoff, Blausäure und Kohlenoxyd mittheile, muss ich noch anführen, dass ich für jede Cigarrensorte die früher gekennzeichnete Ordnung bei einem Versuche stets dahin erweiterte, dass ich zwischen das zweite, mit Kalilauge beschickte Kölbchen und den Aspirator noch ein Kölbchen, welches mit ammoniakalischer Silberlösung beschickt war, einschaltete. Ammoniakalische Silberlösung ist nach der von mir vor Jahren gemachten Mittheilung (Fischer, Zeitschr. f. angew. Chem. Jahrg. 1892, S. 324) ein ausgezeichnetes Reagens auf Kohlenoxyd, indem schon äusserst geringe Mengen dieses Gases die Silberlösung braunroth, irgendwie erhebliche Mengen aber unter Ausscheidung von flockigem Silber fast schwarz färben. Durch die angegebene Versuchserweitterung konnte ich demgemäss den Rauch aller Cigarrensorten mit Leichtigkeit auf das Vorhandensein von Kohlenoxyd prüfen.

Die Resultate der in der angegebenen Richtung vorgenommenen, qualitativen Prüfung des Cigarrenrauehes kann ich in folgenden Sätzen zusammenfassen:

1. Der Rauch aller untersuchten Cigarrensorten enthält Schwefelwasserstoff. Die Menge desselben ist bei den einzelnen 
Cigarrensorten allem Anscheine nach verschieden. Die gemachten Beobachtungen gestatten indessen nicht, allgemein zu sagen, dass die billigen Cigarrensorten viel, die theuren wenig Schwefelwasserstoff entwickeln.

2. Der Rauch aller Cigarrensorten enthält Kohlenoxyd.

3. Bei keiner Cigarrensorte konnte ich in der Absorptionsflüssigkeit der Kölbchen F Cyanwasserstoff nachweisen.

$\mathrm{Zu}$ diesen Punkten will ich folgende Bemerkungen machen :

ad 1. führe ich beispielsweise an, dass die Regalitascigarren, welche per Stück mit 18 Heller bezahlt werden, beim Rauchen allem Anscheine nach ebensoviel Schwefelwasserstoff entwickeln, wie die Portoricocigarren, von welchen das Stück 7 Heller kostet. Mit Rücksicht darauf, dass sich unter den im ersten Condensationsgefäss ansammelnden Produkten stets relativ reichliche Mengen von kohlensaurem Ammon finden, wie dies auch von Kissling constatirt wurde (Dingler's polyt. Journ. Jahrg. 1882, Bd. 244, S. 235), scheint es mir weder durch meine, noch durch die von anderen Forschern ausgeführten Versuche keineswegs erwiesen, dass der nachgewiesene Schwefelwasserstoff als solcher und nicht als Schwefelammonium im Cigarrenrauch enthalten ist. $\mathrm{Da}$ der Dampf der letztgenannten Verbindung nach meinen vielfachen Wahrnehmungen auf die Schleimhäute der Mund- und Rachenhöhle sehr stark ätzend wirkt, scheint mir die Beachtung dieses Umstandes seitens des Physiologen geboten.

ad 2. Der Gehalt des Rauches an Kohlenoxyd wurde bei allen Cigarrensorten quantitativ mit Sicherheit festgestellt und werden die diesbezüglichen Resultate im Zusammenhange mit den quantitativen Bestimmungen der andern, nicht condensirbaren Rauchbestandtheile im folgenden Abschnitte mitgetheilt werden.

ad 3. Meine bezüglich des Cyanwasserstoffes gemachten Beobachtungen scheinen mir, trotzdem sie untereinander völlig übereinstimmen, nicht zu beweisen, dass im Rauche der untersuchten Cigarren überhaupt kein Cyanwasserstoff enthalten war. Derselbe kann ebensogut im ersten Condensationsgefäss zurückgehalten, als von der Bleibaumwolle gebunden worden sein. Die erste Möglichkeit wird von Kissling angenommen, 
indem er im Hinblick auf die negativen Resultate der Untersuchung der zur Absorption der sauren Rauchprodukte verwendeten Natronlauge auf Seite 325 der obcitirten Abhandlung sagt, «dass der im Tabakrauch befindliche Cyanwasserstoff im ersten (leeren) Kolben zurückgehalten wurde.» Ich kann dieser Anschauung Kissling's heute ebensowenig beipflichten als widersprechen, weil bei einigen Untersuchungen der Condensationsprodukte des ersten Kolbens auf Cyanwasserstoff, die ich ausgeführt habe, die Berlinerblaureaction in einer keineswegs unzweifelhaften Bestimmtheit erhalten werden konnte.

Da mir jedoch das Vorhandensein von Cyanwasserstoff oder von Cyanammonium im Tabakrauch selbst in der kleinsten Menge von erheblicher Wichtigkeit $\mathrm{zu}$ sein scheint, gedenke ich den Gegenstand in eingehender Weise zu studiren.

Bestimmung der Kohlensäure, des Sauerstoffs und des Kohlenoxyds im Cigarrenrauch.

Die im vorhergehenden Abschnitte mitgetheilten Beobachtungen rechtfertigen, wie ich meine, das Verfahren hinlänglich, welches ich behufs der quantitativen Bestimmung der nicht condensirbaren Bestandtheile des Cigarrenrauches eingehalten habe und welches die direkte Bestimmung nicht allein des giftigen Kohlenoxyds, sondern auch des Kohlendioxyds und des Sauerstoffs umfasst. Benützt wurde der in dem vorhergehenden Abschnitte beschriebene, dem besonderen Zweck angepasste Apparat. Die Abänderung bestand einzig und allein darin, dass die Absorptionskölbchen $\mathrm{F}$ durch eine Bunte'sche Gasbürette und der Erlenmeyerkolben durch einen Rundkolben von erheblich geringerem Rauminhalte (ca. $300 \mathrm{ccm}$.) ersetzt wurden. Alle gasometrischen Bestimmungen wurden mit der Bunte'schen Bürette ausgeführt und bei der Ausführung nach den allgemein bekannten Methoden vorgegangen. Die folgenden Tabellen enthalten die bezüglichen Resultate nebst Angabe des Gewichtes des verrauchten Theiles der Cigarre und des Volumens des bei dem betreffenden Versuche vom Aspirator abgeflossenen Wassers. Die letztere Angabe gibt annähernd das Volumen des bei dem Versuch entwickelten Cigarrenrauches. 


\section{Tabelle V}

centhaltend die Mengen der im Rauch enthaltenen nicht condensirbaren Bestandtheile $\left(\mathrm{CO}_{2}, \mathrm{O}_{2}, \mathrm{CO}\right)$ nebst dem Gewichte der verrauchten Cigarre, Menge des Aspiratorwassers und Zeit des Rauchens.

\begin{tabular}{|c|c|c|c|c|c|c|c|}
\hline \multirow{2}{*}{$\begin{array}{c}\text { Name } \\
\text { der } \\
\text { Cigarrensorte }\end{array}$} & \multirow{2}{*}{ 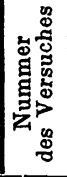 } & \multirow{2}{*}{ 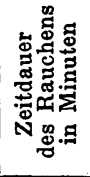 } & \multirow{2}{*}{ 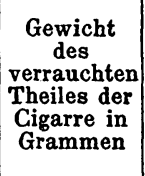 } & \multirow{2}{*}{$\begin{array}{c}\text { Volumen } \\
\text { des ver- } \\
\text { brauchten } \\
\text { Aspirator- } \\
\text { wassers in } \\
\text { ccm. }\end{array}$} & \multicolumn{3}{|c|}{$\begin{array}{l}\text { Gehalt des Rauches } \\
\text { in Volumprocenten an }\end{array}$} \\
\hline & & & & & $\mathrm{CO}_{2}$ & $\mathrm{O}_{2}$ & Co \\
\hline \multirow{4}{*}{ Kurze } & 1 & 30 & 3,04 & 2650 & 2,5 & 12,9 & 1,3 \\
\hline & 2 & 30 & 3,27 & 2120 & 8,2 & 12,6 & 3,0 \\
\hline & 3 & 40 & 2,74 & 37500 & 5,2 & 15,6 & 0,6 \\
\hline & 4 & 30 & 3,03 & 2520 & 6,4 & 15,2 & 1,2 \\
\hline \multirow{7}{*}{ Portorico } & 1 & 40 & 3,73 & 1850 & 21,2 & 3,6 & 4,5 \\
\hline & 2 & 50 & 4,07 & 1615 & 18,2 & 4,6 & 3,8 \\
\hline & 3 & 52 & 3,68 & 1300 & 18,4 & 4,7 & 4,9 \\
\hline & 4 & 49 & 3,31 & 1305 & 20,5 & 4,7 & 4,6 \\
\hline & 5 & 46 & 3,24 & 1000 & 18,2 & 5,1 & 5,5 \\
\hline & 6 & 37 & 3,42 & 1725 & 16,5 & 9,4 & 3,9 \\
\hline & 7 & 29 & 3,25 & 1145 & 22,2 & 3,1 & 7,3 \\
\hline \multirow{9}{*}{$\begin{array}{l}\text { Cuba- } \\
\text { Portorico }\end{array}$} & 1 & 52 & 5,33 & 1720. & 25,0 & 1,4 & 4,1 \\
\hline & 2 & 49 & 5,09 & 1440 & 20,4 & 4,2 & 2,0 \\
\hline & 3 & 49 & 5,33 & 1500 & 20,9 & 3,2 & 3,1 \\
\hline & 4 & 54 & 5,59 & 1680 & 21,2 & 2,9 & 2,9 \\
\hline & 5 & 55 & 4,75 & 1550 & 18,0 & 5,0 & 1,5 \\
\hline & 6 & 62 & 5,78 & 1350 & 21,2 & 3,9 & 5,8 \\
\hline & 7 & 83 & 6,43 & 1800 & 21,4 & 3,8 & 5,5 \\
\hline & 8 & 44 & 5,34 & 1910 & 23,0 & 1,5 & 7,9 \\
\hline & 9 & 41 & 4,97 & 1715 & 22,9 & 3,6 & 7,1 \\
\hline \multirow{8}{*}{ Operas } & 1 & 54 & 4,81 & 1190 & 20,0 & 3,4 & 6,0 \\
\hline & 2 & 50 & 5,04 & 1300 & 19,0 & 5,0 & 5,8 \\
\hline & 3 & 50 & 4,23 & 1320 & 21,1 & 4,0 & 6,4 \\
\hline & 4 & 53 & 5,33 & 1870 & 22,8 & 2,4 & 6,2 \\
\hline & 5 & 47 & 5,11 & 1145 & 20,7 & 4,7 & 4,8 \\
\hline & 6 & 50 & 4,78 & 1175 & 19,4 & 5,3 & 5,4 \\
\hline & 7 & 41 & 5,12 & 1650 & 24,7 & 2,7 & 7,0 \\
\hline & 8 & 43 & 4,97 & 1900 & 24,5 & 2,7 & 7,3 \\
\hline Panetelas: & 1 & 40 & 3,61 & 1600 & 10,2 & 12,8 & 2,6 \\
\hline (Havanna) & 2 & 35 & 3,60 & 1650 & 11,2 & 10,8 & 3,2 \\
\hline
\end{tabular}


Tabelle V (Fortsetzung).

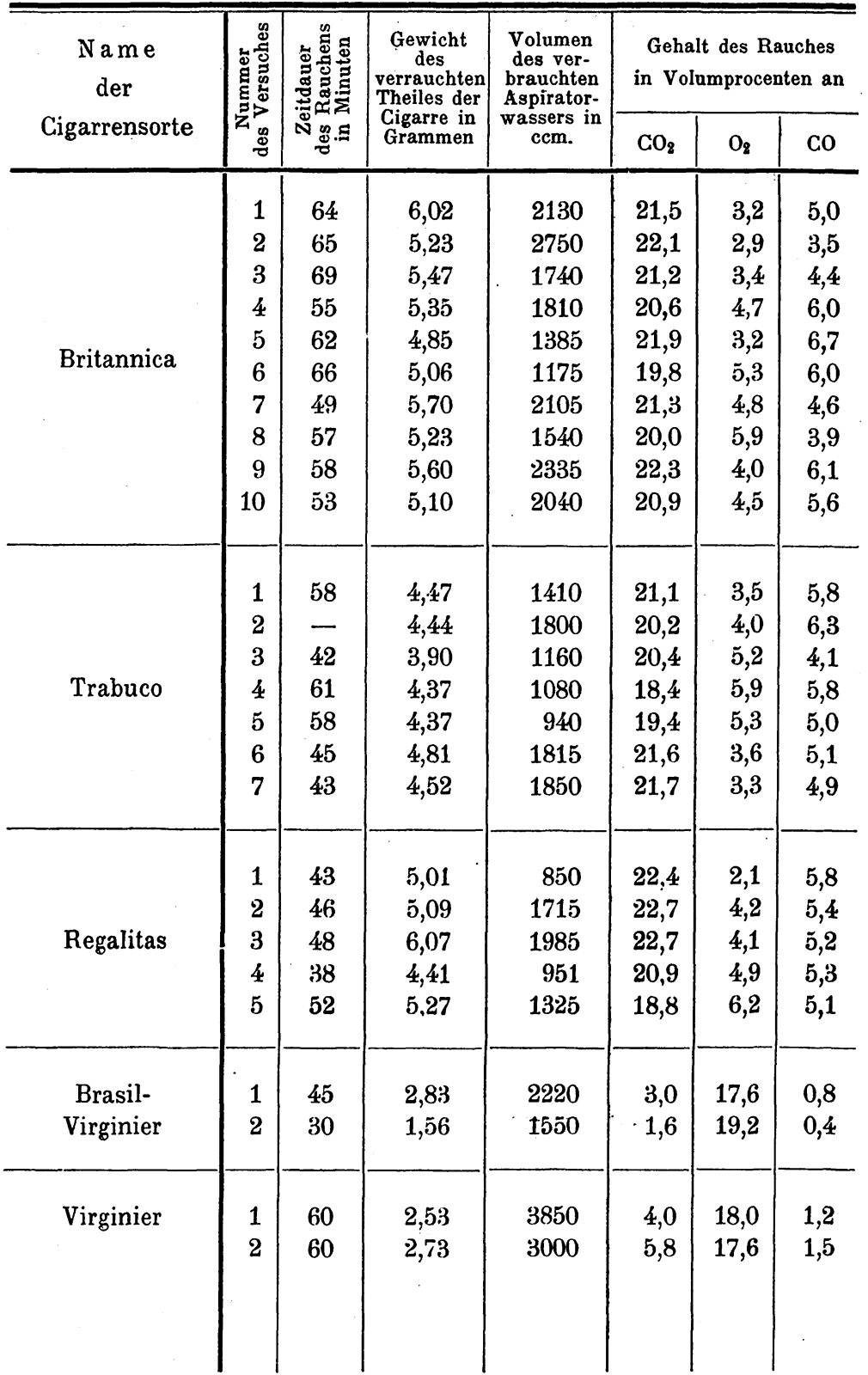




\section{Tabelle VI}

(enthaltend die Mengen des im Cigarrenrauche ermittelten Kohlendioxyds, 'Sauerstoffes und des Kohlenoxyds, nebst Zeit des Rauchens und des verbrauchten Aspiratorwassers, alles berechnet für $1 \mathrm{~g}$ verrauchter

Cigarre.

\begin{tabular}{|c|c|c|c|c|c|c|}
\hline \multirow{2}{*}{$\begin{array}{c}\text { Na me } \\
\text { der } \\
\text { Cigarrensorte }\end{array}$} & \multirow{2}{*}{ 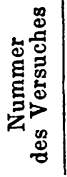 } & \multirow{2}{*}{ 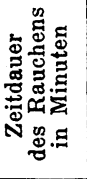 } & \multirow{2}{*}{$\begin{array}{c}\text { Ver- } \\
\text { brauchtes } \\
\text { Aspirator- } \\
\text { wasser in } \\
\text { ccm. }\end{array}$} & \multicolumn{3}{|c|}{ Gehalt in $\mathrm{ccm}$. von } \\
\hline & & & & $\mathrm{CO}_{2}$ & $\mathrm{O}_{2}$ & CO \\
\hline Kurze & $\begin{array}{l}1 \\
2 \\
3 \\
4\end{array}$ & $\begin{array}{r}9,9 \\
9,2 \\
14,6 \\
9,9\end{array}$ & $\begin{array}{r}872 \\
648 \\
1369 \\
832\end{array}$ & $\begin{array}{l}22,8 \\
53,1 \\
71,2 \\
53,2\end{array}$ & $\begin{array}{r}112,5 \\
88,1 \\
213,6 \\
126,5\end{array}$ & $\begin{array}{r}11,3 \\
19,4 \\
8,2 \\
10,0\end{array}$ \\
\hline Portorico & $\begin{array}{l}1 \\
2 \\
3 \\
4 \\
5 \\
6 \\
7\end{array}$ & $\begin{array}{r}10,7 \\
12,3 \\
14,1 \\
14,8 \\
14,2 \\
10,8 \\
8,9\end{array}$ & $\begin{array}{l}496 \\
397 \\
353 \\
394 \\
309 \\
504 \\
352\end{array}$ & $\begin{array}{r}105,2 \\
72,3 \\
64,9 \\
80,8 \\
56,2 \\
83,1 \\
78,1\end{array}$ & $\begin{array}{l}17,8 \\
18,2 \\
16,6 \\
18,5 \\
15,8 \\
47,4 \\
11,0\end{array}$ & $\begin{array}{l}22,3 \\
15,0 \\
17,3 \\
18,1 \\
17,0 \\
19,6 \\
25,7\end{array}$ \\
\hline $\begin{array}{c}\text { Cuba- } \\
\text { Portorico }\end{array}$ & $\begin{array}{l}1 \\
2 \\
3 \\
4 \\
5 \\
6 \\
7 \\
8 \\
9\end{array}$ & $\begin{array}{r}9,8 \\
9,6 \\
9,2 \\
9,7 \\
11,6 \\
10,7 \\
12,9 \\
8,2 \\
8,2\end{array}$ & $\begin{array}{l}323 \\
283 \\
281 \\
301 \\
326 \\
234 \\
280 \\
358 \\
345\end{array}$ & $\begin{array}{l}80,8 \\
57,7 \\
58,7 \\
64,1 \\
58,7 \\
49,6 \\
59,9 \\
82,3 \\
79,0\end{array}$ & $\begin{array}{r}4,5 \\
11,9 \\
9,0 \\
8,7 \\
16,3 \\
9,1 \\
10,6 \\
5,4 \\
12,4\end{array}$ & $\begin{array}{r}13,2 \\
5,7 \\
8,7 \\
8,7 \\
4,9 \\
13,5 \\
15,4 \\
28,3 \\
24,5\end{array}$ \\
\hline Operas & $\begin{array}{l}1 \\
2 \\
3 \\
4 \\
5 \\
6 \\
7 \\
8\end{array}$ & $\begin{array}{r}11,2 \\
9,9 \\
11,8 \\
9,9 \\
9,2 \\
10,5 \\
8,0 \\
8,6\end{array}$ & $\begin{array}{l}247 \\
258 \\
312 \\
351 \\
224 \\
246 \\
322 \\
382\end{array}$ & $\begin{array}{l}49,4 \\
49,0 \\
65,8 \\
80,0 \\
46,3 \\
47,7 \\
79,5 \\
93,6\end{array}$ & $\begin{array}{r}8,4 \\
12,9 \\
12,5 \\
8,4 \\
10,5 \\
13,0 \\
8,6 \\
10,3\end{array}$ & $\begin{array}{l}14,8 \\
14,9 \\
19,9 \\
21,8 \\
10,8 \\
13,3 \\
22,5 \\
27,8\end{array}$ \\
\hline $\begin{array}{l}\text { Panetelas } \\
\text { (Havanna) }\end{array}$ & $\begin{array}{l}1 \\
2\end{array}$ & $\begin{array}{r}11,0 \\
9,7\end{array}$ & $\begin{array}{l}443 \\
458\end{array}$ & $\begin{array}{l}45,2 \\
51,3\end{array}$ & $\begin{array}{l}56,7 \\
49,5\end{array}$ & $\begin{array}{l}11,5 \\
14,7\end{array}$ \\
\hline
\end{tabular}


Tabelle VI (Fortsetzung).

\begin{tabular}{|c|c|c|c|c|c|c|}
\hline \multirow{2}{*}{$\begin{array}{c}\text { Name } \\
\text { der } \\
\text { Cigarrensorte }\end{array}$} & \multirow{2}{*}{ 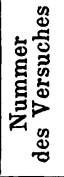 } & \multirow{2}{*}{ 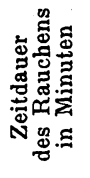 } & \multirow{2}{*}{$\begin{array}{l}\text { Ver- } \\
\text { brauchtes } \\
\text { Aspirator- } \\
\text { wasser in } \\
\text { ccm. }\end{array}$} & \multicolumn{3}{|c|}{ Gehalt in $\mathrm{ccm}$. von } \\
\hline & & & & $\mathrm{CO}_{2}$ & $\mathrm{O}_{2}$ & $\mathrm{CO}$ \\
\hline Britannica & $\begin{array}{r}1 \\
2 \\
3 \\
4 \\
5 \\
6 \\
7 \\
8 \\
9 \\
10\end{array}$ & $\begin{array}{r}10,6 \\
12,4 \\
12,6 \\
10,3 \\
12,8 \\
13,0 \\
8,6 \\
10,9 \\
10,3 \\
10,4\end{array}$ & $\begin{array}{l}354 \\
526 \\
318 \\
338 \\
286 \\
232 \\
369 \\
294 \\
417 \\
400\end{array}$ & $\begin{array}{r}76,1 \\
116,2 \\
67,4 \\
69,6 \\
62,6 \\
45,9 \\
78,6 \\
58,8 \\
92,9 \\
83,6\end{array}$ & $\begin{array}{r}11,3 \\
15,2 \\
10,7 \\
15,8 \\
9,2 \\
12,3 \\
17,7 \\
17,3 \\
16,7 \\
18,0\end{array}$ & $\begin{array}{l}17,7 \\
18,4 \\
13,9 \\
20,3 \\
19,2 \\
13,9 \\
17,0 \\
11,4 \\
25,4 \\
22,4\end{array}$ \\
\hline Trabuco & $\begin{array}{l}1 \\
2 \\
3 \\
4 \\
5 \\
6 \\
7\end{array}$ & $\begin{array}{r}13,0 \\
- \\
10,8 \\
14,0 \\
13,3 \\
9,9 \\
9,5\end{array}$ & $\begin{array}{l}316 \\
405 \\
298 \\
247 \\
215 \\
377 \\
409\end{array}$ & $\begin{array}{l}66,7 \\
81,8 \\
60,8 \\
45,5 \\
41,8 \\
81,4 \\
88,7\end{array}$ & $\begin{array}{l}11,1 \\
16,2 \\
15,5 \\
14,6 \\
11,4 \\
13,5 \\
13,5\end{array}$ & $\begin{array}{l}18,3 \\
25,5 \\
12,2 \\
14,3 \\
10,8 \\
19,3 \\
20,0\end{array}$ \\
\hline Regalitas & $\begin{array}{l}1 \\
2 \\
3 \\
4 \\
5\end{array}$ & $\begin{array}{l}8,6 \\
9,0 \\
8,0 \\
8,6 \\
9,9\end{array}$ & $\begin{array}{l}170 \\
337 \\
327 \\
215 \\
251\end{array}$ & $\begin{array}{l}38,1 \\
76,4 \\
74,1 \\
44,9 \\
47,2\end{array}$ & $\begin{array}{r}3,6 \\
14,2 \\
13,4 \\
10,5 \\
15,6\end{array}$ & $\begin{array}{r}9,9 \\
18,2 \\
17,0 \\
11,4 \\
12,9\end{array}$ \\
\hline $\begin{array}{c}\text { Brasil- } \\
\text { Virginier }\end{array}$ & $\begin{array}{l}1 \\
2\end{array}$ & $\begin{array}{l}15,9 \\
19,3\end{array}$ & $\begin{array}{l}785 \\
994\end{array}$ & $\begin{array}{l}23,6 \\
15,9\end{array}$ & $\begin{array}{l}138,2 \\
190,8\end{array}$ & $\begin{array}{l}6,3 \\
4,0\end{array}$ \\
\hline Virginier & $\begin{array}{l}1 \\
2\end{array}$ & $\begin{array}{l}23,7 \\
22,0\end{array}$ & $\begin{array}{l}1522 \\
1099\end{array}$ & $\begin{array}{l}60,9 \\
63,7\end{array}$ & $\begin{array}{l}274,0 \\
193,4\end{array}$ & $\begin{array}{l}18,3 \\
16,5\end{array}$ \\
\hline
\end{tabular}




\section{Tabelle VII}

enthaltend die aus Tabelle VI für die einzelnen Cigarrensorten berechneten Mittelwerthe.

\begin{tabular}{c|c|c|c|r|r}
\hline $\begin{array}{c}\text { Name } \\
\text { der } \\
\text { Cigarrensorte }\end{array}$ & $\begin{array}{c}\text { Rauchzeit } \\
\text { in } \\
\text { Minuten }\end{array}$ & $\begin{array}{c}\text { Ver- } \\
\text { brauchtes } \\
\text { Aspirator- } \\
\text { wasser in } \\
\text { ccm. }\end{array}$ & \multicolumn{3}{|c}{$\begin{array}{c}\text { Gehalt in ccm. } \\
\text { an }\end{array}$} \\
\cline { 3 - 6 } I. Kurze & 10,9 & 930 & 50,1 & 135,2 & 12,2 \\
\hline II. Portorico & 12,3 & 401 & 77,2 & 20,7 & 19,3 \\
\hline III. Kuba-Portorico & 10,0 & 303 & 65,6 & 9,8 & 13,6 \\
\hline IV. Operas & 9,9 & 293 & 63,9 & 10,6 & 18,2 \\
\hline V. Panetelas (Haranna) & 10,4 & 451 & 48,3 & 53,1 & 13,1 \\
\hline VI. Britannica & 11,2 & 353 & 75,2 & 14,4 & 18,0 \\
\hline VII. Trabuco & 11,7 & 324 & 66,7 & 13,7 & 17,2 \\
\hline VIII. Regalitas & 8,8 & 260 & 56,1 & 11,5 & 13,9 \\
\hline IX. Brasil-Virginier & 17,6 & 890 & 19,8 & 164,5 & 5,2 \\
\hline X. Virginier & 22,9 & 1311 & 62,3 & 233,7 & 17,4 \\
& & & & &
\end{tabular}

Vergleicht man die in der Tabelle VII niedergelegten, für die einzelnen Cigarrensorten berechneten Mittelwerthe, so ergibt sich zunächst in Beziehung auf den Verbrauch an Aspiratorwasser und damit in Uebereinstimmung in Betreff des Gehaltes an Sauerstoff, dass die beiderlei Zahlenwerthe bei den unter I (kurze), IX (Brasil-Virginier) und X (Virginier) angeführten Sorten gegenüber den Zahlenwerthen aller anderen Sorten abnorm gross sind, d. h. dass diese drei Sorten mit einem ausserordentlich grossen Luftüberschuss verraucht worden sind, welcher ein Mehrfaches derjenigen Luftmenge beträgt, die zur Erzeugung der durch die Analyse ermittelten Mengen von Kohlenoxyd und Kohlendioxyd nothwendig war. Bei allen anderen Sorten ist das durch den ermittelten freien Sauerstoff. 
repräsentirte Luftquantum geringer, als das zur Bildung von Kohlendioxyd und Kohlenoxyd erforderliche. Da dieses Verhältniss nicht allein in den Mittelwerthen der Tabelle VII, sondern auch bei den entsprechenden Werthen aller Einzelversuche, wie sie in der Tabelle VI enthalten sind, hervortritt, ist bewiesen, dass diese Verschiedenheit nicht in mangelhafter Leitung der Versuche, sondern allein in der verschiedenen Beschaffenheit des verwendeten Cigarrenmaterials gesucht werden muss. Diesbezüglich mag zunächst auf den eigenthümlichen Bau der Brasil-Virginier- und Virginiercigarren hingewiesen werden, bei welchen durch das Vorhandensein eines besonderen Luftcanals in jeder Cigarre, durch die überaus schlanke Form derselben, sowie durch die nicht seltenen undichten Stellen im Deckblatt Umstände gegeben sind, welche das Eindringen reichlicher Luftmengen in das Innere der brennenden Cigarre nicht allein durch deren glühende Theilchen, sondern auch ausserhalb derselben ermöglichen. Hierzu kommt aber auch noch die Schwierigkeit, diese Cigarrensorten mit ihrem eigenthümlich geformten Mundstück ohne Verletzung der Oberhaut annähernd luftdicht an den Rauchapparat zu befestigen, sowie die einmal angebrannte Cigarre ohne Unterbrechung bis zur Beendigung des Versuches in Brand zu erhalten. Wie bereits früher erwähnt wurde, gelingt letzteres bei diesen beiden Cigarrensorten nur dann, wenn der intermittirend wirkende Aspirator in rasch aufeinanderfolgenden kurzen Intervallen saugt.

Bei der unter I als «Kurze» bezeichneten Cigarrensorten lässt sich der abnorm grosse Sauerstoff- resp. Luftüberschuss des Rauchgases durch die Beobachtung erklären, dass in dieser Cigarrensorte ein Fabrikat vorliegt, bei welchem von vier Cigarren durchschnittlich kaum mehr als eine von solcher Beschaffenheit ist, dass sie beim intermittirenden Rauchen einmal angezündet, zu Ende geraucht werden kann, ohne wiederholt zu verlöschen. Diese üble Eigenschaft der Cigarre ist zum Theil durch das geringwerthige Material, aus welchem sie besteht, und zum Theil durch die bei ihrer Herstellung aufgewendete geringe Sorgfalt bedingt, was zahlreiche undichte 
Stellen in der äussersten Umhüllung und ein sehr unregelmässiges Gefüge im Innern zur Folge hat, was wieder häufiges und kräftiges Ansaugen nothwendig macht $u$. s. w.

Bleiben im Hinblick auf die angeführten Umstände die unter I (Kurze), IX (Brasil-Virginier) und X (Virginier) im Allgemeinen unberücksichtigt, so lässt sich auf Grund der in den Tabellen V, VI, VII niedergelegten Zahlenwerthe Folgendes sagen:

1. Die zum Verrauchen von einem Gramm Cigarre erforderliche Zeit beträgt für alle untersuchten Cigarrensorten im Durchschnitt sämmtlicher Versuche 10,8 Minuten, bei einem Minimum von 8,0 und einem Maximum von 14,8 Minuten, woraus sich für eine mittlere Cigarre von 5,5 g Gewicht eine mittlere Rauchdauer von nahezu einer Stunde ergibt.

2. Die Wassermenge, welche beim Verrauchen von einem Gramm Cigarre vom Aspirator abfliesst, beträgt im Mittel sämmtlicher Versuche nahezu 1/3 Liter. Nimmt man nun an, dass diese Wassermenge dem Volumen des vom Aspirator angesaugten Rauches entspricht, und dass diese Menge des Rauches, welcher sich in den Ruhepausen des Aspirators von der fortbrennenden Cigarre entwickelt, auch $1 / 3$ Liter beträgt, ${ }^{1}$ ) so ergibt sich, dass eine mittlere Cigarre von $5,5 \mathrm{~g}$ Gewicht im: Durchschnitt etwa 3,5 Liter Rauch entwickelt.

3. Der Cigarrenrauch enthält stets neben Kohlendioxyd, Kohlenoxyd und Luftstickstoff auch immer erhebliche Mengen unverbrauchten Luftsauerstoff.

4. Im Durchschnitt der Resultate sämmtlicher Rauchversuche ist die Menge des Kohlendioxyds fast genau viermal so gross als die Menge des Kohlenoxyds. Von diesem Verhältniss weichen die analogen Durchschnittswerte der einzelnen Cigarrensorten nur bei zwei Sorten (Cuba-Portorico und Operas). in bemerkenswerther und entgegengesetzter Weise ab.

5. Die ermittelten Zahlenwerthe sprechen nicht dafür, dass die Form der Cigarren einen erheblichen Einfluss auf das Mengenverhältniss von Kohlendioxyd und Kohlenoxyd ausübt,

1) Nach meinen Beobachtungen dürfte diese Menge erheblich geringer sein. Der Verfasser.

Hoppc-Seyler's Zeitschrift f. physiol. Chemie. XXXIII. 
indem Cigarrensorten von durchaus ähnlicher Form hierin die stärkste Verschiedenheit zeigen. Unter Berücksichtigung dessen, was in Betreff des Gehaltes der Cigarren an Feuchtigkeit gesagt wurde, kann vielmehr angenommen werden, dass dieses Verhältniss ausschliesslich von der Qualität des Tabakes und der Energie des Rauchens, welche in der Rauchzeit und der Menge des verbrauchten Aspiratorwassers ihren Ausdruck findet, bedingt wird.

Bestimmung des Nicotins im Gigarrenrauche und in den nicht verrauchten Gigarrenenden (Stumpfen).

Die ersten Versuche, welche ich bei Anwendung des intermittirend wirkenden Aspirators zur Bestimmung des Nicotins im Cigarrenrauche angestellt habe, wurden ziemlich genau nach dem von Kissling angewendeten Verfahren ausgeführt. Nach dem, was ich im vorhergehenden Abschnitte mitgetheilt habe, muss es selbstverständlich erscheinen, dass zum intermittirenden Verrauchen einer grösseren Anzahl von Cigarren erheblich mehr Zeit erforderlich war, als bei den Versuchen von Kissling. Berücksichtigt man weiter, dass an einem Tage kaum mehr als 6 bis 8 Cigarren mit einem Apparat verraucht werden konnten, so wird es selbstverständlich erscheinen, dass z. B. zum Verrauchen von 150 Stück Cubacigarren mehr als drei Wochen erforderlich waren. Ich hebe dies besonders hervor, weil mir in diesem Umstande, sowie bei Berücksichtigung der Thatsache, dass im Cigarrenrauch, wie ich nachgewiesen habe, stets freier Sauerstoff in erheblicher Menge vorhanden ist, ein Theil der Ursache gelegen zu sein scheint, dass es mir trotz aller Sorgfalt und Mühe nicht gelingen wollte, erhebliche Mengen von Nicotin in unzweifelhaft verlässlicher Weise sicherzustellen. Diese von den Resultaten Kisslings so stark abweichende Beobachtung lässt sich, wie ich meine, zum Theil wenigstens dadurch erklären, dass sich die verharzende Wirkung, welche freier Sauerstoff auf Nicotin ausübt, bei meinen Versuchen viel stärker äussern musste, als bei den Versuchen von Kissling und dass demgemäss bei meinen Versuchen bis zur Abscheidung des Nicotins aus dem Rauchtheer durch 
Destillation im Wasserdampfstrom, erheblich mehr Nicotin verharzt worden war, als bei den Versuchen Kisslings. Zum andern liegt jedoch die Verschiedenheit der beiderseitigen Resultate, wie ich bemerken muss, in dem Umstande, dass es mir nicht gelang, nach der Methode Kissling's Platindoppelverbindungen von einer solchen Reinheit und Beschaffenheit zu gewinnen, wie sie für quantitative Bestimmungen verlangt werden muss.

Ich begnüge mich deshalb, bezüglich dieser Versuche anzuführen, dass bei einem derselben 150 Stück Cuba-PortoricoCigarren aus dem Verschleissbezirk Neutitschein verwendet wurden, deren Gesammtgewicht annähernd $1000 \mathrm{~g}$ betrug, wovon ca. $850 \mathrm{~g}$ verraucht wurden, während nahezu $25 \mathrm{~g}$ auf die abgeschnittenen Spitzen und $122 \mathrm{~g}$ auf die unverbrauchten Cigarrenenden, alle Gewichte auf lufttrockene Substanz bezogen, entfielen. Bezüglich des Nicotingehaltes dieser Cigarrensorte kann ich auf die Tabelle III verweisen.

Für einen anderen Versuch, welcher in seiner Anordnung schon sehr erheblich von allen vorhergehenden Versuchen abwich, wurden 89 Stück «Kurze* (Gemischte Ausländercigarren) verwendet, deren Gesammtgewicht $449 \mathrm{~g}$ betrug, wovon $15,3 \mathrm{~g}$ auf die abgeschnittenen Spitzen und $76,3 \mathrm{~g}$ auf die unverrauchten Enden entfielen, so dass also $357,4 \mathrm{~g}$ thatsächlich verraucht wurden. Hierbei wurde ein System von sechs Condensations- resp. Absorptionsgefässen verwendet, von welchen eines keinerlei Absorptionsmittel enthielt, während drei mit sehr verdünnter Schwefelsäure und die zwei letzten mit verdünnter Natronlauge beschickt waren.

Bei diesem Versuche wurden nach beendigtem Rauchen diejenigen Apparattheile, welche während des Rauchens leer geblieben oder mit verdünnter Schwefelsäure beschickt waren, mit Alkohol von 95 Volumenprocent sorgfältig und wiederholt ausgespült, die Gesammtmenge der hierbei erhaltenen Lösungen in einer Porzellanschale vereinigt und die stark sauer reagirende Flüssigkeit auf dem Wasserbade bei einer $40-50^{\circ}$ nicht übersteigenden Temperatur durch Abdunsten des Alkohols eingeengt. Die noch immer kräftig sauer reagirende 
Flüssigkeit wurde hierauf mit stets neuen Aethermengen so lange geschüttelt, bis der Aether vollständig ungefärbt blieb. Die wässerige Lösung wurde nunmehr mit Natronlauge so weit übersättigt, dass die Flüssigkeit rothes Lackmuspapier kräftig blau färbte, worauf das Ausschütteln zehnmal mit stets neuen Aethermengen fortgesetzt wurde. Von den mit der alkalisch reagirenden Flüssigkeit hergestellten Aetherauszügen wurde der grössere Theil des Aethers bei schwacher Siedehitze abdestillirt und mit dem hierbei erhaltenen Rückstande die Bestimmung des Nicotins nach demselben Verfahren ausgeführt, welches sich in einem früheren Abschnitte angegeben findet, d. h. der Rückstand wurde mit sehr verdünnter Natronlauge übersättigt und im Wasserdampfstrom destillirt, das Destillat in Fractionen von $100 \mathrm{ccm}$. aufgefangen, mit äusserst stark verdünnter Schwefelsäure titrirt und die Destillation so lange fortgesetzt, bis $100 \mathrm{ccm}$. Destillat zur Neutralisation nur noch $0,1 \mathrm{ccm}$. Titerflüssigkeit erforderten. Hierbei wurden bei der Titration sämmtlicher zehn Fractionen 53,1 ccm. einer Schwefelsäure verlangt, von welcher $1 \mathrm{ccm}$. 0,02705 g Nicotin entsprach, wozu ich bemerke, dass der Titer der Säure mit Natriumcarbonat gestellt und mit reinstem Nicotin (bezogen von E. Merck in Darmstadt) kontrollirt worden war. Nach diesem Titer entsprechen die verbrauchten $53,1 \mathrm{ccm}$. Säure $1,432 \mathrm{~g}$ Nicotin. Um nun das Verhältniss dieser Nicotinmenge gegenüber dem Gesammtnicotingehalt der Cigarren, sowie gegenüber dem Nicotingehalt der unverraucht gebliebenen Theile der Cigarren feststellen zu können, wurde zunächst der Nicotingehalt der unverraucht gebliebenen Cigarrenenden durch mehrfach wiederholte Analyse nach dem für die Nicotinbestimmung in den Cigarren eingehaltenen Titrirverfahren festgestellt. Die Ergebnisse dieser Bestimmungen sind die folgenden:

1. $18,0 \mathrm{~g}$ lufttrockene Stumpfe ergaben bei der Titration $0,7839 \mathrm{~g}$ Nicotin.

2. $17,1 \mathrm{~g}$ lufttrockene Stumpfe ergaben bei der Titration $0,6774 \mathrm{~g}$ Nicotin.

Es beträgt der Nicotingehalt der Stumpfe somit nach Analyse $14,36 \%$, nach Analyse 2 3,96\%, im Mittel 4,16\%. 
Auf Grund dieses Ergebnisses der Nicotinbestimmung im Rauchtheer und des in Tabelle III festgestellten mittleren Nicotingehaltes der "Kurzen Cigarren» ergibt sich bezüglich der 89 gerauchten Cigarren folgende, durch das Rauchen bewirkte Vertheilung des Nicotins:

Gesammtmenge des Nicotins in $449 \mathrm{~g}$ Cigarren. . . 8,772 $\mathrm{g}$ Menge des Nicotins in den 15,3 $\mathrm{g}$ der abgeschnittenen

Spitzen . . . . . . . . . 0, . 0,300,

Menge des Nicotins in den $76,3 \mathrm{~g}$ der unverrauchten

Stumpfe . . . . . . . . . . 3,174,

Menge des Nicotins in dem vom Aspirator ange-

saugten Rauche ............ 1,432,

Aus den vorstehenden Werten berechnete Menge des

in dem vom Aspirator nicht angesaugten Theile des Rauches enthaltenen, und des durch das Rauchen zerstörten Theiles des Nicotins. . . . 3,866 * Bezogen auf 100 Gewichtstheile der Cigarren ergibt sich, dass die Nicotinmenge beträgt:

1. in den abgeschnittenen Spitzen ...... 3,6\%

2. in den unverrauchten Enden ...... 36,2\%

3. im angesaugten Rauche .......... 16,3\%

4. im nicht angesaugten Rauche und des zerstörten Nicotins . . . . . . . . . 44,0\%

Nach diesen Daten würde wenig mehr als der sechstè Theil des Gesammtnicotins der Cigarren, oder wenig mehr als $1 / 5$ vom verrauchten Theile der Cigarren, in den angesaugten Rauch übergehen, während in den unverrauchten Enden mehr als $1 / 3$ des Gesammtnicotins zurückbliebe, und fast die Hälfte des Gesammtnicotins in den nicht angesaugten Rauch überginge oder durch das Rauchen zerstört würde, wobei selbstverständlich auch die Annahme gemacht werden muss, dass alle durch die Titersäure neutralisirte Substanz nur aus Nicotin besteht.

Obwohl nun alle meine früheren Beobachtungen dafür sprechen, dass die Menge des im angesaugten Rauche enthaltenen Nicotins verhältnissmässig sehr gering ist, schien es mir denn doch sehr auffällig, dass von dem in einer «kurzen 
Cigarre» per $5 \mathrm{~g}$ Gewicht enthaltenen Gesammtnicotin von $0,094 \mathrm{~g}$ nur $0,015 \mathrm{~g}$ in den angesaugten Rauch übergeht, und ich war deshalb neuerlich bemüht, das Nicotin im angesaugten Rauche auf dem Wege der Gewichtsanalyse zu bestimmen, wobei ich auch die Abscheidung des Nicotins aus den Aetherauszügen mittelst alkoholischer Oxalsäure als Zwischenoperation versucht habe. Die Erfolge aller dieser Bemühungen blieben unbefriedigend, so dass ich zur titrimetrischen Bestimmung des Nicotins zurückkehrte und dem Verfahren schliesslich jene Gestalt gab, welche ich in ihren Umrissen in dem allgemeinen Theile des Abschnittes "Rauchversuche * gekennzeichnet habe. Diesbezüglich erinnere ich zunächst daran, dass zur Condensation aller verdichtbaren Theile des Cigarrenrauches keinerlei chemisch wirksame Absorptionsmittel, wie verdünnte Schwefelsäure etc., angewandt wurden, sondern einzig und allein der früher beschriebene und gekennzeichnete Condensationsapparat (Fig. 3) zur Anwendung kam. Ich ergänze die früher gegebene Beschreibung nur dahin, dass das an dem Condensationsapparat angebrachte Rohr D (Fig. 3) bei allen folgenden Versuchen dasselbe war und eine Länge von $75 \mathrm{~cm}$. besass. Der weitere Verlauf eines jeden Versuches gestaltete sich folgendermassen:

Für die meisten Versuche wurden je 5 Stück, und nur bei einer der zuerst gerauchten Cigarrensorten 10 und auch 15 Stück Cigarren per Versuch geraucht. Für jede Cigarrensorte wurden mindestens zwei Rauchversuche durchgeführt und bei jedem Versuche das Gewicht der zum Verrauchen bestimmten Cigarren, der abgeschnittenen Spitzen und der unverrauchten Cigarrenenden, und zwar durchwegs im lufttrockenen Zustande ermittelt. Nach beendetem Rauchen wurde die Baumwolle aus sämmtlichen Theilen des Apparates herausgezogen, die durch den Rauch mehr oder weniger stark gebräunten oder doch in erkennbarer Weise gefärbten Theile der Baumwolle unmittelbar in einen geräumigen Soxhlet'schen Extractionsapparat gebracht, und jene Theile der Baumwolle des Rohres D, welche nicht gefärbt worden waren, dazu benützt, um mit Hülfe derselben und unter Anwendung von 
alkoholischer Natronlauge, welche genau nach der Vorschrift Kissling's (Zeitschrift für analyt. Chemie, 21. Jahrg. 1882, Seite 75) hergestellt worden war, den in dem Condensationsgefäss verdichteten Rauchteer ohne Verlust in den Extractionsapparat zu schaffen. Zu dem Zweck wurde immer ein Bäuschchen der Baumwolle an dem einen Ende eines genügend langen Glasstabes durch Andrehen befestigt, mit der alkoholischen Natronlauge getränkt und damit die Glasgefässe sorgfältig ausgewischt, das Baumwollbäuschchen mit Hülfe einer Pincette losgelöst, in den Extractionsapparat gebracht und die Operation wenigstens noch dreimal wiederholt. Hierauf wurden sämmtliche Glasgefässe mit dem Rest von $10 \mathrm{ccm}$. der alkoholischen Natronlauge und sodann wiederholt mit Aether ausgespült, die im Extractionsapparate befindliche Baumwolle mit alkoholischer Natronlauge durchtränkt, der Extractionsapparat mit. einem Kochkölbchen von $400 \mathrm{ccm}$. Capacität verbunden und noch soviel Aether nebst dem zum Auswaschen benützten hinzugefügt, dass seine Gesammtmenge annähernd $100 \mathrm{ccm}$. betrug. Das Kölbchen wurde auf ein Dampfbad gestellt, der auf demselben sitzende Extractionsapparat mit einem Rückflusskühler verbunden, die Extraction in Gang gebracht und durch etwa 4 Stunden fortgesetzt. Alle weiteren Operationen wurden nach der Vorschrift Kissling's in der von mir modificirten Art, die ich in dem Abschnitt über den «Nicotingehalt der österreichischen Regiecigarren» gekennzeichnet habe, ausgeführt. Da bei der Destillation des mit verdünnter Natronlauge alkalisch gemachten Nicotinextractes fast immer sehr starkes Schäumen eintrat, musste die Zuführung des Wasserdampfes in das Destillirkölbchen, namentlich im Beginne, mit einiger Vorsicht bewirkt werden. Die Titration des nicotinhaltigen Destillates erfolgte genau in der früher angegebenen Weise.

Bevor ich zur Mittheilung der im Cigarrenrauche auf diese Weise ermittelten Nicotinmengen übergehe, muss ich noch hervorheben, dass bei sämmtlichen Rauchversuchen das Gewicht der lufttrockenen Stumpfe stets ermittelt und der Nicotingehalt derselben genau nach dem für die Nicotinbestimmung im Tabak angegebenen Verfahren ermittelt wurde. 
Die Resultate aller auf die beiderlei Versuchsreihen bezüglichen Wägungen und Bestimmungen sind in der Tabelle VIII niedergelegt.

$\mathrm{Zu}$ den in nebenstehender Tabelle enthaltenen Resultaten sei Folgendes bemerkt:

1. Bei dem Versuche Nr. 4 wurde die Baumwolle mit einer wässerigen Lösung von $1 \%$ Weinsäure getränkt, zwischen Filtrirpapier gepresst, wieder sorgfältig aufgelockert und sodann unmittelbar verwendet. Das Ergebniss dieses Versuches lehrte, dass durch diese Präparation das Absorptionsvermögen der Baumwolle kaum gesteigert wird, weshalb bei allen anderen Versuchen gewöhnliche, entfettete Baumwolle verwendet wurde. Die mit Weinsäure präparirte Baumwolle wurde durch den Rauch ziemlich kräftig schmutzigblau gefärbt.

2. Bei den Brasil-Virginier- und Virginier-Cigarren, welche ein aus einem Stückchen Strohhalm bestehendes Mundstück besitzen, entfallen selbstverständlich in der Tabelle die auf die Cigarrenspitzen bezüglichen Daten.

Bei der Bestimmung des Nicotins in den Stumpfen dieser beiden Cigarrensorten mussten die Strohmundstücke selbstverständlich mitgewogen und zur Analyse mitverwendet werden.

Um aus den in der Tabelle VIII enthaltenen analytischen Zahlenwerthen entsprechende Folgerungen ableiten zu können, wurden diese Werthe in der Tabelle IX mit den Schlussergebnissen der Tabelle III combinirt und in einer dem angestrebten Ziele entsprechenden Weise dargestellt. Dem entsprechend enthält die Tabelle IX ausser der Nummer des Versuches und dem Namen der Cigarrensorte die folgenden Angaben (s. S. 106).

1. Das Gewicht Tabak, welches von $1 \mathrm{~g}$ Cigarre wirklich verraucht wurde.

2. Das Gewicht des beim Verrauchen von $1 \mathrm{~g}$ Cigarre hinterbliebenen Stumpfes.

3. Das Durchschnittsgewicht des in $1 \mathrm{~g}$ Cigarre enthaltenen Nicotins.

4. Das Gewicht der beim Verrauchen von $1 \mathrm{~g}$ Cigarre im Rauche ermittelten Stickstoffbasen. 
Tabelle VIII.

\begin{tabular}{|c|c|c|c|c|c|c|c|}
\hline \multirow{3}{*}{$\begin{array}{c}\text { Nammer } \\
\text { des } \\
\text { Wersuches }\end{array}$} & \multirow{3}{*}{$\begin{array}{c}\text { Nummer } \\
\text { und } \\
\text { Name der } \\
\text { Cigarrensorte }\end{array}$} & \multirow{3}{*}{$\begin{array}{l}\text { Anzahl } \\
\text { der ver- } \\
\text { ranchtell } \\
\text { (ligarren }\end{array}$} & $\mathrm{a}$ & b & c & $d$ & e \\
\hline & & & \multicolumn{3}{|c|}{ Gewicht der lufttrockenen } & \multicolumn{2}{|c|}{$\begin{array}{l}\text { Gewicht der } \\
\text { Stickstoffbasen }\end{array}$} \\
\hline & & & Cigarren & Spitzen & Stumpfe & d.Rauches & d.Stumpfe \\
\hline $\begin{array}{l}1 \\
2\end{array}$ & $\begin{array}{c}\text { I. Kurze } \\
\text { (Gemischte Ansländer) }\end{array}$ & $\begin{array}{l}5 \\
4\end{array}$ & $\begin{array}{l}23,81 \\
18,56\end{array}$ & $\begin{array}{l}0,60 \\
0,47\end{array}$ & $\begin{array}{l}8,55 \\
9,09\end{array}$ & $\begin{array}{l}0,1082 \\
0,0618\end{array}$ & $\begin{array}{l}0,2739 \\
0,2628\end{array}$ \\
\hline $\begin{array}{l}3 \\
4 \\
5 \\
6\end{array}$ & II. Portorico & $\begin{array}{l}10 \\
10 \\
10 \\
15\end{array}$ & $\begin{array}{l}41,71 \\
41,17 \\
39,64 \\
59,42\end{array}$ & $\begin{array}{l}1,06 \\
1,22 \\
1,02 \\
1,47\end{array}$ & $\begin{array}{l}13,18 \\
15,52 \\
13,46 \\
25,17\end{array}$ & $\begin{array}{l}0,2158 \\
0,2267 \\
0,1701 \\
0,1811\end{array}$ & $\begin{array}{l}0,4108 \\
0,3238 \\
0,3335 \\
0,5964\end{array}$ \\
\hline $\begin{array}{r}7 \\
8 \\
9 \\
10 \\
11\end{array}$ & 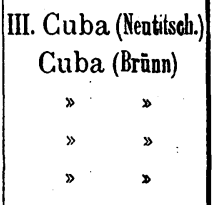 & $\begin{array}{l}4 \\
5 \\
5 \\
5 \\
5\end{array}$ & $\begin{array}{l}25,67 \\
31,33 \\
32,43 \\
29,77 \\
31,82\end{array}$ & $\begin{array}{l}0,66 \\
0,82 \\
0,77 \\
0,65 \\
0,72\end{array}$ & $\begin{array}{r}7,86 \\
11,87 \\
15,26 \\
11,23 \\
16,03\end{array}$ & $\begin{array}{l}0,1546 \\
0,1391 \\
0,1369 \\
0,1325 \\
0,0950\end{array}$ & $\begin{array}{l}0,1900 \\
0,3998 \\
0,5765 \\
0,2650 \\
0,3203\end{array}$ \\
\hline $\begin{array}{l}12 \\
13\end{array}$ & IV. Operas & $\begin{array}{l}5 \\
5\end{array}$ & $\begin{array}{l}26,63 \\
27,69\end{array}$ & $\begin{array}{l}0,59 \\
0,66\end{array}$ & $\begin{array}{r}8,24 \\
13,40\end{array}$ & $\begin{array}{l}0,1833 \\
0,0618\end{array}$ & $\begin{array}{l}0,2231 \\
0,3108\end{array}$ \\
\hline $\begin{array}{l}14 \\
15 \\
16\end{array}$ & $\begin{array}{l}\text { V. Havanna } \\
\text { (Panetelas) }\end{array}$ & $\begin{array}{l}5 \\
5 \\
5\end{array}$ & $\begin{array}{l}25,67 \\
27,99 \\
26,77\end{array}$ & $\begin{array}{l}0,69 \\
0,66 \\
0,64\end{array}$ & $\begin{array}{l}10,39 \\
10,59 \\
12,49\end{array}$ & $\begin{array}{l}0,1149 \\
0,1060 \\
0,1104 \\
\end{array}$ & $\begin{array}{l}0,3181 \\
0,2805 \\
0,3644 \\
\end{array}$ \\
\hline $\begin{array}{l}17 \\
18\end{array}$ & VI. Britannica & $\begin{array}{l}5 \\
5\end{array}$ & $\begin{array}{l}32,84 \\
33,61\end{array}$ & $\begin{array}{l}0,76 \\
0,66\end{array}$ & $\begin{array}{l}10,19 \\
13,65\end{array}$ & $\begin{array}{l}0,1546 \\
0,0994\end{array}$ & $\begin{array}{l}0,3001 \\
0,3313\end{array}$ \\
\hline $\begin{array}{l}19 \\
20\end{array}$ & VII. Trabuco & $\begin{array}{l}5 \\
5\end{array}$ & $\begin{array}{l}26,59 \\
25,64\end{array}$ & $\begin{array}{l}0,71 \\
0,67\end{array}$ & $\begin{array}{r}9,85 \\
11,98\end{array}$ & $\begin{array}{l}0,1391 \\
0,0974\end{array}$ & $\begin{array}{l}0,2983 \\
0,3048\end{array}$ \\
\hline $\begin{array}{l}21 \\
22 \\
23\end{array}$ & VIII.Regalitas & $\begin{array}{l}5 \\
5 \\
5\end{array}$ & $\begin{array}{l}28,11 \\
27,73 \\
28,94\end{array}$ & $\begin{array}{l}0,64 \\
0,73 \\
0,61\end{array}$ & $\begin{array}{r}8,52 \\
11,70 \\
13,18\end{array}$ & $\begin{array}{l}0,1480 \\
0,17 \text { ə் } 6 \\
0,0667 \\
\end{array}$ & $\begin{array}{l}0,3313 \\
0,4935 \\
0,4727\end{array}$ \\
\hline $\begin{array}{l}24 \\
25 \\
26 \\
27\end{array}$ & $\begin{array}{l}\text { IX. Brasil- } \\
\text { Virginier }\end{array}$ & $\begin{array}{l}5 \\
5 \\
5 \\
5\end{array}$ & $\begin{array}{l}25,32 \\
24,88 \\
24,41 \\
23,15\end{array}$ & $\begin{array}{l}- \\
- \\
-\end{array}$ & $\begin{array}{r}7,45 \\
10,13 \\
11,16 \\
10,03\end{array}$ & $\begin{array}{l}0,4020 \\
0,2297 \\
0,1855 \\
0,1634\end{array}$ & $\begin{array}{l}0,2496 \\
0,2982 \\
0,4009 \\
0,3099\end{array}$ \\
\hline $\begin{array}{l}28 \\
29 \\
30\end{array}$ & X. Virginier & $\begin{array}{l}5 \\
5 \\
5\end{array}$ & $\begin{array}{l}24,68 \\
25,51 \\
22,83\end{array}$ & $\begin{array}{l}- \\
- \\
-\end{array}$ & $\begin{array}{l}9,35 \\
8,96 \\
9,53\end{array}$ & $\begin{array}{l}0,3976 \\
0,3401 \\
0,1833\end{array}$ & $\begin{array}{l}0,3932 \\
0,4528 \\
0,3534\end{array}$ \\
\hline
\end{tabular}


Tabelle IX.

\begin{tabular}{|c|c|c|c|c|c|c|c|c|c|}
\hline 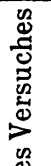 & $\begin{array}{l}\text { Nummer } \\
\text { und } \\
\text { Namen }\end{array}$ & $\begin{array}{r}\text { Von } \epsilon \\
\text { Gra } \\
\text { Cige }\end{array}$ & $\begin{array}{l}\text { einem } \\
\text { amm } \\
\text { arre }\end{array}$ & 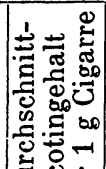 & $\begin{array}{l}\text { Beim Ve } \\
\text { ron } 1 \mathrm{~g} \\
\text { ward } \\
\text { Stickst } \\
\text { nachg }\end{array}$ & $\begin{array}{l}\text { orranchen } \\
\text { Cigarre } \\
\text { len an } \\
\text { offbasen } \\
\text { efwiesen }\end{array}$ & 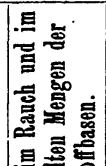 & 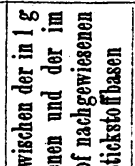 & 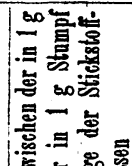 \\
\hline 总 & $\begin{array}{l}\text { Cigarren- } \\
\text { sorte }\end{array}$ & $\begin{array}{l}\text { 1) warden } \\
\text { verrancht }\end{array}$ & $\begin{array}{l}\text { 2) hinter- } \\
\text { blieb als } \\
\text { Stampf }\end{array}$ & 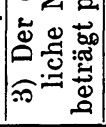 & $\begin{array}{l}\text { 4) im } \\
\text { Ranch }\end{array}$ & $\begin{array}{l}\text { 5) im } \\
\text { Stampf }\end{array}$ & 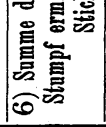 & 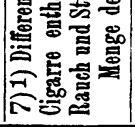 & 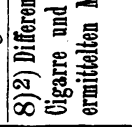 \\
\hline $\begin{array}{l}1 \\
2\end{array}$ & $\begin{array}{l}\text { I. Kurze } \\
\text { (Aem. Ausländer) }\end{array}$ & $\begin{array}{l}0,6157 \\
0,4849\end{array}$ & $\begin{array}{l}0,3591 \\
0,4898\end{array}$ & \begin{tabular}{|l|}
0,0188 \\
0,0188
\end{tabular} & $\begin{array}{l}0,0047 \\
0,0034\end{array}$ & $\begin{array}{l}0,0118 \\
0,0145\end{array}$ & $\begin{array}{l}0,0164 \\
0,0179\end{array}$ & $\begin{array}{l}+0,0024 \\
+0,0009\end{array}$ & \\
\hline $\begin{array}{l}3 \\
4 \\
5 \\
6\end{array}$ & II. Portorico & $\begin{array}{l}0,6589 \\
0,5934 \\
0,6347 \\
0,5517\end{array}$ & $\begin{array}{l}0,3160 \\
0,3770 \\
0,3396 \\
0,4236 \\
\end{array}$ & $\begin{array}{l}0,0141 \\
0,0141 \\
0,0141 \\
0,0141 \\
\end{array}$ & $\begin{array}{l}0,0053 \\
0,0057 \\
0,0044 \\
0,0031 \\
\end{array}$ & $\begin{array}{l}0,0101 \\
0,0081 \\
0,0086 \\
0,0103\end{array}$ & & $\begin{array}{r}-0,0013 \\
+0,0003 \\
+0,0011 \\
+0,0007 \\
\end{array}$ & \\
\hline $\begin{array}{r}7 \\
8 \\
9 \\
10 \\
11 \\
\end{array}$ & $\begin{array}{c}\text { III. Cuba (Nentitsch.) } \\
\text { Cuba (Brünn) } \\
\searrow \\
\searrow\end{array}$ & $\begin{array}{l}0,6681 \\
0,5950 \\
0,5057 \\
0,6009 \\
0,4737 \\
\end{array}$ & \begin{tabular}{|l|}
0,3023 \\
0,3787 \\
0,$4 ; 06$ \\
0,3773 \\
0,5038 \\
\end{tabular} & $\begin{array}{l}0,0250 \\
0,0151 \\
0,0151 \\
0,0151 \\
0,0151\end{array}$ & $\begin{array}{l}0,0062 \\
0,0046 \\
0,0043 \\
0,0045 \\
0,0035 \\
\end{array}$ & $\begin{array}{l}0,0076 \\
0,0131 \\
0,0182 \\
0,0091 \\
0,0103 \\
\end{array}$ & $\begin{array}{l}0,0136 \\
0,0177 \\
0,0225 \\
0,0136 \\
0,0138 \\
\end{array}$ & $\begin{array}{r}+0,0114 \\
-0,0026 \\
-0,0074 \\
+0,0015 \\
+0,0013 \\
\end{array}$ & $\begin{array}{r}-0,0009 \\
0,0186 \\
0,0227 \\
0,0085 \\
0,0049 \\
\end{array}$ \\
\hline $\begin{array}{l}12 \\
13 \\
\end{array}$ & IV. Operas & $\begin{array}{l}0,6684 \\
0,4923 \\
\end{array}$ & $\begin{array}{l}0,3094 \\
0,4840 \\
\end{array}$ & & $\begin{array}{l}0,0070 \\
0,0023 \\
\end{array}$ & & & $\begin{array}{r}-0,0013 \\
+0,0005 \\
\end{array}$ & \\
\hline $\begin{array}{l}14 \\
15 \\
16 \\
\end{array}$ & $\begin{array}{l}\text { V. Panetelas } \\
\text { (Havanna) }\end{array}$ & $\begin{array}{l}0,5684 \\
0,5980 \\
0,5096\end{array}$ & $\begin{array}{l}0,4048 \\
0,3784 \\
0,4666 \\
\end{array}$ & $\begin{array}{l}0,0181 \\
0,0181 \\
0,0181 \\
\end{array}$ & $\begin{array}{l}0,0046 \\
0,0039 \\
0,0042 \\
\end{array}$ & $\begin{array}{l}0,0127 \\
0,0103 \\
0,0140\end{array}$ & $\begin{array}{l}0,0173 \\
0,0142 \\
0,0182\end{array}$ & $\begin{array}{r}+0,0008 \\
+0,0039 \\
-0,0001\end{array}$ & $\begin{array}{l}0,0125 \\
0,0084 \\
0,0111 \\
\end{array}$ \\
\hline $\begin{array}{l}17 \\
18 \\
\end{array}$ & VI. Britannica & $\begin{array}{l}0,6666 \\
0,5742 \\
\end{array}$ & $\begin{array}{l}0,3103 \\
0,4061 \\
\end{array}$ & $\begin{array}{l}0,0129 \\
0,0129 \\
\end{array}$ & $\begin{array}{l}0,0048 \\
0,0030\end{array}$ & $\begin{array}{l}0,0094 \\
0,0101 \\
\end{array}$ & $\begin{array}{l}0,0142 \\
0,0131\end{array}$ & $\begin{array}{r}-0,0013 \\
-0,0002 \\
\end{array}$ & \\
\hline $\begin{array}{l}19 \\
20 \\
\end{array}$ & VII. Trabuco & $\begin{array}{l}0,6029 \\
0,5066 \\
\end{array}$ & \begin{tabular}{l|}
0,3705 \\
0,4673 \\
\end{tabular} & $\begin{array}{l}0,0161 \\
0,0161 \\
\end{array}$ & $\begin{array}{r}0,0054 \\
0,0039 \\
\end{array}$ & $\begin{array}{l}0,0115 \\
0,0122 \\
\end{array}$ & $\begin{array}{l}0,0169 \\
0,0161 \\
\end{array}$ & $\begin{array}{r}-0,0008 \\
0,0000\end{array}$ & \\
\hline $\begin{array}{l}21 \\
22 \\
23 \\
\end{array}$ & VIII. Regalitas & $\begin{array}{l}0,6741 \\
0,5517 \\
0,5235 \\
\end{array}$ & $\begin{array}{l}0,3031 \\
0,4220 \\
0,4554 \\
\end{array}$ & $\begin{array}{l}0,0290 \\
0,0290 \\
0,0290 \\
\end{array}$ & $\begin{array}{l}0,0054 \\
0,0065 \\
0,0024\end{array}$ & $\begin{array}{l}0,0121 \\
0,0163 \\
0,0167\end{array}$ & $\begin{array}{l}0,0175 \\
0,0228 \\
0,0191 \\
\end{array}$ & $\begin{array}{r}+0,0115 \\
+0,0062 \\
+0,0099 \\
\end{array}$ & $\begin{array}{l}0,0099 \\
0,0086 \\
0,0069 \\
\end{array}$ \\
\hline $\begin{array}{l}24 \\
25 \\
26 \\
27 \\
\end{array}$ & $\begin{array}{l}\text { IX. Brasil- } \\
\text { Virginier }\end{array}$ & $\begin{array}{l}0,6918 \\
0,5928 \\
0,5428 \\
0,5667 \\
\end{array}$ & $\begin{array}{l}0,3082 \\
0,4702 \\
0,4572 \\
0,4333 \\
\end{array}$ & $\begin{array}{l}0,0147 \\
0,0147 \\
0,0147 \\
0,0147 \\
\end{array}$ & $\begin{array}{l}0,0159 \\
0,0092 \\
0,0076 \\
0,0071 \\
\end{array}$ & $\begin{array}{l}0,0099 \\
0,0120 \\
0,016 \\
0,0134 \\
\end{array}$ & $\begin{array}{l}0,0258 \\
0,0212 \\
0,0240 \\
0,0205 \\
\end{array}$ & $\begin{array}{r}-0,0111 \\
-0,006 \mathrm{o} \\
-0,0093 \\
-0,0058 \\
\end{array}$ & $\begin{array}{l}0,0188 \\
0,0144 \\
0,0212 \\
0,0162 \\
\end{array}$ \\
\hline $\begin{array}{l}28 \\
29 \\
30\end{array}$ & $\mathrm{X}$. Virginier & $\begin{array}{l}0,6212 \\
0,6488 \\
0,5825\end{array}$ & $\begin{array}{l}0,3788 \\
0,3512 \\
0,4175\end{array}$ & $\begin{array}{l}0,0399 \\
0,0399 \\
0,0399\end{array}$ & $\begin{array}{l}0,0161 \\
0,0133 \\
0,0080\end{array}$ & $\left|\begin{array}{l}0,0160 \\
0,0177 \\
0,0155\end{array}\right|$ & $\left|\begin{array}{l}0,0321 \\
0,0310 \\
0,0235\end{array}\right|$ & $\begin{array}{l}+0,0078 \\
+0,0089 \\
+0,0164\end{array}$ & $\begin{array}{r}0,0022 \\
0,0106 \\
-0,0028\end{array}$ \\
\hline
\end{tabular}

1) Der Differenz wurde das Zeichen + vorgesetzt, wenn der Nicotingehalt der Cigarre grösser, das Zeichen -, wenn dieser Gehalt kleiner war als die Summe der Stickstoffbasen des Rauches und des Stumpfes.

2) Das Zeichen - wurde der Differenz vorgesetzt, wenn der Gehalt an Stickstoffbasen des Stumpfes kleiner war als der Nicotingehalt der Cigarre. 
5. Das Gewicht der beim Verrauchen von $1 \mathrm{~g}$ Cigarre im Stumple ermittelten Stickstoff basen.

6. Das Gesammtgewicht des beim Verrauchen von $1 \mathbf{g}$ Cigarre im Rauche und in dem Stumpfe ermittelten Nicotins.

7. Die Differenz der Gewichte, des in $1 \mathrm{~g}$ Cigarre enthaltenen Nicotins einerseits und der im Rauche und Stumpfe andererseits nachgewiesenen Stickstoffbasen, wobei das Nicotingewicht der Cigarre mit + , die Summe der Gewichte der Stickstoffbasen des Rauches und des Stumpfes mit - angesetzt ist.

8. Die Differenz der in $1 \mathrm{~g}$ Cigarrenstumpf und in $1 \mathrm{~g}$ Cigarre ermittelten Nicotinmenge.

Prüft man die in den Tabellen VIII und IX niedergelegten Zahlenwerthe, so èrgibt sich:

a) Aus den Rubriken $a, b$ und c der Tabelle VIII und den Rubriken 1 und 2 der Tabelle IX, dass bei den Versuchen Nr. 1, 3, 5, 7, 10, 12, 17, 19, 21, 24, 28, 29 nahezu $2 / 3$, bei den Versuchen Nr. 2, 9, 11, 13, 16, 20 hingegen nahezu die Hälfte vom Gewichte der Cigarren verraucht wurde, während sich die betreffenden Werthe bei den übrigen jetzt nicht genannten Versuchen zwischen $2 / 3$ und $1 / 2$ bewegen.

b) Aus den Rubriken 3,4 und 5, respective aus der die Rubriken 3, 4 und 5 zusammenfassenden Rubrik 7 der Tabelle IX ergibt sich, dass nur bei dem Versuche 20 im Rauche und in den Stumpfen zusammen genau ebensoviel Stickstoffbasen gefunden wurden, als die Trabuco-Cigarre Nicotin im Mittel enthält, dass hingegen bei den Versuchen Nr. 1, 2, 4, 5, 6, $7,10,11,13,14,15,21,22,23,28,29$ und 30 im Rauch und in den Stumpfen zusammen weniger, bei den Versuchen Nr. 3, 8, 9, 12, 16, 17, 18, 19, 24, 25, 26, 27 hingegen mehr Stickstoffbasen gefunden wurden, als der mittlere Nicotingehalt der betreffenden Versuchscigarren beträgt.

Bezogen auf die einzelnen Cigarrensorten sind diese Differenzen bei allen Versuchen der Sorten I «Gemischte Ausländer» (kurże), VIII «Regalitas» und X «Virginier» durchweg positiv, d. h. der mittlere Nicotingehalt dieser Sorten ist durchwegs grösser, als die Summe der im Rauch und in den 
Stumpfen aufgefundenen Mengen der Stickstoffbasen; bei den Sorten VI «Britannica» und IX «Brasil-Virginier» durchwegs negativ, d. h. die mittleren Nicotingehalte dieser Sorten sind stets kleiner, als die Summe der im Rauche und in den Stumpfen ermittelten Mengen Stickstoffbasen. Bei den Sorten II «Portorico», III «Cuba-Portorico», IV «Operas», V «Panetelas» (Havanna) ist die Differenz bei den einzelnen Versuchen jeder Sorte im obigen Sinne theils positiv, theils negativ.

Bei jenen Cigarrensorten, bei welchen die aus den Einzelversuchen sich ergebenden Differenzen der Tabelle IX, Rubrik 7 im Sinne der früher gemachten Bemerkung durchwegs positiv sind, also bei den Sorten I «Kurze», VIII «Regalitas» und $\mathrm{X}$ "Virginier», oder bei welchen die negative Differenz an sich sehr gering oder gleich Null ist, wie z. B. bei der Sorte VII «Trabuco», lässt sich die Entstehung dieser Differenzen unschwer durch die Annahme erklären, dass diese Differenzen dem Verluste an Stickstoffbasen respective Nicotin entsprechen, welcher beim intermittirenden Rauchen durch, vom Aspirator in den Ruhepausen nicht angesaugten Rauch eintreten muss.

Bei jenen Gigarrensorten, bei welchen die Einzelversuche theils positive, theils negative Differenzen ergeben, können die negativen Differenzen durch die Annahme von Versuchsfehlern mit Berechtigung wohl nur in jenen Fällen erklärt werden, wo alle negativen Differenzen einer Sorte im Verhältniss zum mittleren Nicotingehalt derselben gering sind, was unbedingt für die Sorte V «Panetelas» angenommen werden kann, bei welcher die einzige negative Differenz den $1 / 181$ Theil vom mittleren Nicotingehalt dieser Cigarren beträgt, und wohl auch für die Sorte IV «Operas» zulässig ist, wo die negative Differenz $1 / 29$ des mittleren Nicotingehaltes der Cigarre ausmacht. $\mathrm{Ob}$ die Erklärung des Auftretens einer negativen Differenz gegenüber drei positiven durch die Annahme eines entsprechenden Versuchsfehlers auch bei der Sorte II «Portorico» zulässig ist, lasse ich dahingestellt, obwohl diese eine negative Differenz nur $1 / 11$ der mittleren Nicotinmenge dieser Sorte ausmacht. 
Aber. unter allen Umständen unzulässig erscheint mir diese Erklärung bei der Cigarrensorte III ("Cuba-Portorico»). Bei dieser Sorte stehen drei positiven Differenzen, welche 1/2; $1 / 1 \mathrm{n}$ und $1 / 12$ ihres mittleren Nicotingehaltes ausmachen, zwei negative Differenzen von $1 / 2$ und $1 / 6$ gegenüber. Man wird nicht fehlgehen, wenn man annimmt, dass in diesem Falle die im mathematischen Sinne entgegengesetzten, verhältnissmässig sehr grossen Differenzen in starken Schwankungen in der Qualität des Tabakes gesucht werden müssen, wobei es noch wahrscheinlich ist, dass diese Schwankungen weniger in einer starken Verschiedenheit des Nicotingehaltes, als vielmehr durch erhebliche Unterschiede im Gehalt an Eiweissstoffen des Tabakes gesucht werden müssen. Dass diese Auffassung ihre Berechtigung hat, zeigen einerseits in sehr deutlicher. Weise die in den Cuba-Portorico-Cigarren experimentell mehrfach ermittelten Nicotingehalte (siehe Tabelle III), welche untereinander. insoweit in sehr befriedigender Weise übereinstimmen, als sie Cigarren desselben Verschleissbezirkes betreffen, und andererseits die folgende Mittheilung:

In sechs fermentirten Tabaksorten fand Feska (R. Kissling's Tabakkunde, S. 54, oder Landwirthschaftliche Jahrbücher, 1888, S. 329 ff.), dass von 100 Theilen Gesammtstickstoff im Durchschnitte

als Nicotinstickstoff . . . . 39 Theile
als Amidostickstoff . . . . 34 ,
und als Eiweissstickstoff . . 27

enthalten sind. Während indessen bei diesen sechs Sorten der Nicotingehalt zwischen 31 bis $490^{\circ}$ io schwankt, bewegt sich der Gehalt derselben an Eiweissstickstoff zwischen 10 und 40\%, also in viel weiteren Grenzen.

Da es nun keinem Zweifel unterliegen kann, dass ein sehr ansehnlicher Theil des Eiweissstickstoffes in den Tabakrauch in Form von Pyridinbasen übergeht, und dass die Grösse dieses Theiles sich den Schwankungen im Gehalte an Eiweissstickstoff anpassen wird,.. so muss es gestattet sein, die grosse, im Sinne früher gemachter Ausführungen, negative Differenz, welche wenigstens in einem Falle bei den Cuba- 
Portorico-Cigarren beobachtet wurde, auf einen verhältnissmässig bedeutenden Gehalt dieser Cigarren an Eiweiss zurückzuführen.

Diese Auffassung schliesst selbstverständlich die weitere in sich, dass die im Tabakrauche und in den nicht verrauchten Cigarrenenden (Stumpfen) ermittelten Mengen von Stickstoffbasen keineswegs nur aus Nicotin und den unmittelbaren Zersetzungsprodukten des Nicotins bestehen. Es kann vielmehr keinem Zweifel unterliegen, dass ein erheblicher Theil der im Cigarrenrauche und in den Stumpfen aufgefundenen Stickstoffbasen durch die trockene Destillation der Eiweissstoffe des Tabakes entstanden ist. Die früher mitgetheilten, von Feska ermittelten Zahlen bieten im Zusammenhalte mit den Erfahrungen, welche wir. über die trockene Destillation der Eiweissstoffe besitzen, einen genügenden Anhaltspunkt dafür, um sagen zu können, dass dieser Antheil kein unbedeutender sein kann. Letzteres geht, wie mir scheint, mit Folgerichtigkeit aus den bei der Cigarrensorte IX (Brasil-Virginier) durch die Analyse ermittelten Werthen hervor, insbesondere dann, wenn man diese mit jenen vergleicht, welche bei der Sorte X (Virginier) erhalten worden sind.

Diese beiden Cigarrensorten sind, wie schon früher gesagt wurde und wie ein Blick auf die Abbildungen lehrt, untereinander durchaus sehr ähnlich geformt und gebaut und unterscheiden sich von allen übrigen in Betracht kommenden Cigarrensorten in beiden Richtungen in sehr aufälliger Weise. Während jedoch die in der Rubrik 7 der Tabelle IX enthaltenen, durch drei Versuche resp. Analysen ermittelten Differenzzahlen bei den Virginier-Cigarren (Sorte $\mathrm{X}$ ) durchwegs positiv sind und sich zwischen $1 / 5$ und $1 / 2$ des mittleren Nicotingehaltes dieser Cigarrensorte bewegen, sind die bei der Sorte IV (Brasil-Virginier) durch vier Versuche ermittelten Differenzwerthe durchwegs negativ und bewegen sich von $1 / 2$ bis $\mathrm{zu}^{2 / 3}$ des mittleren Nicotingehaltes der Brasil-VirginierCigarren, d. h. mit anderen Worten: Während bei den VirginierCigarren im Mittel von drei Versuchen die im angesaugten Rauche und in den unverrauchten Enden zusammen ermittelte 
Menge von Stickstoffbasen nur etwa $2 / 3$ vom mittleren Nicotingehalte dieser Cigarren beträgt, ist die Menge der bei den Brasil-Virginier-Cigarren (IX) im Mittel von vier Versuchen im angesaugten Rauche und den unverrauchten Enden (Stumpfen) zusammen aufgefundene Menge der Stickstoffbasen fast doppelt so gross wie der mittlere Nicotingehalt dieser Cigarren. Es dünkt mir schwer möglich, diese bei zwei im Bau und in der Form durchaus ähnlichen Cigarrensorten constatirte, so auffällige Verschiedenheit anders als in der früher angegebenen Weise zu erklären, und ich erachte es deshalb als erwiesen, dass der Tabak der Virginier-Cigarren (X) arm, derjenige der Brasil-Virginiercigarren (IX) hingegen relativ reich an Eiweissstoffen ist. Hierzu glaube ich bemerken zu sollen, dass mit der zuletzt gemachten Folgerung die Thatsache übereinstimmt, dass die Brasil-Virginier-Cigarren (IX) trotz ihres geringeren Preises (8 Heller per Stück) wegen des minder angenehmen Geschmackes und Geruches ihres Rauches bei den österreichischen Rauchern viel weniger beliebt sind als die VirginierGigarren (X), welche per Stück 10 Heller kosten, und dass diese Thatsache die Anschauung Kissling's (Tabakkunde, S. 54, letzter Absatz) rechtfertigt, welche dahin geht, «dass der Gehalt der Tabakblätter an Pflanzeneiweiss insofern von besonderer Bedeutung ist, als die Güte des Tabaks seinem Eiweissgehalt umgekehrt proportional zu sein scheint. " Durch die beim Verrauchen der Brasil-Virginier-Cigarren bezüglich des Gehaltes an Nicotin resp. Stickstoffbasen erzielten Resultate scheint mir aber auch der experimentelle Beweis erbracht zu sein, dass es ganz unzulässig ist, die im Tabakrauche ermittelten Stickstoff basen kurzweg als « Nicotin » anzusprechen. Es kann vielmehr keinem $Z$ weifel unterliegen, dass eine erhebliche Menge der im Rauche aufgefundenen Stickstoffbasen aus Pyridinbasen besteht, von welchen gewiss nur ein Theil von dem beim Rauchen zerstörten Nicotin herrühren kann, ein anderer, wahrscheinlich grösserer Theil, hingegen aus dem Eiweiss des Tabakes durch trockene Destillation entstanden sein muss. Ich habe bereits Versuche eingeleitet, diese Folgerung direkt experimentell zu prüfen. 
In gewissem Sinne kaum weniger interessant wie der Vergleich der in der Rubrik 3 einerseits und der Rubrik 6 andererseits der Tabelle IX enthaltenen Werthe gestaltet sich der Vergleich der in der Rubrik 3 einerseits und der Rubrik 5 andererseits der Tabelle IX enthaltenen Zahlen.

Bildet man die Differenzen aus den correspondirenden Zahlen dieser beiden Rubriken, indem man jene der Rubrik 5 mit +, jene der Rubrik 3 mit - in Rechnung setzt, so erfährt man die Grössen der Veränderung, welche der Nicotingehalt resp. der Gehalt an Stickstoffbasen im unverrauchten Theile der Cigarre (Stumpf) durch das Rauchen erfahren hat. Diese gebildeten Differenzen sind in der Rubrik 8 der Tabelle IX enthalten. Ein Blick auf diese Tabelle lehrt, dass diese Differenz nur bei zwei Versuchen, und zwar bei dem Versuche 7 (Cuba-Portorico aus dem Verschleissbezirke Neutitschein) und 30 (Virginier) negativ ausgefallen ist, dass demnach in diesen beiden Fällen im Stumpf weniger Stickstoffbasen aufgefunden wurden, als der mittlere Nicotingehalt der betreffenden Cigarrensorte beträgt. Wie indessen die Rechnung ergibt, beträgt diese Differenz beim Versuche 7 nur 1/25, beim Versuche 30 weniger als 1/14 des mittleren Nicotingehaltes der betreffenden Cigarrensorte. Diese beiden negativen Differenzen können demnach wegen ihrer Geringfügigkeit als in der Mangelhaftigkeit der Versuche begründet angesehen und im Folgenden vernachlässigt werden.

Alle anderen Zahlen der Rubrik 8 sind positiv, d. h. bei allen anderen 28 Versuchen wurden in dem unverrauchten Theile der Cigarre mehr Stickstoffbasen gefunden, als der mittlere Nicotingehalt der betreffenden Cigarre beträgt.

Die mittlere Zunahme des Gehaltes an Stickstoffbasen in den Stumpfen, gegenüber dem mittleren Nicotingehalte der betreffenden Cigarrensorte, lässt sich aus der folgenden kleinen Tabelle, erste Rubrik, entnehmen, welche jene Grösse, bezogen auf den mittleren Nicotingehalt der Cigarrensorte, auch in Procenten (zweite Rubrik) enthält. 


\begin{tabular}{r|r|r}
\hline \multicolumn{1}{c|}{$\begin{array}{c}\text { Nummer und Name } \\
\text { der Cigarrensorte }\end{array}$} & 1. & 2. \\
\hline I. Kurze . . . . . . . & 0,0117 & $62 \%$ \\
II. Portorico . . . . . . . & 0,0111 & $78 \%$ \\
III. Cuba-Portorico . . . . & 0,0137 & $91 \%$ \\
IV. Operas . . . . . . . & 0,0109 & $76 \%$ \\
V. Panetelas (Havanna) . . & 0,0107 & $59 \%$ \\
VI. Britannica . . . . . . & 0,0139 & $108 \%$ \\
VII. Trabuco . . . . . . & 0,0118 & $73 \%$ \\
VIII. Regalitas . . . . . . & 0,0085 & $29 \%$ \\
IX. Brasil-Virginier . . . . & 0,0174 & $118 \%$ \\
X. Virginier . . . . . . . & 0,0064 & $16 \%$
\end{tabular}

Aus dieser Tabelle, namentlich aus der zweiten Rubrik derselben, ergibt sich, dass die Menge der in den unverrauchten Enden ermittelten Stickstoffbasen bei acht Cigarrensorten ganz erheblich grösser ist, als der mittlere Nicotingehalt der betreffenden Sòrten. Dieses Plus beträgt bei diesen 8 Sorten 59 (V) bis $118 \%$ (IX). Bei den beiden übrigen Sorten beträgt das Plus 16\% (X) und 29\% (VIII). Auffallender Weise sind dies gerade jene Cigarrensorten, welche gegenüber allen anderen in Betracht kommenden Cigarren den weitaus grössten, zumeist mehr als doppelt so grossen mittleren Nicotingehalt besitzen. Im Bau und in der Form sind diese beiden Sorten, wie ein Blick auf die früher mitgetheilte Abbildung lehrt, völlig verschieden. Andererseits beträgt das Plus an Stickstoffbasen der Stumpfe gegenüber dem mittleren Nicotingehalt der Cigarren bei zwei Sorten mehr als $100 \%$, und zwar sind dies gerade diejenigen beiden Sorten, bei welchen im Verhältniss zu ihrem mittleren Nicotingehalte auch im Rauche erhebliche Mengen Stickstoffbasen nachgewiesen wurden. Es sind dies die mit.VI (Britannica) und IX (Brasil-Virginier) bezeichneten Cigarren. Da diese beiden Cigarrensorten im Bau und in der Form ebenso verschieden sind, wie jene beiden Sorten (VIII und $\mathrm{X}$ ), bei welchen die entgegengesetzten Beobachtungen gemacht wurden, so kann mit Sicherheit gefolgert werden, dass die condensirende 
und absorbirende Wirkung des unverrauchten Theiles der Cigarre auf den Tabakrauch von der Form der Cigarre so gut wie völlig unabhängig ist. Die Thatsache nun, dass bei den Cigarrensorten mit dem grössten mittleren Nicotingehalte (VIII und X) im nichtverrauchten Theile eine auffallend geringe Anhäufung der Stickstoffbasen des Rauches stattfindet, während sie bei zwei nicotinarmen Sorten (VI und IX) eine auffallend bedeutende ist, spricht mit Bestimmtheit dafür, dass diese Anhäufung von Stickstoff basen in den Stumpfen unmöglich vom Nicotingehalt in überwiegendem Maasse abhängen kann und vielmehr höchstwahrscheinlicher $\mathrm{H}^{\top}$ eise mit dem Gehalte des Tabaks an Eiweissstoffen in innigem Zusammenhange steht.

c) Vergleicht man endlich die mittleren Nicotingehalte der Cigarren (Rubrik 3 der Tabelle IX) mit den im angesaugten Rauche ermittelten Mengen Stickstoffbasen (Rubrik 4), so ergibt sich zunächst, dass die letzteren durchwegs erheblich kleiner sind als die ersteren, was durch die folgende Tabelle deutlich wird, in welcher die erste Rubrik per Gramm Tabak den mittleren Nicotingehalt der Cigarre, die zweite Rubrik den mittleren Gehalt des angesaugten Rauches an Stickstoffbasen per $1 \mathrm{~g}$ verrauchten Tabak, und die dritte Rubrik die in der zweiten enthaltenen Werthe in Procenten, bezogen auf den mittleren Nicotingehalt der betreffenden Cigarrensorte, enthält.

\begin{tabular}{|c|c|c|c|c|}
\hline \multirow{2}{*}{\multicolumn{2}{|c|}{ Cigarrensorte }} & \multicolumn{2}{|c|}{ Per ein Gramm Tabak } & \multirow{2}{*}{$\begin{array}{l}\text { Gehalt des } \\
\text { Rauches an } \\
\text { Stickstoff- } \\
\text { basen in } \\
\text { Procenten }\end{array}$} \\
\hline & & $\begin{array}{l}\text { 1) mittlerer } \\
\text { Nicotin- } \\
\text { gehalt }\end{array}$ & $\begin{array}{c}\text { 2) mittlerer } \\
\text { Gehalt an } \\
\text { Stickstofrbasen } \\
\text { des Rauches }\end{array}$ & \\
\hline I. (Kurze) . . . . & • . • & 0,0188 & 0,0041 & $22 \%$ \\
\hline II. (Portorico) . . . . & . . • & 0,0141 & 0,0046 & $33 \%$ \\
\hline III, (Cuba-Potorico) . . . & . . . & 0,0151 & 0,0042 & $28 \%$ \\
\hline IV. (Operas) . . . . . & . . . & 0,0143 & 0,0046 & $32 \%$ \\
\hline V. (Panetelas [Havanna]) & - . & 0,0181 & 0,0042 & $23 \%$ \\
\hline VI. (Britannica) $\cdot \cdot \cdot \cdot$ & . . . & 0,0129 & 0,0039 & $30 \%$ \\
\hline VII. (Trabuco) $\cdot \cdot \cdot \cdot$ & . • & 0,0161 & 0,0046 & $29 \%$ \\
\hline VIII. (Regalitas) . • • • • & . • & 0,0290 & 0,0048 & $17 \%$ \\
\hline IX. (Brasil-Virginier) . • • & . . . & 0,0147 & 0,0099 & $67 \%$ \\
\hline X. (Virginier) . • • • & . . & 0,0399 & 0,0125 & $31 \%$ \\
\hline
\end{tabular}


Wie ein Blick auf die dritte Rubrik der vorstehenden zusammenfassenden Tabelle lehrt, beträgt die im angesaugten Rauche nachgewiesene Menge von Stickstoffbasen bei 9 Sorten 17 bis $33 \%$, d. h. also zwischen $1 / 6$ und $2 / 6$ des mittleren Nicotingehaltes der betreffenden Cigarrensorte. Nur eine Sorte (IX, Brasil-Virginier) zeigt wieder ein stark abweichendes Verhalten, indem die Menge der im angesaugten Rauche ermittelten Stickstoffbasen $67 \%$ oder $2 / 3$ des mittleren Nicotingehaltes dieser Cigarrensorte ausmacht. Die Erklärung für diese $\mathrm{Ab}$ weichung lässt sich leicht in den früher gemachten Ausführungen finden.

Berücksichtigt man die unter b) gemachten Ausführungen, welche dahin gehen, dass es auf Grund der gemachten Beobachtungen unzulässig ist, die Gesammtmenge der im angesaugten Tabakrauche aufgefundenen Stickstoffbasen kurzweg als Nicotin zu bezeichnen, so gelangt man zu dem bestimmten Resultate, dass von dem in den Cigarren enthaltenen Nicotin ein verhältnissmässig nur kleiner Theil in den angesaugten Theil des Tabakrauches übergeht. Dieses Ergebniss steht, wenn auch nicht gerade in vollständigem Widerspruche, so doch auch nicht im Einklange mit der bisher allgemein verbreiteten Anschauung, dass ein relativ grosser Antheil des Nieotins in den Rauch übergeht. Von einem vollständigen Widerspruche kann deshalb nicht ohne Weiteres gesprochen werden, weil bei allen früheren Untersuchungen der continuirlich wirkende Aspirator angewendet worden ist, also die Gesammtmenge des Tabakrauches in Untersuchung gezogen wurde, während bei dem von mir intermittirend bewirkten Rauchen nur der vom Aspirator angesaugte Theil des Rauches für die Untersuchung in Betracht gezogen wurde. $\mathrm{Da}$ ich indessen früher schon dargethan habe, dass der angesaugte Theil des Rauches mindestens die Hälfte des Gesammtrauches bei allen Versuchen ausgemacht hat, so kann es kaum einem Zweifel unterliegen, dass das von mir erzielte Resultat mit der bisher allgemein verbreiteten Anschauung, welche insbesondere auch von Kissling vertreten wird (Tabakkunde, S. 258), nicht in Einklang gebracht werden kann. 
Das von mir erzielte Resultat steht aber auch, wie mir scheint, mit verschiedenen, allgemein bekannten Thatsachen besser im Einklang, als die Lehre, dass ein relativ grosser Antheil des Nicotins in den Rauch übergeht. Ich will einige dieser Thatsachen einer kurzen Besprechung unterziehen.

Alle Litteraturangaben stimmen darin überein, dass das Nicotin im Tabak in welchselnder Menge, an Aepfel- oder Citronensäure gebunden, enthalten ist. Ebenso unzweifelhaft ist es durch die vorliegenden Beobachtungen sicher gestellt, dass das Nicotin, obwohl es eine starke zweisäurige Salzbasis ist, in den meisten Salzen als einsäurige Basis auftritt, so zwar, das Kissling in sehr kennzeichnender, wenn auch nicht ganz zutreffender Weise sagen kann, «dass das Nicotin sich gegenüber Wasserstoffsäuren zweibasisch, den Sauerstoffsäuren gegenüber einbasisch verhält». Im Hinblick auf dieses Verhältniss, sowie mit Rücksicht auf den Umstand, dass der Gehalt an "wasserfreier Aepfel- und Citronensäure in der wasserfreien Trockensubstanz des Tabaks $10-14 \%$ beträgt» (Kissling, Tabakkunde, S. 43), wozu noch an sauren Bestandtheilen 1-2\% Oxalsäure sowie Gerbsäure, Salpetersäure, Schwefelsäure und Chlor kommen, deren Menge zusammen wieder 4-5\% betragen kann, wird die Annahme berechtigt sein, dass das Nicotin im Tabak in Form der sauren Salze der Aepfel- uud Citronensäure enthalten ist, trotzdem der Gehalt der Tabakblätter an basischen Mineralsubstanzen, wie Kali, Natron, Kalk, Magnesia und Eisenoxyd, bezogen auf die Trockensubstanz der Tabakblätter, $13 \%$ und selbst darüber betragen kann.

Aehnliches lässt sich wohl auch bezüglich der Nicotinsalze in den fermentirten 'Tabaken behaupten, allerdings mit dem Unterschiede, dass in diesen die Aepfel- und Citronensäure durch Bernsteinsäure, Fumarsäure, Buttersäure, Essigsäure und andere niedrige Glieder der Fettsäurereihe ersetzt sind. Vergleicht man nun die Nicotinsalze der genannten Säuren in Beziehung auf ihr Verhalten gegen höhere Temperaturgrade mit den Ammonsalzen dieser Säuren, so lässt sich zunächst Folgendes constatiren: 
Bezüglich der Ammonsalze fast all der genannten organischen Säuren ist experimentell festgestellt, dass sie beim genügend starken Erhitzen nicht wie das Chlorammonium in freie Säure und Ammoniak zerfallen, sondern in der Regel in Amido- und Imidoderivate übergehen, so dass auf dieses Verhalten eine ziemlich häufig anwendbare Methode zur Darstellung von Amido- und Imidoverbindungen organischer Säuren begründet werden konnte. Bezüglich der in Betracht kommenden Säuren sei im Speciellen daran erinnert, dass das saure, äpfelsaure Ammon beim Erhitzen in Fumarimid, die beiden Ammonsalze der Bernsteinsäure in Succinimid, das Ammonsalz der Buttersäure in Butylamid übergehen u. s. w.

Wenn nun auch zugegeben werden muss, dass bisher der experimentelle Beweis fehlt, dass die Nicotinsalze organischer Säuren sich den Ammonsalzen derselben ähnlich verhalten, so wird es andererseits denn doch als unwahrscheinlich bezeichnet werden können, dass sich die Nicotinsalze organischer Säuren gegenüber den Ammonsalzen so völlig verschieden verhalten, dass, während bei den letzteren die Salzbasis an dem Zerfall der Salze unter dem Einflusse hoher Temperaturgrade in hervorragender Weise betheiligt ist, bei den Nicotinsalzen nur der saure Antheil Zersetzung erfährt, der basische hingegen, also das Nicotin, ganz unverändert abdestillirt, obwohl festgestellt ist, dass Nicotindampf, durch ein rothglühendes Rohr geleitet, eine tiefgreifende Zersetzung erfährt.

Dass ein Vergleich der Nicotinsalze organischer Säuren mit den analogen Ammonsalzen in Bezug auf ihr Verhalten gegenüber hohen Temperaturgraden nicht unzulässig sein kann, lässt sich, wie ich meine, durch eine Gegenüberstellung zu dem Verhalten der Salze des Trimethylamins darthun. Das Trimethylamin gehört, wie das Nicotin, zu den tertiären Salzbasen, steht in Beziehung auf seinen ganzen chemischen Habitus von allen tertiären Basen dem Ammoniak am nächsten und zeigt in Beziehung auf das Verhalten seiner Salze bei hohen Temperaturgraden gegenüber den Ammonsalzen eine Verschiedenheit, welche kaum in dem Sinne gedeutet werden kann, dass die Nicotinsalze bei hoher Temperatur in freie Säure und freies Nicotin zerfallen, wie dies bei Ammonsalzen; 
z. B. beim Salmiak, der Fall ist, welcher bei $350^{\circ}$ schon vollständig in Chlorwasserstoffsäure und Ammoniak dissociirt ist. Demgegenüber ist sichergestellt, dass das salzsaure Trimethylamin bei $285^{\circ}$ nach der Gleichung $3 \mathrm{~N}\left(\mathrm{CH}_{3}\right)_{3} \cdot \mathrm{HCl}=$ $\mathrm{N}\left(\mathrm{CH}_{3}\right) \mathrm{H}_{2} \cdot \mathrm{HCl}+2 \mathrm{~N}\left(\mathrm{CH}_{3}\right)_{3}+2 \mathrm{CH}_{3} \mathrm{Cl}$ zerfällt, d. h. während das salzsaure Ammoniak vollständig in Chlorwasserstoff und Ammoniak zersetzt wird, werden beim salzsauren Trimethylamin nur $2 / 3$ als tertiäre Salzbase und der Rest theils als salzsaures Monomethylamin, theils als Methylchlorid abgeschieden. Nach der allgemeinen Erfahrung, dass Zersetzungen organischer Substanzen durch Wärme sich um so verwickelter gestalten, je verwickelter der Bau des Moleküls und je grösser das Molekulargewicht ist, wird die Folgerung berechtigt erscheinen, dass es mindestens unwahrscheinlich ist, dass bei der trockenen Destillation von äpfelsaurem oder citronensaurem Nicotin die Hauptmenge des Nicotins als solches abgeschieden wird und die Zersetzung der Salze sich démgemäss, wenigstens in Beziehung auf das Nicotin, höchst einfach gestaltet. Man kann dagegen nicht einwenden, dass die neutralen Ammonsalze mehrbasischer Säuren sich sehr häufig anders verhalten, als das Chlorammonium, das salzsaure Trimethylamin u. s. w. Viele neutrale Ammonsalze mehrbasischer Säuren zerfallen in der That beim Erhitzen so, dass sie einen Theil des Ammoniaks verlieren und in saures Salz übergehen. So zersetzt sich das neutrale Ammoniumsuccinat nach der Gleichung

$$
\mathrm{C}_{8} \mathrm{H}_{4}\left(\mathrm{CO}_{2} \cdot \mathrm{NH}_{4}\right)_{2}=\mathrm{C}_{8} \mathrm{H}_{4} / \mathrm{CO}_{2} \mathrm{NH}_{4}+\mathrm{NH}_{8} \text {. }
$$

Beispiele ähnlicher Zersetzungen finden sich bei den neutralen Ammonsalzen mehrbasischer, organischer Säuren der verschiedensten homologen Reihen, und es scheint mir darum der Gedanke vollberechtigt, dass sich auch das neutrale Nicotinsalz der zweibasischen Aepfelsäure und das der dreibasischen Citronensäure analog verhalten. Dass bei der trockenen Destillation, z. B. des neutralen, äpfelsauren Nicotins, das Nicotin zur grösseren Hälfte als solches in das Destillat übergehen wird, ist wahrscheinlich, nachdem erwartet werden kann, dass der Uebergang des neutralen in das saure Nicotinmalat schon bei verhältnissmässig niedriger Temperatur erfolgt, die Hälfte 
des Nicotins dabei in das Destillat übergeht und ein Theil des im sauren Nicotinmalat enthaltenen Nicotins im Destillat zu diesem noch hinzukommt, wenn das saure Salz bei steigender Temperatur Zersetzung erfährt. Aehnliches lässt sich bezüglich des neutralen Nicotincitrates annehmen.

Dass diese Möglichkeiten indessen sich auf den vorliegenden Fall nicht anwenden lassen, kann ich mit dem Hinweise darthun, dass wir von den Sauerstoffsäuren überhaupt und insbesondere von den mehrbasischen, organischen Säuren von beständigen Salzen nur saure Nicotinsalze kennen, wie z. B. das Nicotindioxalat $\left(\mathrm{C}_{10} \mathrm{H}_{14} \mathrm{~N}_{2} \cdot 2 \mathrm{C}_{4} \mathrm{H}_{5} \mathrm{O}_{6}+2 \mathrm{H}_{2} \mathrm{O}\right)$ und dass ich schon früher gezeigt habe, dass die Mengenverhältnisse zwischen sauren und basischen Bestandtheilen im Tabak solche sind, welche es an sich wahrscheinlich erscheinen lassen, dass das Nicotin im Tabak als saures Salz enthalten ist.

Eine andere allgemein bekannte Thatsache ist die, dass Nicotindämpfe eine äusserst reizende Wirkung auf die Schleimhäute der Athmungswege ausüben. Nach Kissling macht die Verdampfung von einigen Tropfen Nicotin die Luft eines Zimmers völlig unathembar. (Tabakkunde S. 263.)

In einer meiner früheren Darlegungen habe ich auf Grund meiner Beobachtungen dargethan, dass beim Verrauchen einer mittleren Cigarre von $5,5 \mathrm{~g}$ Gewicht im Durchschnitt etwa 3,5 Liter Rauch entwickelt werden, wovon beim intermittirenden Rauchen etwa die Hälfte vom Raucher angesaugt wird. Nimmt man nun an, dass von dem angesaugten Rauche das Nicotin der Hauptmenge nach in der Mundhöhle des Rauchers zurückgehalten wird, so kann gesagt werden, dass von dem Nicotin des Rauches etwas mehr direkt in die Luft des Locales, in welchem das Rauchen stattfindet, übergeht. Bei einer Cigarre von $5,5 \mathrm{~g}$ Gewicht und $2 \%$ Nicotingehalt würde das den Uebergang von ca. $0,05 \mathrm{~g}$ Nicotin in die Zimmerluft unter der einzigen Voraussetzung bedeuten, «dass ein relativ grosser Theil des Nicotins in den Rauch übergeht». Wenn man nun noch annimmt, dass die $0,05 \mathrm{~g}$ Nicotin einen Tropfen repräsentieren, eine Annahme, die sich von der Wahrheit nicht allzuweit entfernen dürfte, dann müsste das Verrauchen von 3-4 Cigarren der gekennzeichneten Qualität genügen, "um 
die Luft eines Zimmers ebenso völlig unathembar zu machen, wie einige Tropfen Nicotin». Die Erfahrung lehrt jedoch, dass das nicht der Fall ist. Raucher und Nichtraucher werden mir zustimmen, wenn ich behaupte, dass die Luft eines Zimmers schon durch das Verrauchen von 3-4 Cigarren in ihrer Qualität keineswegs soweit verschlechtert wird, dass sie als völlig unathembar bezeichnet werden könnte. Uebrigens ist die Wirkung selbst der durch geringe Mengen von reinem Nicotindampf verunreinigten Luft wenigstens auf die Schleimhäute meiner Athmungsorgane viel unangenehmer als die Wirkung von Luft, welche durch den Rauch von Cigarren verunreinigt wurde.

Ich glaube deshalb folgern zu können, dass es in Uebereinstimmung mit den von mir erhaltenen analytischen Daten auch mit Rücksicht auf die gekennzeichneten Wahrnehmungen nicht richtig sein kann, dass ein relativ grosser Theil des Nicotins in den Rauch unverändert übergeht.

Alle diese meine Ausführungen können und sollen keineswegs den Zweck verfolgen, die Schädlichkeit oder Unschädlichkeit des Tabakrauches darzuthun. Sie können und sollen es schon aus dem Grunde nicht, weil es, nach meiner Auffassung, unmöglich Sache des Chemikers sein kann, die Wirkungen des Tabakrauches auf den menschlichen Organismus zu studiren. Der Chemiker soll sich naturgemäss darauf beschränken, die Frage zu beantworten, welche Stoffe im Tabakrauche enthalten sind, in welchen Mengenverhältnissen sich die einzelnen Bestandtheile finden, woran sich bezüglich einzelner Rauchbestandtheile, wie der Pyridinbasen, Untersuchungen darüber anschliessen können, aus welchen Bestandtheilen des Tabaks jene Stoffe beim Rauchen entstehen und welche Umstände ihr Auftreten im Rauch zu begünstigen vermögen. Aufgabe des Physiologen muss es dann sein, die vom Chemiker festgestellten Resultate dahin zu ergänzen, dass er den Einfluss der verschiedenen Rauchbestandtheile auf den Organismus des Rauchers nach ihrer Qualität und Menge untersucht.

Indem ich glaube, dass ich bei meinen Untersuchungen und den daran geknüpften Ausführungen stets innerhalb der dem Chemiker gezogenen Grenzen geblieben bin, glaube ich diese Grenzen auch nicht zu überschreiten, wenn ich in ähn- 
licher Weise, wie ich es bezüglich des Nicotins gemacht habe, einige Bemerkungen über die gasförmigen Bestandtheile des Tabakrauches mache. Diesbezüglich scheint es mir nicht uninteressant, Untersuchungen darüber anzustellen, ob das Kohlendioxyd und das Kohlenoxyd des Tabakrauches überwiegend als Produkte der Verbrennung oder der trockenen Destillation der organischen Substanz der Cigarren angesehen werden müssen. Die in der Tabelle. VII enthaltenen Zahlen bilden ein geeignetes Material, um dieser Frage näher zu treten. Lässt man die Zahlen dieser Tabelle, welche das verbrauchte Aspiratorwasser per 1 Gramm verrauchter Cigarren angeben, als Gesammtvolumen der angesaugten, gasförmigen Rauchbestandtheile bei Zimmertemperatur gelten, und reducirt man dieses mit Wasserdampf gesättigte Gesammtgasvolumen, wie auch die auf Kohlendioxyd, Sauerstoff und Kohlenoxyd bezüglichen Werthe auf wasserfreie Gase, so erhält man Zahlenwerthe, welche in den ersten vier Rubriken der folgenden Tabelle zusammengestellt sind, während die fünfte Rubrik jene Luftmengen enthält, welche sich aus den auf Sauerstoff bezüglichen Angaben nach dem Verhältniss 21 Volumen Sauerstoff zu 100 Volumen Luft rechnen lassen.

\begin{tabular}{|c|c|c|c|c|c|}
\hline \multirow{4}{*}{$\begin{array}{c}\text { Name } \\
\text { der } \\
\text { Cigarrensorte }\end{array}$} & \multicolumn{4}{|c|}{1 Gramm Cigarre gibt im Mittel } & \multirow{4}{*}{$\begin{array}{c}\text { Der ge- } \\
\text { funde- } \\
\text { nen } \\
\text { Menge } \\
\text { Sauer- } \\
\text { stoff } \\
\text { ent- } \\
\text { spricht } \\
\text { trockene } \\
\text { Luft }\end{array}$} \\
\hline & \multirow{2}{*}{$\begin{array}{c}\text { nicht } \\
\text { conden- } \\
\text { sirbaren } \\
\text { Rauch }\end{array}$} & \multicolumn{3}{|c|}{$\begin{array}{l}\text { von den nicht condensir- } \\
\text { baren Rauchbestand- } \\
\text { theilen entlallen auf }\end{array}$} & \\
\hline & & \begin{tabular}{|c|} 
Kohlen- \\
dioxyd
\end{tabular} & $\begin{array}{c}\text { Sauer- } \\
\text { stoff }\end{array}$ & $\begin{array}{c}\text { Kohlen- } \\
\text { oxyd }\end{array}$ & \\
\hline & \multicolumn{4}{|c|}{ im wasserfreien Zustande } & \\
\hline I. Kurze (g & 911 & 49 & 132 & 12 & 629 \\
\hline II. Portorico & 393 & 75 & 20 & 11 & 98 \\
\hline III. Cuba-Portorico & 297 & 64 & 9 & 13 & 43 \\
\hline IV. Operas & 287 & 62 & 10 & 18 & 48 \\
\hline V. Panetelas (Havanna) & 442 & 47 & 52 & 13 & 248 \\
\hline VI. Britannica & 346 & 74 & 14 & 17 & 66 \\
\hline VII. Trabuco & 318 & 65 & 1.3 & 17 & 62 \\
\hline VIII. Regalitas & 25 & 55 & 11 & 13 & 53 \\
\hline IX. Brasil-Virginier & 87 & 19 & 161 & 5 & 768 \\
\hline $\mathrm{X}$. Virginier & 1284 & 61 & 229 & 17 & 1090 \\
\hline
\end{tabular}

Aus den Daten der vorstehenden Tabelle lässt sich, wie leicht verständlich, der beim Verrauchen des Tabaks zurückgebliebene Luftstickstoff und aus diesem der zur Verbrennung 
von $1 \mathrm{~g}$ Cigarre verbrauchte Luftsauerstoff nach dem Verhältniss $79: 21$ berechnen.

Die nachfolgende Zusammenstellung enthält in der ersten Rubrik diese MengenSauerstoff in Cubikcentimetern per 1 Gramm Cigarre der betreffenden Sorte und in der zweiten Rubrik die durch die aufgefundenen Mengen von Kohlendioxyd und Kohlenoxyd repräsentirten Mengen Sauerstoff der bezüglichen Sorte.

\begin{tabular}{l|c|c}
\hline $\begin{array}{c}\text { Name } \\
\text { der } \\
\text { Cigarrensorte }\end{array}$ & $\begin{array}{c}\text { Beim } \\
\text { Verrauchen } \\
\text { verbrauchter } \\
\text { Luftsauerstoff }\end{array}$ & $\begin{array}{c}\text { Sauerstoff, in } \\
\text { dem } \mathrm{CO}_{2} \\
\text { und dem CO } \\
\text { enthalten }\end{array}$ \\
\hline I. Kurze (gemischte & 59 & 55 \\
Ausländer) & 56 & 81 \\
II. Portorico & 47 & 71 \\
III. Cuba-Portorico & 42 & 71 \\
IV. Operas & 36 & 53 \\
V. Panetelas (Havanna) & 50 & 82 \\
VI. Britannica & 49 & 73 \\
VII. Trabuco & 36 & 61 \\
VIII. Regalitas & 21 & 22 \\
IX. Brasil-Virginier & 31 & 69 \\
X. Virginier &
\end{tabular}

Wie ein Blick auf die vorstehende Tabelle lehrt, sind bei allen Cigarrensorten bis auf die mit «I» (kurze) bezeichneten die aus dem Gehalt des Rauches an Kohlendioxyd und Kohlenoxyd gerechneten Sauerstoffmengen durchwegs grösser, als der beim Verrauchen verbrauchte Luftsauerstoff, dessen grösste Menge (Cigarrensorte I, $59 \mathrm{ccm}$.), wie die Rechnung lehrt, kaum ausreicht, um 0,01 $\mathrm{g}$ Wasserstoff oder $0,03 \mathrm{~g}$ Kohlenstoff der organischen Substanz der Cigarre zu Wasser resp. Kohlendioxyd zu verbrennen.

Wenn man nun aus den bei einer früheren Gelegenheit entwickelten Gründen das gegenüber den meisten anderen Cigarrensorten stark abweichende Verhältniss der Zahlen der ersten zu den Zahlen der zweiten Rubrik bei der Sorte "I» (kurze) und auch jenes der Sorte "IX (Brasil-Virginier) ausser Betracht lässt, so ergibt sich, dass die Menge des durch das Kohlenoxyd und Kohlendioxyd repräsentirten Sauerstoffes die zur Verbrennung verbrauchte Luftsauerstoffmenge bei den noch in Betracht kommenden acht Sorten um annähernd $62 \%$ über- 
steigt, womit gesagt ist, dass das Kohlenoxyd nebst einem Theile des Kohlendioxyds des angesaugten Tabakrauches nicht durch Verbrennung, sondern durch trockene Destillation entstanden ist, ein Umstand, der, wie mir scheinen will, insofern volle Beachtung verdient, als dadurch und zwar in Uebereinstimmung mit mannigfaltigen anderen Beobachtungen der beim Rauchen von Cigarren stattfindende chemische Vorgang in der Hauptsache als trockene Destillation gekennzeichnet wird, bei welcher nur in untergeordnetem Grade auch Verbrennung stattfindet.

Dieser Auffassung entsprechend müsste der Rauchprocess in der Weise verlaufen, dass zunächst beim Anzünden der Cigarre trockene Destillation eingeleitet und diese sodann durch Verbrennung eines Theiles der organischen Substanz mittelst hinzutretender. Luft weitergeführt würde. Dieser Auffassung nach entstände als Destillat der gesammte Tabakrauch (der condensirbare und der nicht condensirbare Antheil) und der Destillationsrückstand, welch letzterer sich aus der gesammten Mineralsubstanz (Asche) und der in derselben fein vertheilten, hauptsächlich aus Kohlenstoff bestehenden, verkohlten, organischen Substanz zusammensetzen würde. Bei der Fortführung des Rauchprocesses durch das Ansaugen käme hauptsächlich diese fein vertheilte, verkohlte, organische Substanz als Brennmaterial in Betracht. Chemische Processe, welche in der gekennzeichneten Art verlaufen und deren charakteristisches Merkmal darin besteht, dass durch die Verbrennung eines kleinen Theiles der organischen Substanz die Hauptmenge der letzteren trockene Destillation erleidet, sind in der chemischen Technik mehrfach bekannt. Ich erinnere diesbezüglich nur an die Verkohlung des Holzes in den Kohlenmielern, bei welchen es allerdings ausschliesslich auf die $\mathrm{Ge}$ winnung des Destillationsrückstandes, also der Holzkohle, abgesehen ist, während beim Tabakrauchen das angestrebte Produkt im Destillat, d. i. dem Tabakrauch besteht. Mit dieser Auffassung steht die verhältnissmässig sehr reichliche Bildung von Rauchteer, das constante Auftreten von Kohlenoxyd selbst bei einem sehr grossen Luftüberschuss im angesaugten Rauche, das Auftreten von Stickstoffbasen im Teer des angesaugten 
Rauches in so reicher Menge, dass diese das Gesammtgewicht des Nicotins des verrauchten Theiles der Cigarre übertrifft, der. stetige Gehalt des Tabakrauches an Schwefelammonium und kohlensaurem Ammon in sehr guter Uebereinstimmung. Alle diese Thatsachen und das Auftreten aller der genannten Substanzen lassen sich durch die Annahme der trockenen Destillation der im Tabak enthaltenen Salze nicht flüchtiger, organischer, mehrbasischer Säuren, wie z. B. der Oxalsäure, der Nicotinsalze, der stickstoff- und schwefelhaltigen Eiweissstoffe als beim Rauchen vorherrschenden Process im Sinne obiger Ausführungen in ungezwungener Weise erklären, und es werden deshalb die gemachten. Bemerkungen nicht als überflüssig oder gezwungen angesehen werden können.

Dabei muss ich allerdings zugestehen, dass es den von mir durch die Analyse ermittelten Zahlenwerthen nicht selten an der gewünschten Genauigkeit fehlt und dass auch die von mir benutzten analytischen Methoden keineswegs einwandfrei sind. Meine ganzen Ausführungen beweisen, dass ich mir dieser Mängel völlig bewusst war und bin, und ich kann mich diesbezüglich mit dem Hinweise begnügen, dass ich durch häufige Wiederholung der Versuche, wenn möglich unter etwas geänderten Versuchsbedingungen, bemüht war, der Unvollkommenheit der Methode entgegenzuwirken.

Am Schlusse meiner Darlegungen will ich darauf hinweisen, dass ich bei jedem Abschnitte meiner Untersuchung die betreffenden Resultate in kurzen Bemerkungen zusammengefasst habe und mich deshalb nunmehr darauf beschränken kann, zu sagen, dass das Hauptresultat meiner Arbeit'darin besteht, dass ich den Nachweis erbracht habe, dass beim intermittirenden Rauchen von Cigarren, von dem in der verrauchten Cigarre enthaltenen Nicotin nur ein verhältnissmässig kleirer Theil in den angesaugten Rauch übergeht.

Dass die Untersuchung des beim gewöhnlichen Pfeifenrauchen entwickelten und angesaugten Rauches in Bezug auf die Qualität der Rauchbestandtheile und den Verlauf des Rauchprocesses zu Resultaten führen wird, welche den beim Ciggrrenrauchen erhaltenen ähnlich sein werden, kann ohne 
Weiteres angenommen werden, wozu ich bemerke, dass nach einigen Vorversuchen das Rauchen mit der Wasserpfeife zu erheblich verschiedenen Ergebnissen führen dürfte. Inwieweit das eine oder das andere beim Rauchen von Cigarretten der Fall ist, lässt sich, wie mir scheint, a priori nicht sagen und bildet deshalb den Gegenstand einer von mir bereits eingeleiteten, besonderen Untersuchung, die ich mir vorbehalten will. Ebenso habe ich bezüglich der Ermittelung der sauren Bestandtheile des Cigarrenrauches mit Einschluss der Blausäure, wie ich schon früher bemerkt habe, verschiedene Beobachtungen gemacht, die ich nunmehr fortführe und demnächst zum Abschluss zu bringen hoffe, um dadurch das meiner Arbeit unterlegte Programm in thunlichster Vollständigkeit zu erledigen.

Während der Drucklegung des vorstehenden Elaborates wurde ich von befreundeter Seite darauf aufmerksam gemacht, dass vor kurzer Zeit von $H$. Thoms eine Arbeit «Ueber die Rauchprodukte des Tabaks» erschienen ist, deren Titel, wenn nicht auf den gleichen, so doch auf einen ähnlichen Inhalt schliessen lässt. Ich habe diese Arbeit, welche in dem "Bericht der deutschen pharmaceutischen Gesellschaft" (X. J. 1900, S. 19) erschienen ist, seither gelesen und finde, dass sich dieselbe nach Plan und Arbeitsmethode ebenso stark an die von mir eingehend gewürdigte Publication von Kissling anlehnt, wie sie sich von meiner vorstehend mitgetheilten Arbeit unterscheidet.

Am stärksten tritt dies dadurch hervor, dass das Verrauchen der Cigarre von $\mathrm{H}$. Thoms geradeso wie von Kissling continuirlich, von mir hingegen, wie beim Gewohnheitsrauchen intermittirend ausgeführt wurde. Da nun auch die von H. Thoms mitgetheilten Resultate mit den von mir erzielten in keinem Widerspruch stehen und sich im zweiten Theil der Abhandlung auf eine ganz specielle Cigarrensorte (Wendt's Patentcigarren Nr. 15 Delicados und Nr. 31 Torpedo) beziehen, finde ich keine Veranlassung, auf diese arbeit näher einzugehen. 